\title{
2001 APS/MSA/SON Joint Meeting Abstracts of Session Presentations
}

\section{Biology of Pathogens}

\section{Association of Resistance Genes to Nematodes with Nematode Virulence Genes and to Other Pathogens and Pests}

Resistance to soybean cyst nematode: Bigenic inheritance and clustering with resistance to Fusarium solani. K. MEKSEM (1), A. Jamai (1), E. Ruben (1), K. Zobrist (1), K. Triwitakorn (1), P. Arelli (2), and D. A. Lightfoot (1). (1) So. Illinois Univ., Carbondale, IL 62901; (2) Univ. of Missouri, Columbia, MO 65211. Phytopathology 91:S147. Publication no. P-2001-0001-SSA.

A chromosomal region on molecular linkage group $\mathrm{G}$ in the soybean cultivar Forrest underlies co-inheritance of field resistance to sudden-death syndrome caused by $F$. solani f.sp. glycines and soybean cyst nematode $(\mathrm{SCN})$ race 3 . A high-density genetic map was constructed around the Rhgl and Rhg4 loci that underlie SCN resistance. Seven recombinants were positioned in a 150-kbp interval containing Rhg1. Candidate gene sequences for Rhgl and Rhg4 were isolated. A leucine rich repeat sequence (LRR), a trans-membrane spanning domain, and a kinase domain were isolated. The identified gene shows high homology to the Xa21 rice disease resistance gene and to an Arabidopsis receptor-like kinase. The Forrest allele contains 76 leucines in 13 extra-cellular GXXP motifs and a kinase on the intracellular domain. A gene closely homologous to Rhgl is found in the Forrest Rhg4 interval. This gene duplication and the large number of LRRs imply Rhg genes function by dimerization, which may explain variation in host-pathogen recognition.

Genetic analysis of soybean cyst nematode parasitism. C. OPPERMAN. North Carolina State University, Raleigh, NC 27604. Phytopathology 91:S147. Publication no. P-2001-0002-SSA.

During the past several years, we have developed a forward genetic system using the soybean cyst nematode (Heterodera glycines - SCN) as a model parasite. Forward genetic analysis has revealed that the parasite contains multiple unlinked loci that enable it to evade or circumvent host resistance genes, termed ror genes for "Reproduction On a Resistant" host. These individual ror genes appear in either dominant or recessive states. Controlled crosses have been performed between several SCN strains. Segregation analyses have revealed that inheritance of parasitic ability is Mendelian in nature. The genes controlling parasitic ability on a specific host differential appear to be unlinked loci. The SCN gene controlling ability to parasitize PI 88788 is inherited as a dominant allele, whereas the genes conferring parasitic ability on PI 90763 and Pickett are recessive. Genetic mapping of these loci places them at the ends of separate linkage groups, known to be recombinationally active areas in the free-living nematode Caenorhabditis elegans. Analysis of one of these areas in $H$. glycines reveals the presence of mobile genetic elements closely associated with the Ror- 1 locus. A genetic map of the H. glycines genome has been constructed. The $92.5 \mathrm{Mb}$ genome has nine linkage groups. Construction of a physical map by BAC fingerprinting is under way and will be complete soon. In addition to the ror genes, we have placed ESTs on the map, including those with homology to $C$. elegans.

Tomato resistance genes against root-knot nematodes and aphids. V. M. Williamson, S. K. Seah, C. F. Hwang, R. L. Wrobel, and J. Yaghoobi CEPRAP, University of California, Davis, CA 95616. Phytopathology 91:S147. Publication no. P-2001-0003-SSA.

The tomato gene Mi-1 confers resistance against several species of root-knot nematodes and to specific isolates of potato aphid. This gene encodes a protein that belongs to the NB-LRR class of resistance genes. The Mi-1 region of the genome carries two clusters of Mi-1 homologs on chromosome 6 within the chromosomal region that was introgressed from the wild species Lycopersicon peruvianum. One cluster carries the functional nematode resistance copy, $M i$ 1.2 , an expressed homolog, Mi-1.1, and a pseudogene, Mi-1.3. The other cluster carries at least four additional homologs. There are at least 8 homologs in the corresponding chromosomal locations in susceptible tomato and at least two homologs on a different chromosome. DNA blots indicate that homologous sequences are present in other Solanaceous plant species. Structural and function analysis of $M i$ and its homologs is in progress. The phenotypes of domain swaps and single nucleotide changes between $M i-1.1$ and $M i-1.2$ are being characterized to dissect the mechanisms of signal transduction mediated by $M i$.

R-gene homologs in potato confer resistance against distinct pathogens: Nematodes and viruses. A. GOVERSE (1), E. Bakker (1), G. Smant (1), H Sandbrink (2), E. van der Vossen (2), and J. Bakker (1). (1) Lab. Nematology, Wageningen Univ., the Netherlands; (2) BU Genomics, Plant Research International, the Netherlands. Phytopathology 91:S147. Publication no. P2001-0004-SSA.

Genome analysis of a single R-gene cluster in potato led to the isolation of two highly homologous resistance genes: Gpa2 and Rxl. Both genes confer resistance to completely unrelated pathogens, namely the potato cyst nematode Globodera pallida and potato virus X. To get more insight into the evolutionary relationship between the two genes, new homologues were identified. All the homologues mapped to the same cluster on chromosome 12 of the diploid potato clone SH83. Sequence data of the homologues were used to perform phylogenetic analysis of this R-gene cluster. Sequence conservation between the effector domain of Gpa2 and Rxl indicate the activation of a similar resistance mechanism. However, infection studies and histological observations showed a relatively slow resistance response for Gpa2, while $R x 1$ results in extreme resistance. To gain more insight into the mechanism underlying nematode and virus resistance, structure-function analysis of Gpa2 and RxI are currently under investigation.

\section{Biology of Magnaporthe grisea on Turfgrass}

Gray leaf spot research: Recent advances and current challenges. W. UDDIN. Dept. Plant Pathology, Pennsylvania State Univ., University Park, PA 16802. Phytopathology 91:S147. Publication no. P-2001-0005-SSA.

The abstracts are published as submitted. They were formatted but not edited at the APS headquarters office.
Gray leaf spot, caused by Magnaporthe grisea, is a newly emerging problem for the turf industry. The disease has long been associated with Stenotaphrum secundatum and Lolium multiflorum; however, it has become an important disease of L. perenne and Festuca arundinacea in recent years. Severe outbreaks of gray leaf spot epidemics in L. perenne fairways and roughs have resulted in significant loss of turf in golf courses in several geographic regions of the U.S. A number of research studies are currently underway in various institutions in U.S. Significant research progress has been made in pathogen 
population structure and genetic relatedness, molecular biology, rapid disease diagnosis techniques, overwintering, influence of environmental and cultural factors on disease development, and biological, cultural, and fungicidal control. However, major challenges still remain that include disease forecasting, pathogen population diversity, breeding for resistance and host-pathogen interactions. A historical overview, current status and future directions in research, and its implications on turfgrass health management will be discussed.

Population structure and host specificity of Magnaporthe grisea causing gray leaf spot (blast) of perennial ryegrass. G. VIJI (1), W. Uddin (1), B. Wu (1), S. Kang (1), and D. R. Huff (2). Depts. (1) Plant Pathology and (2) Agronomy, The Pennsylvania State Univ., University Park, PA 16802. Phytopathology 91:S148. Publication no. P-2001-0006-SSA.

Isolates of Magnaporthe grisea causing gray leaf spot of perennial ryegrass (PR) were characterized using molecular markers and pathogenicity assays on various gramineous hosts. Phylogenetic analyses using Pot2 and MGR586 probes, analyzed with AMOVA, showed that these isolates consist of three lineages. All the isolates belonged to a single mating type, MAT1-2. Of the 20 isolates from 16 hosts other than PR, only the isolates from wheat showed notable similarity to the PR isolates based on their Pot 2 fingerprints. The PR isolates had the same sequence in the internal transcribed spacer of the genes encoding ribosomal RNA as that of the wheat isolates, but exhibited sequence polymorphisms to that of rice isolates. In pathogenicity assays, the PR isolates were highly virulent on triticale and several wheat types. None of the PR isolates caused the disease on rice and vice versa. Understanding the population structure and genetic relatedness of $M$. grisea from PR may aid in management of gray leaf spot of PR.

Perennation of Magnaporthe grisea in the Midwest: Disease management implications. P. F. HARMON and R. Latin. Dept. Botany and Plant Pathology, Purdue University, West Lafayette, IN 47906. Phytopathology 91:S148. Publication no. P-2001-0007-SSA.

The recent evolution of gray leaf spot into a serious disease in parts of the Midwest threatens the use of perennial ryegrass in all turf settings. This research addresses perennation of the pathogen which is presumed to occur in infested turf residue. Knowledge of the extent to which the pathogen population will survive will improve the ability of turf managers to anticipate gray leaf spot outbreaks and manage the disease effectively and efficiently. Our investigations involve periodic sampling of turf leaf debris infested with $M$. grisea exposed to winter conditions outdoors and stored in controlled environments. Samples were evaluated for pathogen sporulation potential (SP), a quantitative measure of sporulation on infested debris. Assessing SP through winter and spring will help describe the threat to perennial ryegrass stands during the following summer. Our data suggest that $M$. grisea populations are substantially reduced during winter months. Further studies should provide a better understanding of perennation and the degree to which it influences subsequent epidemics.

The population biology of the rice blast pathogen Magnaporthe grisea in the United States. J. C. CORRELL and Y. Jia. Department of Plant Pathology, University of Arkansas, Fayetteville 72701 and Dale Bumpers National Rice Research Center, USDA/ARS, Stuttgart, AR 72160. Phytopathology 91:S148. Publication no. P-2001-0008-SSA.

Genetic and molecular markers have been used to characterize population diversity of the $M$. grisea, and include DNA fingerprinting with the repetitive element MGR586, mating type genes, avirluence genes, and vegetative compatibility. Eight DNA fingerprint lineages of $M$. grisea have been identified in the US, but only four appear to be common in the contemporary population. Tests for vegetative compatibility have been useful for genetically characterizing isolates and the data indicate that certain statistically robust MGR586 lineages are nested within certain vegetative compatibility groups. The various markers support the hypothesis that $M$. grisea is reproducing asexually and novel virulences originate through mutation of avirulence genes within the endemic population. Isolates of $M$. grisea can readily be recovered from non-rice hosts near rice fields, but the vast majority of these isolates are unable to infect rice and appear to be genetically distinct from the rice blast pathogen.

Population genetics of Magnaporthe grisea and implications to gray leaf spot management. L. P. TREDWAY, K. L. Stevenson, and L. L. Burpee. Dept. Plant Pathology, University of Georgia, Athens, GA 30602. Phytopathology 91:S148. Publication no. P-2001-0009-SSA.

Population genetics is the study of forces that drive evolutionary changes in populations. These forces, including selection, mutation, recombination, gene flow, and genetic drift, act together to determine the genetic structure of populations. The genetic structure of a plant pathogen population directly determines how it will respond to implemented control practices. Therefore, knowledge of population structure may be used to enhance the durability of resistant cultivars or delay the occurrence of fungicide resistance. Several researchers have analyzed the genetic structure of $M$. grisea populations associated with rice and other hosts worldwide. Population structure varies from clonal populations with little genetic diversity to highly diverse populations with evidence of genetic recombination. In some cases, analysis of population structure has led to the development of new, effective strategies for managing diseases caused by $M$. grisea. The current knowledge of genetic structure of $M$. grisea turfgrass populations will be reviewed, and implications to disease management strategies will be discussed.

Breeding for gray leaf spot resistance. A. M. HAMBLIN and N. E. Hofmann. Dept. of Natural Resources and Environmental Sciences, University of Illinois, Urbana, IL 61801. Phytopathology 91:S2. Publication no. P-20010010-SSA

The development of perennial ryegrass resistant to gray leaf spot (Magnaporthe grisea) may be an effective way to control this disease. However, previous disease trials failed to identify varieties with acceptable levels of resistance. To identify novel sources of resistance, we screened 200 USDA accessions representing worldwide sources using a conidial suspension. While field trials were unsuccessful in 1999 and 2000, greenhouse screening identified accessions that covered the spectrum of resistance and susceptibility. Commercial field evaluations in Sept. 2000 identified several varieties with moderate resistance. Two mapping populations were developed separately from a two-parent tall fescue cross and a perennial ryegrass topcross. We are currently identifying patterns of inheritance and DNA markers associated with resistance from these crosses. Further genetic studies will map these genes, compare homologues with related host-pathogen systems, and create expressed sequence tags to use in germ plasm screening.

Best management practices for the control of gray leaf spot. B. B. CLARKE and S. S. Vaiciunas. Dept. Plant Pathology, Rutgers University, New Brunswick, NJ 08901. Phytopathology 91:S2. Publication no. P-2001-0011-SSA.

Management practices can influence the development of gray leaf spot (GLS) on perennial ryegrass (PRG), tall fescue (TF), and St. Augustinegrass (SA). For all three grasses, the incidence and severity of GLS typically increases with increasing nitrogen $(\mathrm{N})$ rate above an application rate of $24.4 \mathrm{~kg} \mathrm{~N} \mathrm{ha}^{-1} . \mathrm{N}$ source has also been reported to affect GLS in PRG and TF, but not SA. Compared to controls, water-soluble $\mathrm{N}$ sources can increase the severity of GLS, but slow release $\mathrm{N}$ sources may reduce the disease. In a New Jersey study, there was a consistent positive association between mowing height and the severity of GLS, whereas no association was reported in a Kentucky study. Removal of infested clippings does not appear to affect GLS. The herbicides dithiopyr and ethofumesate can increase GLS. Fungicides are most effective when used preventively. Azoxystrobin and thiophanate-methyl are most efficacious, whereas propiconazole, trifloxystrobin, and chlorothalonil often provide good to excellent control under moderate GLS pressure. SA and TF germ plasm has a wide range of resistance to GLS, but little natural resistance has been reported for PRG.

\section{Role of Fungal Extracellular Matrix in Host Infection}

Concept, visualization and function of the extracellular matrix in host infection. R. L. Nicholson. Dept. of Botany and Plant Pathology, Purdue University, West Lafayette, IN 47907. Phytopathology 91:S148. Publication no. P-2001-0012-SSA.

When observed closely, fungi are found to release a matrix of extracellular material (ECM) upon contact with a substratum. To date, all ECM materials are complexes of high molecular weight glycoproteins. In addition, low molecular weight materials such as germination inhibitors, stimulants, or toxins, are also present in the matrices of some organisms. Major differences among the fungi are when an ECM is released (at what stage of the germination process or simply upon contact), and whether a specific signal triggers the release. Such signals could be host surface morphology (topography) or chemical stimuli that originate from the host itself. A primary function of the ECM seems to be adhesion. When the substratum is a potential 
host, it is possible that the ECM is involved in recognition. Such recognition could involve simply that of the host by the fungus, or in a more complex manner, it could involve signaling that would alert the host to the presence of the pathogen. In such a scenario, it is possible to imagine that the "signal" either "turns on" or "turns off" the capacity of the host to respond to the pathogen's presence.

Extracellular fungal matrix: Role in adhesion. L. EPSTEIN. Dept. of Plant Pathology, University of California, Davis, CA 95616. Phytopathology 91:S149. Publication no. P-2001-0013-SSA.

Many fungi produce glues that spread and cure while under water. Adhesion of macroconidia of Nectria haematococca (anamorph, Fusarium solani) is consistent with the following model. Within $5 \mathrm{~min}$ of incubation in an adhesion-inducing medium, at the macroconidial apices, the spores secrete a sticky lower-molecular-weight and more-water-soluble precursor of a $90 \mathrm{kDa}$ glycoprotein. At the spore apex, the glycoprotein is partially polymerized by a transglutaminase into a somewhat sticky $90 \mathrm{kDa}$ form. After $1-2 \mathrm{~h}$, the $90 \mathrm{kDa}$ glycoprotein is exocellularly modified so that is no longer sticky. After $2 \mathrm{~h}$, adhesion is no longer localized at the spore apex; the macroconidia adhere along the entire lower spore surface, and later along the germ tube substratum interface. Mutant analysis suggests that compounds other than the $90 \mathrm{kDa}$ glycoprotein are involved in this later stage of adhesion. However, inhibition of both spore and germling adhesion by anti- $90 \mathrm{kDa}$ IgGs suggest that related compounds may be involved in spore and germling adhesion. The $90 \mathrm{kDa}$ compound is hydrophobic, contains mannose, N-linkages, and has an amino acid composition with approx. 38\% hydrophobic and 62\% hydrophilic residues.

The extracellular matrix of Bipolaris sorokiniana. D. APOGA (1), H.-B. Jansson (1), B. Ek (2), and A. Tunlid (1). (1) Dept. Microbial Ecology, Lund University, Ecology Building, S-223 62 Lund, Sweden; (2) Dept. Plant Biology, The Swedish University of Agricultural Sciences, Box 7080, S-750 07, Uppsala, Sweden. Phytopathology 91:S149. Publication no. P-2001-0014-SSA.

The cereal pathogen $B$. sorokiniana secretes an extracellular matrix (ECM) that is thought to be important for adhering the fungus to the host surfaces. The ultrastructure and composition of the ECM were investigated using electron and light microscopy based methods. The ECM labeled intensively for both proteins and polysaccharides but the proportion of these compounds changed with the morphological stage of the fungus. A series of experiments studying the adhesion of $B$. sorokiniana to artificial solid surfaces provided evidence that glycoproteins in the ECM mediated germling adhesion. ECM proteins were labeled with a membrane impermeable biotinylating agent and extracted using a $\mathrm{HCl}$-glycine buffer. Two-dimensional gel electrophoresis revealed the presence of about 40 proteins on the fungal cell surface. Four of the ECM proteins were isolated, in gel digested with the enzyme trypsin and sequenced by MS/MS. No significant sequence similarities to proteins in NCBI databases were obtained.

Colletotrichum graminicola and Bipolaris maydis ECM, release and interaction-specific gene expression. J. A. SUGUI (1,2), H. B. Deising (2), and R. L. Nicholson (2). (1) Phytopathology and Plant Protection, Faculty of Agriculture, Martin-Luther-University Halle-Wittenberg, Germany; (2) Dept. Botany and Plant Pathology, Purdue University, W. Lafayette, IN. Phytopathology 91:S149. Publication no. P-2001-0015-SSA.
C. graminicola and B. maydis release ECM. Proteins and carbohydrates were visualized by silver stain and FITC-lectin fluorescent labeling. Labeling showed residues of alpha-D-mannose and/or alpha-D-glucose and $\mathrm{N}$ acetylglucosamine. The same was seen in ECM from B. maydis hyphae and from ungerminated and germinated conidia of $C$. graminicola. $C$. graminicola ECM contained glycoprotein (ca. $200 \mathrm{kDa}$ ). When $C$. graminicola conidia were removed, ECM remained on the surface. Thus, ECM may function as adhesive and have a role in sensing host signals which initiate infection structure differentiation. Appressoria, infection vesicles and hyphae are essential for host colonization. Structure development requires specific gene expression. cDNAs corresponding to gene transcripts expressed at early stages of pathogenesis with Zea mays leaves were cloned. Some of these specific cDNAs showed homology with proteins expressed in other pathosystems.

Surface sensing and response in Blumeria graminis- micromanipulation and geometric modelling. A. J. WRIGHT and T. L. W. Carver. IGER, Aberystwyth, SY23 3EB, UK. Phytopathology 91:S149. Publication no. P2001-0016-SSA.

Blumeria graminis appressorium formation depends on conidial germ tubes making host contact. On cereal leaves, up to $98 \%$ of first-formed germ tubes made contact. A 'surface point' geometric method showed contact frequency was significantly higher (up to 10x) than expected if germ tubes arise randomly from the conidial wall. Thus, emergence site is determined accurately in response to sensing the leaf surface. Further, contact frequency was greater on leaf epidermal cells than artificial substrata suggesting specific recognition of leaf characteristics promotes directional emergence. Micromanipulation indicated that the site of germ tube emergence is determined extremely fast, within $1 \mathrm{~min}$. of deposition. Touching with a microneedle or with spider's thread stimulated directional emergence showing that a very small interface can be sensed. On leaves, the conidium interface is restricted to the tips of a few wall projections touching epicuticular leaf wax plates. On dewaxed leaves, extracellular material was released, probably from conidial wall projections, within $1 \mathrm{~min}$. of deposition. This release is implicated in recognition of the conidium-leaf interface.

Visualization of the extracellular matrix and conidial morphology of Pestalotia malicola. A. J. GEVENS and R. L. Nicholson. Dept. of Botany and Plant Pathology, Purdue University, West Lafayette, IN 47906. Phytopathology 91:S149. Publication no. P-2001-0017-SSA.

Pestalotia malicola conidia incubated on artificial and natural substrata release extracellular matrix (ECM) material. SEM imaging has indicated the presence of ECM beneath conidial appendages and suggests the presence of ECM beneath the germinal segment of the conidium. Indoxyl acetate staining for non-specific esterase activity reveals that enzyme activity occurs initially at the site of the conidial appendages. Later in conidial development, enzyme activity moves to the inner wall of the germinal segment. Gelatin surface lifts observed with light microscopy and SEM indicate that a strong initial conidial adhesion occurs at the site of the sticky appendages which flank the conidium. These lifts also indicate cuticular erosion beneath hyphal segments. That the ECM and enzyme activity were seen beneath firmly adhered conidial appendages suggests that both components have a role in adhesion. SEM reveals the structural morphology of the segmented conidia in addition to the smooth surface features of conidial walls.

\section{Discussion: Mycoviruses}

Viruses of fungi: an introduction to systems. B. I. HILLMAN. Dept. Plant Pathology, Rutgers University, New Brunswick, NJ 08901-8520. Phytopathology 91:S149. Publication no. P-2001-0018-SSA.

With its origins in the 1960's, the study of mycoviruses is a relatively young science. Many fungal viruses remain virtually unstudied, but some systems have become very well understood in the last few years. Intriguing details are coming to light in some of the of these systems. Of the plant pathogenic fungi, Cryphonectria parasitica, the chestnut blight fungus, is the most thoroughly studied in terms of its molecular, evolutionary, and population biology. Viruses of Helminthosporium victoriae, Rhizoctonia solani, Ustilago maydis, and Ophiostoma novo-ulmi are among the other systems for which understanding has deepened considerably over the last few years. This presentation will examine the overall state of fungal virology as a science and will summarize major points of our progress to date with these systems.
Molecular basis of disease in a virus-infected plant pathogenic fungus. S. A. GHABRIAL. Plant Pathology Dept., University of Kentucky, Lexington, KY 40546. Phytopathology 91:S149. Publication no. P-2001-0019-SSA.

Diseased isolates of Helminthosporium (Cochliobolus) victoriae harbor two isometric dsRNA viruses, Hv190SV and Hv145SV. Transformation of virusfree isolates with full-length cDNA of Hv190S dsRNA conferred a diseased phenotype. Disease severity correlated well with the copy number of Hv190S cDNA and with the level of capsid protein accumulation. Furthermore, we cloned and sequenced a cDNA containing the coding region of a novel cellular alcohol oxidase/RNA-binding protein (Hv-p68) that co-purifies with viral dsRNAs, mostly that of the Hv145SV. Sequence analysis revealed that Hv-p68 belongs to the family of FAD-dependent GMC oxidoreductases and that it shares significant sequence identity $(>67 \%)$ with the alcohol oxidases of the methylotrophic yeasts. Significantly higher levels of Hv-p68 mRNA (10-20 fold) were detected in virus-infected isolates compared to virus-free ones. The toxic aldehydes that may accumulate as a consequence of overexpression of Hv-p68 could account for the lytic phenotype associated with virus infection. 
Hv-p68 is proposed to play a role in viral RNA packaging/replication and in regulating viral pathogenesis.

Quinate induction of dsRNA and hypovirulence in Rhizoctonia solani. S. M. TAVANTZIS, D. K. Lakshman, and C. Liu. Dept. Biological Sciences, University of Maine, Orono, ME 04469. Phytopathology 91:S150. Publication no. P-2001-0020-SSA.

Our goal is to understand the genetic and biochemical basis of hypovirulence in Rhizoctonia solani. Based on biological data and sequence analysis, we proposed that the putative polypeptide A (p83), which is encoded by a $3.6 \mathrm{~kb}$ dsRNA (M2) in strain Rhs 1A1, might interfere with the regulation of the quinate and shikimate pathways. In western blot analyses, we showed that a protein binds p83-specific antibodies, has the expected migration rate, and is detected in M2-containing, but not in M2-lacking cultures. The mRNA encoding this protein has a sequence identical to that of the M2 dsRNA. In the virulent, M2-lacking isolate Rhs 1AP (isogenic of Rhs 1A1), quinate reduces virulence dramatically, and induces synthesis of $\mathrm{p} 83$ and its respective mRNA. The quinate-induced hypovirulence in Rhs $1 \mathrm{AP}$ cannot be overturned by chorismate (end-product of the shikimate pathway), which, when used alone, increases virulence dramatically. As predicted by our hypothesis, the normally inducible quinate pathway is constitutively expressed in the M2-containing, hypovirulent Rhs $1 \mathrm{~A} 1$.

Symptom induction by the mycovirus CHV1-EP713. N. K. VAN ALFEN, P. M. McCabe, M. Turina, and P. Kazmierczak. Dept. Plant Pathology, University of California, Davis, CA 95616. Phytopathology 91:S150. Publication no. P-2001-0021-SSA.

We are investigating the mechanism of symptom induction by the hypovirus CHV1-EP713 in order to better understand the role and limitations of this virus as a biological control agent of the chestnut blight fungus, Cryphonectria parasitica. Our approach is to identify fungal gene products that are not expressed when the fungus is infected with the virus. The symptoms of virus infection are a perturbation of fungal development, i.e. the fungus grows normally as a saprophyte but does not sporulate nor is it virulent. We have found that the products of most of the genes selected have common endoprotease cleavage sites suggesting they are processed and secreted by a mechanism similar to the Kex2p secretory pathway of yeast. We have also found that replication of the virus occurs on a vesicle fraction containing at least one of these secreted proteins, that the virus blocks the normal secretory process of this cargo protein, and that a Kex $2 p$ protease inhibitor reproduces the symptoms of the virus. Our evidence strongly suggests that the virus causes symptoms by replicating on specific fungal secretory vesicles perturbing normal developmental process.

Engineering hypoviruses for fundamental and practical applications. B. Chen, N. Suzuki, and D. L. NUSS. Center for Agricultural Biotechnology, University of Maryland Biotechnology Institute, College Park, MD 207423351. Phytopathology 91:S150. Publication no. P-2001-0022-SSA.

The concept of using a parasite of a parasite for disease control is appealing from both an intellectual and an ecological perspective. The phenomenon of transmissible hypovirulence, in which virulence of the chestnut blight fungus, Cryphonectria parasitica, is attenuated by double-stranded RNA viruses in the family Hypoviridae, is often cited as a classic example of this approach to biological disease control. Progress in the development of an infectious cDNAbased reverse genetics system for hypoviruses has provided the means for engineering these viral agents for both fundamental and practical applications. We describe recent progress in using these technologies to identify virusencoded determinants responsible for altering fungal host phenotype, to gain insights into dispensable and essential elements of viral replication, and to finetune the interaction between a fungal pathogen and its plant host.

Horizontal transmission in populations of fungal viruses. M. G. MILGROOM. Dept. Plant Pathology, Cornell University, Ithaca, NY 14853. Phytopathology 91:S150. Publication no. P-2001-0023-SSA.

Most fungal viruses have little or no deleterious effects on their hosts. This is consistent with theories on the evolution of virulence: high virulence can only evolve when transmission between host individuals (horizontal transmission) occurs frequently in relation to parent-offspring (vertical) transmission. Horizontal transmission rates are likely to be low in most fungal populations because vegetative incompatibility generally inhibits the transmission of viruses between vegetative compatibility (vc) types. In Cryphonectria parasitica, vegetative incompatibility (vic) genes at different loci have variable effects on virus transmission between vc types. At the population level, we can detect horizontal transmission directly by analyzing virus sequences. In two populations, we found that virus gene flow is not restricted between vc types, but is restricted between populations. By combining knowledge of the effect of each vic gene and vic genotype frequencies we can predict the average horizontal transmission rate within populations. Expected transmission correlates negatively with vc type diversity, but not with the observed incidence of virus infection in Italy.

\section{Soilborne and Fungal Transmitted Viruses}

Molecular and biochemical studies of the interaction between cucumber necrosis virus and zoospores of the fungal vector, Olpidium bornovanus. $D$. ROCHON (1), K. Kakani (2), and R. Reade (1). (1) Agriculture and Agri-Food Canada, Pacific Agri-Food Research Centre, Summerland, B.C. VOH 1Z0; Dept. Plant Science, Univ. British Columbia, Vancouver, B.C. V6T $1 Z 4$. Phytopathology 91:S150. Publication no. P-2001-0024-SSA.

Efficient transmission of many plant viruses requires distinct invertebrate or fungal vectors. In most cases, transmission has been shown to be a highly specific process in which only certain vectors can transmit certain viruses. These observations suggest that virus particles as well as vectors contain specific sites that mediate recognition. Cucumber necrosis virus (CNV) is naturally transmitted in the soil by zoospores of the fungal vector, $O$. bornovanus. Successful transmission requires that virus particles attach to the surface of zoospores prior to zoospore encystment on roots. Evidence is presented that the quasi-threefold axis of the CNV icosahedron contains important determinants for virus attachment to zoospores. Evidence implicating a specific zoospore receptor in the attachment process is also described.

Identification of a distinct Tombusvirus that causes disease of lettuce and tomato in the western United States. G. C. WISLER (1), C. Obermeier (2), J. L. Sears (1), H. Y. Liu (1), K. O. Sschleuter (1), E. J. Ryder (1), J. E. Duffus (1), and S. T. Koike (3). (1) USDA-ARS, 1636 E. Alisal St., Salinas, CA 93905; (2) Humboldt-Universität zu Berlin, Institut für Gartenbauwissenschaften, Fachgebiet Phytomedizin, Lentzeallee 55-57, D-14195 Berlin, Germany; (3) University of California, Cooperative Extension, 1432 Abbott St., Salinas, CA 93901. Phytopathology 91:S150. Publication no. P-20010025-SSA.
A new soilborne virus related to Tomato bushy stunt virus (TBSV) causing necrosis and dieback has been found in romaine and leaf lettuce in California and Arizona. Heavy rains and flooded land in the past several years may have caused the emergence of this soil- and water-borne virus. At the same time, a tombusvirus has also been found to be responsible for a necrosis-inducing disease of greenhouse tomatoes in Colorado, New Mexico, and Texas. Sequences of cDNA clones generated from the 3'-end of viral genomic RNA from diseased lettuce and tomato plants were identical. These sequences were divergent $(12-17 \%)$ from those of previously described strains of TBSV; TBSV-Cherry, Petunia asteroid mosaic virus, Artichoke mottled crinkle virus and Carnation Italian ringspot virus. Western blot analysis revealed the new tombusvirus from diseased lettuce and tomato plants as serologically distinct from previously described tombusvirus species and strains. Based on genomic and serological properties we propose to classify this virus as a new tombusvirus species termed Lettuce necrotic stunt virus.

Interactions between BNYVV and BSBMV in sugarbeet affect virus titer and beet development. W. M. WINTERMANTEL, G. C. Wisler, R. T. Lewellen, H.-Y. Liu, and J. Sears. USDA-ARS, Salinas, CA 93905. Phytopathology 91:S150. Publication no. P-2001-0026-SSA.

Beet necrotic yellow vein virus (BNYVV), which causes rhizomania disease of sugarbeet, produces striking hairy root symptoms and results in severely diminished sugar yield and root weight. Beet soil-borne mosaic virus (BSBMV) does not produce these severe symptoms, but may also reduce yields based on greenhouse tests. Both Benyviruses are transmitted by the soil-borne fungus, Polymyxa betae. The Rz gene, which is highly effective in controlling rhizomania symptoms, does not confer resistance to BSBMV. These viruses are frequently found together in western U.S. beet fields. We are attempting to determine how the presence of both viruses together affects beet yield, sugar content and virus concentration. To address these questions, sterile soils were inoculated with viruliferous beet roots containing $P$. betae, or $P$. betae carrying 
one and/or both viruses as single and mixed infections. Results demonstrated that concentrations of both viruses individually increased early, then began to decline. In addition, BSBMV levels were suppressed in mixed infections with BNYVV, and BNYVV levels appear to increase in the presence of BSBMV, suggesting synergism between these viruses.

Soilborne wheat mosaic virus moves long distance through the xylem. J. VERCHOT, B. A. Driskel, Y. Zhu, and L. J. Littlefield. Department of Entomology and Plant Pathology, Oklahoma State University, Stillwater, OK 74078. Phytopathology 91:S151. Publication no. P-2001-0027-SSA.

Soilborne wheat mosaic virus (SBWMV) is a bipartite positive strand RNA virus that is transmitted to wheat roots by the plasmodiophorid vector Polymyxa graminis. Experiments were conducted to determine the path SBWMV utilizes to move from the roots to aerial parts of the plant. Using SBWMV antiserum, immunogold labeling and silver enhancement, SBWMV was detected in the xylem of infected wheat plants. Cross sections of wheat roots, stems, and leaves were analyzed and in all cases SBWMV was detected in the xylem and rarely in the phloem. Root cross sections were also treated with geimsa and toluidine blue to detect viral inclusion bodies. Viral inclusion bodies were observed inside xylem vessels. In situ hybridization was also conducted to detect viral RNAs in root cross sections. Viral RNAs were detected in xylem vessels in wheat roots. In four-week-old wheat roots, SBWMV was detected early in infection in xylem tissue that had not undergone programmed cell death. SBWMV may enter immature xylem tissue and then after programmed cell death virion particles may remain inside vessels.

Identification of genes involved in the transmission of viruses by plasmodiophorid vectors. M. J. ADAMS (1), J. F. Antoniw (1), and J. G. L. Mullins (2). (1) Plant Pathology and Bioinfomatics Depts, IACR-Rothamsted; (2) Univ. of Luton. Phytopathology 91:S151. Publication no. P-2001-0028SSA.

The sequences of several furovirus isolates from oats and wheat in Europe and China have been determined. Two complementary transmembrane (TM) domains were identified in the coat protein readthrough (CP-RT) domains of these viruses, a region believed to be important for transmission by plasmodiophorid vectors. Computer analysis of published sequences of other viruses with similar vectors identified paired TM domains also in the CP-RT of benyviruses and pomoviruses and in the $\mathrm{P} 2$ proteins of bymoviruses. The second TM domain is absent or disrupted in spontaneous deletion mutants that cannot be fungally transmitted. Structural arrangements consistent with tight packing of these TM helices were identified. Because there are few other similarities between the genomes of these viruses, it seems likely that these transmembrane helices are essential for fungus transmission. They may act by facilitating the movement of virus particles across the fungal membrane that separates the vector and host cytoplasm in infected root cells.

\section{What Is a Fungal Species?}

Lineages, phenotype and the practical species. T. C. HARRINGTON. Dept. Plant Pathology, Iowa State University, Ames, IA 50011. Phytopathology 91:S151. Publication no. P-2001-0029-SSA.

In phylogenetic species concepts (PSC), species are delimitated by characters. Modifying the original PSC, fungal species are the smallest aggregation of populations with a common lineage that share unique, diagnosable phenotypic characters. Genetic (DNA based) characters are useful in identifying lineages, while phenotype determines which lineages are species. All members of a species must be of the same lineage, but not all lineages are species, e.g., asexual species are a collection of many closely related lineages. Also, geographically isolated populations are unique lineages, although they may be indistinguishable by morphology, physiology or ecology. Phylogenetic analyses of DNA sequences, population genetics, and intersterility (biological species) have proven valuable for identification of lineages, but there is little practical information to be gained in describing such lineages as distinct species, unless there is some phenotypic character that distinguishes them. Physiological characters, such as host specialization, are often more useful than morphological characters for distinguishing species, and special forms (f. spp.) could be considered species.

Species concepts and classification of asexual fungi. J. W. TAYLOR. Dept. Plant and Microbial Biology, University of California, Berkeley, CA 947203102. Phytopathology 91:S151. Publication no. P-2001-0030-SSA.

Under an evolutionary species concept, fungal species are commonly recognized by phenotype, mating tests or phylogenetics, corresponding to morphological, biological and phylogenetic species recognition. The mycological emphasis on the morphology of sex, and the necessity of sex for mating tests has not served asexual fungi. By comparing the topologies of several gene genealogies, species can be diagnosed using the transition from topological congruence to conflict. This gene genealogy concordance version of the Phylogenetic Species Concept has become popular with all fungi, including uncultivatable fungi and mitosporic fungi. Recent application of this PSC in pathogenic fungi such as Fusarium, Coccidioides, Aspergillus, and Histoplasma, as well as the symbiotic fungus Letharia has revealed genetically isolated groups of fungi in what had been considered to be single morphological species. Apparently, the phylogenetic approach recognizes evolutionary species earlier than do the morphological or biological approaches, and accommodates asexual, mitosporic fungi. Once mitosporic species are recognized, they may prove to be recombining.

Regulatory issues: Why species identification is important. M. E. PALM. USDA/APHIS, Systematic Botany and Mycology Laboratory, Beltsville, MD 20705. Phytopathology 91:S151. Publication no. P-2001-0031-SSA.

To protect plant resources it is critical to prevent the introduction of plant pathogens into new regions. This activity relies on the ability to distinguish fungi not present in an area from those already present. Traditionally, decisions to exclude pathogens have been based on species defined by morphological criteria. However, in many cases taxon names may not be biologically meaningful. For example, many fungal species considered to be host specific have a wider host range than has been reported. Morphologically similar but genetically distinct fungi may infect the same host species. Additionally, some morphological species have been found to be genetically diverse. Do those genetic differences correlate with a differing ability to cause plant disease? Decisions regarding regulation of different biological entities presents a challenge to phytosanitary organizations worldwide. Systematic studies, utilizing morphological, biological, and genetic characteristics, can provide new tools for identifying fungi as well as biologically meaningful names, which are vital to safeguarding plant resources.

Application of the phylogenetic species concept in Fusarium. K. O'DONNELL and T. Ward. USDA, ARS, NCAUR, Peoria, IL 61604. Phytopathology 91:S151. Publication no. P-2001-0032-SSA.

Multiallelic genealogies are being constructed from DNA sequences of mostly single-copy nuclear genes to investigate species boundaries and the evolution of mycotoxins, host range and biogeography within the most important mycotoxigenic and phytopathogenic lineages of Fusarium. Due to the paucity of phenotypic traits, application of Genealogical Concordance Phylogenetic Species Recognition [GCPSR; Taylor et al. 2000] has revealed that this genus is about 10 times more species-rich than previously recognized using morphology alone [Nelson et al. 1983]. Although we strongly advocate GCPSR, gene-gene discordances have been encountered within all major lineages of Fusarium. One of the most striking examples is illustrated by a 19 $\mathrm{kb}$ region of the trichothecene toxin gene cluster within the Gibberella zeae species complex. The evolutionary history of this gene cluster is highly discordant with a species phylogeny inferred from genes outside the cluster. Evolutionary processes that have contributed to the gene tree-species tree discordances within Fusarium include transspecies polymorphisms, introgressive hybridization and paralogy.

Defining species boundaries in the smut fungi. L. M. CARRIS (1) and L. A. Castlebury (2). (1) Dept. Plant Pathology, Washington State University, Pullman, WA 99164; (2) Systematic Botany and Mycology Lab, USDA ARS, Beltsville, MD 20705. Phytopathology 91:S151. Publication no. P-2001-0033SSA.

Taxonomic concepts in smut fungi range from extreme splitting based primarily on hosts, resulting in a proliferation of names, to extreme lumping based on similar teliospore morphology. Synonymies resulting from the latter view may mask the number of genetically diverse taxa, but attempts to determine host specificity by experimental means may overestimate natural host range. Similarly, high levels of inoculum that develop on cultivated crops may produce "accidental" hosts and result in wide host ranges such as reported for the dwarf bunt pathogen Tilletia controversa. Our applications of RAPD and DNA sequence analyses to the characterization of Tilletia species infecting wild grass hosts have in general supported narrow species boundaries corresponding to 
specialization at the host species level. The focus on agriculturally important smut fungi, which represent a small proportion of known taxa, may provide a misleading view of host range and specificity and, hence, underestimate the genetic diversity present in this group of obligate plant parasites.

Defining species boundaries with gene flow analysis. S. B. GOODWIN. USDA-ARS, Purdue Univ., W. Lafayette, IN. Phytopathology 91:S152. Publication no. P-2001-0034-SSA.

Reproductive isolation is the first step in species formation. Detecting when this has occurred can be difficult, because morphological differentiation usually is not evident during the early stages of species formation. Gene flow analysis estimates the number of migrants between populations per generation.
Populations exchanging fewer than one migrant every other generation are reproductively isolated and may be beginning the speciation process. Gene flow analysis can be used with any type of discrete genetic marker, including those commonly employed by plant pathologists and mycologists (e.g., isozymes, RAPDs, AFLPs). Gene flow analysis of the oomycetes Phytophthora infestans and $P$. mirabilis indicated that these taxa were reproductively isolated and clearly represent two species, even though their ITS sequences are identical and would not have been separated by sequence analysis of that region. Analysis of the rice blast pathogen Magnaporthe grised indicated that most host-associated forms are reproductively isolated from the others and probably represent different species. This technique can be a powerful tool for testing the level of gene flow among closely related, morphologically similar taxa.

\section{Diseases of Plants}

\section{The Use of Conserved Sequences for the Detection of Plant Pathogens}

The use of conserved DNA sequences in molecular taxonomy and detection of fungi. C. A. LEVESQUE. Eastern Cereal \& Oilseed Research Centre, Agriculture and Agri-Food Canada, Ottawa, ON, Canada, K1A 0C6. Phytopathology 91:S152. Publication no. P-2001-0035-SSA.

One can safely say that PCR and conserved sequences are largely responsible for the DNA-based advances in phylogeny and detection of fungi. PCR primers have been designed with various levels of resolution from all eukaryotes down to strains. Some of these primers were used in PCR and sequencing reactions to develop databases on a wide range of taxa. More recently, primers targeting phyla are used to study obligate biotrophs, or determine fungal diversity and ecology in DNA extracted from different sample environments. PCR products can be either cloned and sequenced, or labeled and hybridized to DNA arrays. It is likely that many nonculturable fungi will be found with new molecular approaches. Establishing confidence in the resolution level of PCR, or hybridization assays with conserved sequences, will required an extensive sequence database or thorough testing of the assay. With the rapid expansion of GenBank into more fungal taxa and the development of novel tools in bioinformatics, it should become more straightforward to find and design robust conserved sequences for a wide range of applications at a selected resolution.

Detection and identification of phytoplasmas using PCR primers derived from conserved and semiconserved gene sequences. B. C. KIRKPATRICK and C. L. Blomquist. Dept. of Plant Pathology, Univ. of California, Davis, CA. Phytopathology 91:S152. Publication no. P-2001-0036-SSA.

Our knowledge of the genetic diversity of plant pathogenic phytoplasmas has been revolutionized by sequencing evolutionarily conserved genes. After the first phytoplasma 16S rRNA sequences were determined, PCR primer sequences were quickly identified that directed the amplification of $16 \mathrm{~S}$ rDNA from phylogenetically diverse phytoplasmas. Analysis of these diverse phytoplasmas identified primers that amplified rDNA from specific phylogenetic clades. Analysis of semi-conserved sequences, such as ribosomal protein, tuf genes, and 16/23S rRNA spacer regions, identified additional clade-specific PCR primers. Analyses of less conserved genes, such as membrane proteins, have identified strain-specific PCR primers. PCR has been used to identify phytoplasma plant reservoirs and insect vectors, thus facilitating epidemiology studies on phytoplasma diseases. The development of quantitative and colorimetric PCR assays, which have greater throughput capabilities, suggests that PCR detection and identification of phytoplasmas will become easier and less expensive in the future.

Molecular diagnostics of nematodes as part of the pest-pathogen complex in cropping system soils. J. CURRAN. CSIRO Entomology, PO Box 1700, Canberra, ACT 2601, Australia. Phytopathology 91:S152. Publication no. P2001-0037-SSA.

Conserved DNA sequence data is a reliable means of identifying plantparasitic nematodes. rDNA, mtDNA and other "standard" gene regions have provided diagnostic markers for many of the economically important taxa. Rapid progress has been made with the cyst- and root-lesion nematodes, but the root-knot nematodes have proven less tractable. The latter perhaps reflects the more complex evolutionary relationships within root-knot nematodes and the challenges of using repetitive DNA sequences to unravel polyploid and often parthenogenetic (and clonal) lineages. Notwithstanding the challenges of establishing taxon boundaries, any diagnostic that is to have value in decision support needs to quantify the range of pests and pathogens found in the soil of cropping systems. Not surprisingly, no single gene region has proven to be useful in diagnosing all pests and diseases of interest. Thus a routine diagnostic for soil pests and diseases requires technological approaches that develop cost-effective test formats and are a compromise between taxon identification, quantification and the level of information required for decision support.

PCR tests based on required, host-specific, pathogenicity genes. D. W. GABRIEL. Dept. of Plant Pathology, Univ. of Florida, Gainesville, FL 32615. Phytopathology 91:S152. Publication no. P-2001-0038-SSA.

Citrus canker disease is caused by several groups of Xanthomonas strains, some of which are phylogenetically distinct. A pathogenicity gene, pthA, is required, and present, in all Xanthomonas strains tested causing citrus canker disease, and absent in non-canker causing xanthomonads isolated from citrus. Presence or absence of a $p t h A$ allele is therefore diagnostic for strains having capacity to cause canker on citrus. A series of PCR primers was designed to detect any canker causing strains and to distinguish known canker strain groups. A "universal" canker primer set was designed to detect pthA, the gene required by all known citrus canker strains. Primers to distinguish Asiatic canker groups from South American canker strains were also designed. Canker strain-specific primers did not react with $X$. campestris pv. citrumelo strains tested that cause bacterial leaf spot of citrus. The minimum number of bacterial cells detected from cell culture and from diseased lesions was ca. 6 CFU and $360 \mathrm{CFU}$, respectively. The method was adapted to a RAPID Cycler, providing the possibility of developing a 1-h canker assay.

Conserved nucleotide sequence-based applications for detection and differentiation of plant viruses. B. W. FALK (1), T. Tian (1), H.-X. Lin (1), L. Rubio (2), and P. L. Guy (3). (1) Dept. of Plant Pathology, Univ. of California, Davis, CA 95616; (2), IVIA, 46113 Moncada, Valencia, Spain; (3) Univ. of Otago. Phytopathology 91:S152. Publication no. P-2001-0039SSA.

Contemporary efforts in organismal biology and taxonomic classification are rapidly becoming more genome-based. Viruses are no exception, and numerous nucleotide (and deduced amino acid) sequence-based approaches have been developed for identifying and/or differentiating plant viruses. The rapidly accumulating database of virus genomic sequences in conjunction with powerful DNA-based techniques including the polymerase chain reaction (PCR) and nucleotide sequence analysis offer tremendous opportunities for studies of plant viruses ranging from etiology, to epidemiology, to virus genetic diversity. By utilizing nucleotide sequence conservation at the family, genus and/or species levels PCR and/or nucleotide sequence-based approaches can be used to identify viruses at each of these respective taxonomic levels, or even to study intraspecies variation and virus evolution. Examples of our own work as well as those of others will be discussed. 


\section{Importance of Plant Pathology in Global Trade}

Science-based initiatives to expedite global trading and exchange of seeds and commodities. D. C. MCGEE. Seed Science Center and Dept. of Plant Pathology, Iowa State Univ., Ames, IA. Phytopathology 91:S153. Publication no. P-2001-0040-SSA.

The overall goal of a world phytosanitary system is to protect against the spread of economically important pathogens without posing unnecessary barriers to worldwide movement of seeds, germ plasm, and commodities. The present world phytosanitary system is not doing this effectively or efficiently. Resources are being misdirected on unnecessary regulations and many potentially important seed-borne pathogens are being ignored. This presentation describes initiatives to improve this regulatory environment by utilizing newly developed seed-borne disease information sources and by national and international efforts to establish standards for seed health testing methods. Recently completed projects in Central America, East Africa and the USA where these objectives have been met will be described.

The smuts and their effect on global wheat trade. D. E. MATHRE. Dept. of Plant Sciences and Plant Pathology, Montana State University, Bozeman, MT 59717. Phytopathology 91:S153. Publication no. P-2001-0041-SSA.

Prior to 1973, wheat grain generally moved around the world with little restraint. Things changed dramatically in 1973 when the acronym TCK hit the grain trade. For the next 27 years, TCK, better known as dwarf bunt of winter wheat caused by Tilletia controversa Kuhn, was a major obstacle in the movement of wheat from the United States to the People's Republic of China (PRC) and sometimes into other countries e. g. Brazil. Grain carrying any number of teliospores of TCK was not acceptable to these countries. This obstacle was removed in the year 2000 after years of research and negotiation. Currently, grain with a limited quantity of TCK teliospores is accepted by the PRC. At the current time another smut, karnal bunt, is also affecting the global movement of wheat carrying teliospores of Tilletia indica, the cause of karnal bunt. A less than perfect understanding of the etiology of karnal bunt disease and its effect on yield and quality of harvested grain has caused embargoes to be placed against it by a number of countries. Hopefully, a better scientific understanding of this disease will allow rationale decisions to be made by regulatory agencies affecting the global trade of wheat.

International trade and late blight of tomatoes and potatoes. W. E. Fry. Department of Plant Pathology, Cornell University, Ithaca, NY 14853. Phytopathology 91:S153. Publication no. P-2001-0042-SSA.

Potatoes are a commodity for which plant diseases are particularly important There is particular emphasis on viruses. As such, phytosanitary considerations have been implemented in production systems and in international commerce. For example, quarantine considerations stipulate a process requiring 12-24 months to import a particular genotype of potato into the USA from many different countries. Other countries have similarly stringent rules governing importation of tubers and plantlets for research or production. However, commercial trade of potato tubers and tomato fruit for direct consumption has different rules. The commercial trade of potatoes and tomatoes is most certainly responsible for the recent global movement of exotic strains of Phytophthora infestans from Mexico. While P. infestans previously had a global distribution, the recent global distribution of exotic strains has worsened the late blight problem. This situation raises the question about whether it is experimentally possible to predict the ecological effect of different strains.

\section{Teach-In: Development and Application of Pest Risk Assessments}

An introduction to plant pest risk analysis. E. V. PODLECKIS. USDA, APHIS, Plant Protection and Quarantine, Riverdale, MD 20737-1236. Phytopathology 91:S153. Publication no. P-2001-0043-SSA.

The purpose of risk analysis is to improve decisions and the decision-making process. Pest risk analysis (PRA) is defined in standards developed by the International Plant Protection Convention as "the process of evaluating biological or other scientific and economic evidence to determine whether a pest should be regulated and the strength of any phytosanitary measures to be taken against it." PRA is often described as having three components: risk assessment, risk management and risk communication. In the context of regulatory plant pathology, risk assessment is defined as "the determination of whether a pest is a quarantine pest and evaluation of its introduction potential." Risk management is defined as the decision-making process of reducing the risk of introduction of a quarantine pest. PRA is iterative and requires clear communication of risk among risk analysts, risk managers, decision-makers and stakeholders throughout the process. Risk is a pervasive part of trade and trade requires phytosanitary choices. Risk analysis provides a way to seek out correct decisions when faced with imperfect knowledge.

International standards and obligations for pest risk analysis. R. L. GRIFFIN. International Plant Protection Convention, Secretariat, FAO, Rome. Phytopathology 91:S153. Publication no. P-2001-0044-SSA.

Free and fair trade objectives promoted by the World Trade Organization intersect with objectives of plant protection under the International Plant Protection Convention (IPPC) where the hybrid "safe trade" is addressed by global harmonization of phytosanitary measures. Pest risk analysis (PRA) is crucial as the accepted basis to justify phytosanitary measures in the absence of international standards or if governments wish to deviate from those standards. Key concepts, principles and procedures in international standards are the basis for globally harmonized phytosanitary measures. IPPC standards provide guidelines for PRA. Governments experience with application of PRA guidelines developed a decade ago contributed to improvement in the understanding and practice of PRA. Greater detail and more emphasis on analytical methods emerged as priorities for future development. Development of specific PRA applications for transgenic organisms and environmental protection have been raised as needs for guidelines from the IPPC. Such initiatives offer opportunities for PRA to serve as a catalyst for harmonizing trade, plant protection, and environmental obligations.
The safeguarding review and its impact on plant pest risk assessment in USDA. D. ZADIG. Plant Health and Pest Prevention Services, California Department of Food and Agriculture, Sacramento, CA. Phytopathology 91:S153. Publication no. P-2001-0045-SSA.

"The problem with the future is that it isn't what it used to be" - Paul Valery.-The Safeguarding Review Panel found that one of the most important roles of government must fulfill is the management of risk. Key to remaining relevant in plant protection will be the institutionalization of continuous improvement in all its risk analysis and risk management programs, service to its stakeholders, and control and management of its information and knowledge. A critical benchmark for success will be implementation of a risk communication strategy that does away with its historic decide, announce, and defend (DAD) approach.

A risk analysis model using the CABI database. D. C. MCGEE. Seed Science Center and Department of Plant Pathology, Iowa State University, Ames, IA. Phytopathology 91:S153. Publication no. P-2001-0046-SSA.

Dramatic increases in phytosanitary regulations over the last 20 years has had serious adverse effects on the trading and exchange of seeds throughout the world. The validity of regulations often are subject to challenge. Conventional quantitative Pest Risk Analysis (PRA) methods tend to be too complex for evaluation of the large numbers of questionable regulations involved. The Database of Seedborne Diseases (DSD) is a component of the CABI Crop Protection Compendium that includes datasheets on almost 300 seedborne pathogens in CD-Rom format. The utilization of the DSD as the core information source in concert with standard PRA systems, such as the FAO PRA Guidelines, allows the development of "fast-track" PRAs that can rapidly resolve the issue of justification of large numbers of phytosanitary regulations. Effective use has been made over the period 1998-2000 of this system in reducing numbers of phytosanitary regulations affecting seeds by approximately 90 percent in Central American and East African countries.

Climate analysis to predict range size of introduced species. R. C. VENETTE. USDA-APHIS and Dept. of Entomology, University of Minnesota, St. Paul, MN 55108. Phytopathology 91:S153. Publication no. P-20010047-SSA

Predicting the geographic range of an introduced species is critical to assess the risks it may pose. As range size increases, the potential for severe economic or ecological impacts also increases. The climatic software, Climex, has been used in a number of contexts to predict if and where a species might become established, should it arrive in a country. The model relies on the assumption that climate is the fundamental determinant of establishment success. The 
software contains climatic summaries for about 3,000 locations worldwide. Climatic similarity between any two locations is expressed in a number of similarity indices based on minimum temperature, maximum temperature, total precipitation, precipitation pattern, and relative humidity. If areas can be identified where establishment has occurred and has not occurred due to climatic constraints, logistic regression analysis of similarity indices can be employed to estimate the probability of establishment given a specified degree of climatic similarity. Application of this technique to pink bollworm, Pectinophora gossypiella (Saunders), will be discussed.

\section{Epidemiology/Ecology/Environmental Biology}

\section{Antimicrobial Resistance: A Cross-Cutting Issue Facing the Agricultural, Clinical and Veterinary Communities}

Agricultural antibiotic resistance: Fire blight as a case study. P. S McMANUS. Department of Plant Pathology, University of Wisconsin, Madison, WI 53706. Phytopathology 91:S154. Publication no. P-2001-0048-SSA.

In the 1950s, shortly after the introduction of antibiotics in human medicine, nearly 40 of these "miracle drugs" were screened on plants. By the 1960s, only streptomycin was used widely, primarily to manage fire blight of apple and pear. By the early 1970s, streptomycin-resistant strains of Erwinia amylovora, the fire blight pathogen, were curtailing disease control in pear orchards in the western U.S. Streptomycin-resistant E. amylovora has since been reported from additional regions, and two distinct genetic mechanisms have been elucidated: (i) ribosomal mutation which prevents the binding of streptomycin; and (ii) production of an enzyme which inactivates streptomycin. Both mechanisms also have been described in diverse bacteria, including pathogens of animals and humans. This has raised concerns that antibiotic use on plants, which some see as an imprudent luxury, may contribute to the public health threat of antibiotic resistance. The political controversy surrounding antibiotic use on plants comes at a time when apple and pear growers are suffering devastating losses from fire blight but have few effective disease management tools.

Potential sources of antimicrobial resistant microbes in postharvest handling of edible horticultural crops. T. V. SUSLOW. Dept. of Vegetable Crops, University of California, Davis, CA 95616-8631. Phytopathology 91:S154. Publication no. P-2001-0049-SSA.

Fecal waste pollution and the intentional application of managed fecal matter to soil or foliar plant parts intended for edible crop production are issues of concern in the microbial food safety management of horticultural crops. Indirectly through contaminated water or by cross-contamination from animal production facilities, inadequately composted animal manure or biosolids, there exists a potential for persistent pathogen populations to be transferred to edible crops. Pathogens, such as Salmonella and E. coli O157:H7 grow extremely well on many fruits and fruit-vegetables above 59F (15C). Wounds and areas of decay initiation have been shown to be sites for multiplication of these human pathogens. The realities of postharvest distribution make it highly likely that temperature abuse may occur. These strains may harbor multiple antimicrobial resistance (MAR) factors. Multiple antibiotic resistances are also reported in genera that are common plant epiphytes, like Klebsiella. Some consider these as opportunistic pathogens. Genetic insensitivity to sanitizers, biocides such as quats and chlorophenols, are reported.

A public health action plan to combat antimicrobial resistance (Part I: Domestic Issues). J. T. WEBER. Centers for Disease Control and Prevention, Atlanta, GA 30333. Phytopathology 91:S154. Publication no. P-2001-0050SSA.

Drug-resistant pathogens are a growing menace to all people, regardless of age, gender, or socioeconomic background. Examples of clinically important microbes that are rapidly developing resistance to available antimicrobials include bacteria that cause pneumonia, ear infections, and meningitis, skin, bone, lung, and bloodstream infections, foodborne infections, and infections transmitted in health care settings. A Federal Interagency Task Force on Antimicrobial Resistance that was created in 1999. The Task Force is cochaired by CDC, FDA, and NIH, and also includes AHRQ, USDA, DoD, DVA, EPA, HCFA, and HRSA. An action plan was developed and released in January 2001. The Action Plan provides a blueprint for specific, coordinated federal actions to address the emerging threat of antimicrobial resistance. The Action Plan has four focus areas: surveillance, prevention and control, research and product development. Included among surveillance action items for implementation is the monitoring of antimicrobial resistance in agricultural settings to protect the public's health by ensuring a safe food supply as well as animal and plant health.

\section{Enhancing Microbial Biocontrol of Postharvest Fruit Pathogens}

Next generation of biological control of postharvest diseases of fruits. W. J. JANISIEWICZ. USDA, ARS, Appalachian Fruit Research Station, Kearneysville, WV 25430. Phytopathology 91:S154. Publication no. P-20010051-SSA.

Commercial use of biological control against postharvest decays (BCPD) of fruits has been in effect for the past six years. Two antagonists were registered for postharvest use by the United States EPA in 1995, a saprophytic strain of Pseudomonas syringae and a yeast Candida oleophila, which are the active ingredients in the commercial products Bio-Save 110 and Aspire, respectively. Use of Bio-Save 110 to control decays of pome fruits has been increasing steadily for the past 6 years. Recently the label has been extended to postharvest application on cherries and potatoes. Although Bio-Save 110 is a commercial success, the BCPD in general have some limitations, many of which can be overcome by applying higher doses of the antagonists, improving antagonist fitness and biocontrol traits, combining mutually compatible antagonists, or combining antagonists with other non-fungicidal control methods. Significant progress has been made in those areas in various laboratories worldwide and the next generation of biocontrol products approaches commercialization. This progress could be accelerated further by developing a more basic knowledge of this biocontrol system.

Assessing microbial habitats on plants to understand processes leading to biological control of diseases. S. E. Lindow. Department of Plant and Microbial Biology, University of California, Berkeley, CA 94720. Phytopathology 91:S154. Publication no. P-2001-0052-SSA.
Understanding the nutritional composition of plant surfaces is critical to understanding biological control; competition for limiting resources such as nutrients will be an effective strategy of control only if they are limiting to pathogen growth. Production of anti-microbial compounds by antagonists likewise will depend on sufficient nutrients to allow active metabolism on plants. We have developed whole cell "biological sensors" comprised of bacteria harboring fusions of a promoter responsive to a particular environmental component fused to either ice nucleation or gfp reporter genes to assess the spatial and temporal variability of sugars, ferric iron, amino acids and other nutrients and their patterns of their depletion by plant-associated. Nutrient availability on plant surfaces is highly variable spatially, placing limits on the degree to which competition or antibiosis can mediate biological control

Use of molecular tools to enhance antagonistic activity of yeasts against postharvest diseases of apples. M. H. JIJAKLI, D. Declerq, S. Cognet, S. Massart, C. Grevesse, and P. Lepoivre. Unité de Phytopathologie, Faculté des Sciences Agronomiques, 2, Passage des Déportés, 5030 Gembloux, Belgium. Phytopathology 91:S154. Publication no. P-2001-0053-SSA.

Two genes encoding exo-b-1,3-glucanases, PaEXG1 and PaEXG2, were isolated from Pichia anomala strain K, an antagonistic yeast against Botrytis cinerea on postharvest apples. PaEXG1 disruption had no effect on the in vitro or in situ extracellular exo-b-1,3-glucanase activity production while PaEXG2 disruption abolished all detectable activity in vitro and in vivo. The separate disruption of PaEXG1 or PaEXG2 had no detectable effect on the biocontrol of the yeast against $B$. cinerea. Nevertheless, the in situ stimulation of exo-beta1,3-glucanase activity from the wild strain was related to an increase of its efficacy. In this context, the possibility to achieve formulation enhancing antagonistic efficacy will be discussed. On the other hand, the study of the 
ecological fitness influence on strain K efficacy requires a specific method able to monitor its population among the naturally occurring microflora. The SCAR marking of strain $\mathrm{K}$ and the subsequent development of its quantification by competitive PCR-ELOSA will be described.

Enhancing the antagonist's ecological fitness by manipulation of endogenous polyols and sugars to improve efficacy of biocontrol of fruit decays. J. USALL (1), N. Teixidó (1), N. Magan (2), I. Viñas (1). (1) Postharvest Unit, CeRTA, Centre UdL-IRTA, Lleida, Catalonia, Spain; (2) Applied Mycology Group, Biotechnology Centre, Cranfield University, Cranfield, Bedford, UK. Phytopathology 91:S155. Publication no. P-2001-0054-SSA.

Physiological methods were used to improve ecological fitness, environmental stress tolerance, and biocontrol activity of Candida sake against postharvest decays of pome fruits. The intracellular content of major polyols and sugars was significantly modified by reducing water activity $\left(a_{\mathrm{w}}\right)$ of the growth medium using glucose or glycerol. This change improved viability of the antagonist over a wider range of relative humidity and enhanced biocontrol efficacy in laboratory tests. The physiologically manipulated inocula of $C$. sake, that were sprayed on apples in the orchard, survived better than the unmodified antagonist, but did not differ in biocontrol of $P$. expansum after 4 months of cold storage. The unmodified yeast cells adhered to the apple surface better than those grown on media with reduced water activity. Further research is needed to improve adherence of modified Candida sake cells to the apple surface and consequently the efficacy of biocontrol.

Control of postharvest diseases of pome fruits by field application of biocontrol agents. D. SUGAR. Oregon State University, Southern Oregon Research and Extension Center, Medford. Phytopathology 91:S155. Publication no. P-2001-0055-SSA.

Most postharvest diseases of pome fruit are initiated at wounds, and many fruit wounds occur during harvest and postharvest handling. Application of biocontrol agents in the field prior to harvest can potentially allow prompt wound colonization by biocontrol agents, facilitating control. Survival of four yeast species on pear surfaces and their ability to control postharvest decay were studied by applying yeast suspensions $3 \mathrm{wk}$ or 1 day prior to harvest. Cryptococcus laurentii, Rhodotorula glutinis, and C. infirmo-miniatus (CIM) maintained steady or slowly declining populations over $3 \mathrm{wk}$ under hot, dry conditions, while Candida oleophila populations declined sharply over this period. In harvested fruit wounded with a sterile nail, decay from natural inoculum evaluated after 2-4 mo storage at $-1 \mathrm{C}$ was least where CIM had been applied either 3 wk or 1 day before harvest. C. oleophila reduced decay only when applied 1 day before harvest. Populations of CIM were reduced on trees previously sprayed with ziram fungicide but were not consistently affected by prior calcium chloride treatments.

Bioactive coating for the control of postharvest diseases of fruits. A. El GHAOUTH (1), C. Wilson (2), M. Wisniewski (2), S. Droby (3), J. Smilanick (4), and L. Korsten (5). (1) Micro Flo Co., Memphis, TN; (2) AFRS, USDAARS, 45 Wiltshire Road, Kearneysville, WV; (3) Dept of Postharvest Science, Volcani Center, Israel; (4) USDA-ARS, 2021 South Peach Av, Fresno, CA; (5) Dept. Plant Pathology, Univ. of Pretoria, Pretoria, SA. Phytopathology 91:S155. Publication no. P-2001-0056-SSA.

Worldwide, postharvest losses of fruits and vegetables are estimated at more than $25 \%$ and much of this is due to postharvest decay. Currently, fungicides are the primary means of controlling postharvest diseases. Growing health and environmental concerns over pesticide disposal and residue levels has generated a growing interest in the development of safer alternatives. Presently, four microbial biological products are commercially available. Microbial biocontrol products, however, confer only a protective effect and often do not provide control of previously established infections to an extent similar to synthetic fungicides. Recent attempts to overcome the variable performance of microbial antagonists have lead to the development of a combination of complementary biological approaches. The fundamental basis, the potential, and limitation of bioactive coatings will be discussed.

\section{Landscape Pathology: Toward Understanding Ecological Interactions of Forest Dwelling Microbes at the Landscape}

Landscape pathology: Defining a framework. J. E. LUNDQUIST (1) and G. I. McDonald (2). (1) USDA Forests Service, RMRS, Fort Collins, CO; (2) USDA Forest Service, RMRS, Moscow, ID 83843. Phytopathology 91:S155. Publication no. P-2001-0057-SSA.

Specific diseases are seldom expressed evenly across the forest landscape. Variable expression has both causes and effects that interact to create changing landscape patterns and processes. These dynamics have ecological and socioeconomic impacts. Ecological impacts can extend to spatial distribution and genetic composition of pathogen and host populations. Describing and understanding landscape dynamics associated with forest pathogens posses many challenges. Landscape pathology adapts tools, techniques, and concepts of landscape ecology, disturbance ecology, genecology, and spatial statistics to study impact assessment, host and pathogen ecology, and epidemiology. This approach will facilitate analyses among spatial scales, enable descriptions of microbe-mediated characteristics of the landscape that create and maintain diversity, and provide a foundation for managing ecosystem sustainability.

Blister rust in white pine ecosystems: The imminent decline of western montane biodiversity. D. F. TOMBACK. Dept. Biology, University of Colorado at Denver, Denver, CO 80217. Phytopathology 91:S155. Publication no. P-2001-0058-SSA.

We are experiencing unprecedented change in western montane forests with the loss of white pine ecosystems to the introduced disease white pine blister rust (Cronartium ribicola). The blister rust life cycle alternates between fiveneedled white pines (Genus Pinus, Subgenus Strobus) and shrubs of genus Ribes. Introduced to the West in 1910, blister rust has since infected western white pine ( $P$. monticola), whitebark pine (Pinus albicaulis), sugar pine $(P$. lambertiana), foxtail pine $(P$. balfouriana), limber pine $(P$. flexilis), and southwestern white pine ( $P$. strobiformis), with the potential to move into the bristlecone pines ( $P$. longaeva and $P$. aristata). The large, wingless seeds of whitebark pine, a rapidly declining species, are an important food source for many birds and small mammals, and particularly for the Clark's nutcracker (Nucifraga columbiana), the pine's primary seed disperser, and grizzly bears (Ursus arctos). Rangewide, white pine ecosystems together represent many habitat types and considerable plant and animal biodiversity that will decline as blister rust infection spreads and intensifies.

Human influences on pathogen dynamics in the Sierra Nevada and Sierra San Pedro Martir, Baja, Mexico. D. M. RIZZO. Department of Plant Pathology, University of California, Davis, CA 95616. Phytopathology 91:S155. Publication no. P-2001-0059-SSA.

We investigated the interaction of pathogens, insects, and management in mixed-conifer forests of the Sierra Nevada and the Sierra San Pedro Martir (SSPM), Baja, Mexico. It is important to understand how past forest management has changed the dynamics and ecosystem role of pathogens and insects, and how this will affect future stand manipulations. In the Sierra Nevada, our data indicate that fire exclusion and logging have led to changes in tree species composition and increases in tree density, and that pathogens and insects have now replaced fire as the main stand thinning agents. Many management proposals seek to return Sierra Nevada forests to pre-European settlement stand conditions through the use of prescribed fire and thinning. Our data suggest that forest and pathogen responses to such management actions may take decades to manifest themselves and that this should be considered in developing management plans. In contrast to the Sierra Nevada, SSPM mixedconifer forests are still influenced by the historical fire regime and have never been logged. Therefore, most stand thinning is due to fire at the seedling and sapling stage, and mortality caused by insects and diseases is largely confined to older trees. The SSPM can serve as a valuable site to study the current role of fire and pest species in unmanaged forests.

Interaction of various ecosystem components with prescribed fires in ponderosa pine stands in the southern Blue Mountains. W. THIES and C. Niwa. USDA Forest Service, Corvallis, OR 97331. Phytopathology 91:S155. Publication no. P-2001-0060-SSA.

Prescribed burning to reintroduce fire into ponderosa pine (PP) ecosystems is being done with inadequate knowledge of the influence of fire on many ecosystem components. A study in PP forest type compared season of burn with the incidence of root diseases and insect attacks. Three treatments (fall 1997 burn, spring 1998 burn, and no burn) were applied to 30-acre plots and replicated in six stands in southeastern Oregon. Burns achieved a 2-foot flame height. Measured variables included: tree, stand, and site characteristics, and first order fire effects. In general, duff consumption, basal charring, crown 
scorch and tree mortality were less with spring burns than with fall burns. Two growing seasons following burning there was a higher incidence of black stain root disease (BSRD) on burned than on non-burned plots. Seven of eight species of root feeding beetles (potential vectors of BSRD), captured in flight traps, showed an attraction to burned sites. Most of these insect species preferred fall burned plots. Lichen species are dramatically better able to survive heat from fire than PP needles or buds but are not good predictors of tree survival.

Spatial molecular analysis of forest disease epidemics. R. C. Hamelin. Natural Resources Canada, Laurentian Forestry Centre, 1055 rue du P.E.P.S., Ste-Foy, Québec, Canada G1V 4C7. Phytopathology 91:S156. Publication no. P-2001-0061-SSA.

The advent of molecular tools has changed our ways of looking at microorganisms. This revolution is affecting entire areas of biology, most notably the study of pathogens of medical importance. However, forest pathology offers unique opportunities to adapt these molecular approaches to answer fundamental questions at the landscape and ecosystem levels. For example, the perennial nature of tree hosts and pathogens and their potential for long term co-evolution is not paralleled in other areas of biology. Combining spatial coordinates of samples with molecular data (sequences or markers) can provide powerful datasets to test hypotheses about biology, evolution, and epidemiology. Molecular spatial analysis can be used at the small scale, for example to determine whether or not a pathogen is spreading clonally, to assess the size of clones, or to estimate the probable age of infection. At the large scale, hypotheses about, the source of epidemics, probable means of spread, migration intensity and routes can be tested. These multidimensional databases can be extremely informative, in particular if phenotypic information can be incorporated.

Describing the spatial distribution of forest diseases. R. M. REICH. Dept. Forest Sciences, Colorado State University, Fort Collins, CO 80523. Phytopathology 91:S156. Publication no. P-2001-0062-SSA.

Forest managers need reliable and up-to-date information on forest health. Knowledge of the large and small-scale spatial variability associated with an individual pathogen would allow forest managers to focus on management practices that could reduce risk, both ecologically and economically. In trying to assess risk, one is generally dealing with data collected at several scales and from different sources. Thus, one of the most daunting challenges one faces is a way to integrate this information and still maintain the spatial integrity of the data. In this paper, I explore the potential of using spatial statistics in modeling the spatial variability in pest populations at both the local and landscape level. Such techniques hold promise in assessing how pests and other types of forest disturbances affect forest health.

Disturbance agents on the landscape of production forests. F. A. BAKER (1), K. Knowles (2), and Y. Beaubien (2). (1) Dept. of Forest Resources, Utah State University, Logan, UT 84322; (2) Manitoba Conservation, Forestry Branch, 200 Saulteaux Cres., Winnipeg, MB. R3J 3W3, CANADA. Phytopathology 91:S156. Publication no. P-2001-0063-SSA.

Many forest pests occur in production forests from stand establishment until harvest, but only some threaten the survival and quality of crop trees. Some of these pests can be detected with remotely sensed data, others require ground surveys. GPS technology helps crews find the stand and sampling areas, and streamlines data processing and reporting. Specific pests can be relocated for collecting more information, or to manage them. After wildfires, dwarf mistletoe infected residuals are mapped by GPS from the air, and killed by ground crews to protect new stands. Spatially explicit data are improving our understanding of pest occurrence. Although root diseases are not always obvious, foresters usually recognize bark beetles. In several stands, spruce beetles attacked trees first in areas with greater root disease intensity. Armillaria ostoyae, occupies stumps of mistletoe - killed jack pines, but causes serious losses in other species planted on these sites. With time, obvious disease problems will be associated with their more subtle underlying causes.

Armillaria spp. in Ozark Landscapes. J. N. BRUHN and J. D. Mihail. Dept. Plant Microbiol. \& Pathol., Univ. of Missouri, Columbia. Phytopathology 91:S156. Publication no. P-2001-0064-SSA.

Armillaria root disease contributes to oak decline in Ozark landscapes. Armillaria gallica, A. mellea, and A. tabescens occur regionally with different distributions. Nearly ubiquitous, A. mellea often occurs alone on exposed slopes; A. tabescens and A. gallica occur on ridges or protected landforms, respectively. Behaviorally, A. gallica fruits poorly, produces most rhizomorphs, and is least aggressive. Most root disease is caused by A. mellea, which fruits prolifically but produces far fewer rhizomorphs. Least common, A. tabescens produces few rhizomorphs, fruits well, and causes some disease. Most overstory mortality is $Q$. coccinea and Q. velutina. Understory mortality is mainly Cornus florida. Tree mortality is commonly associated with root crown invasion by Armillaria. Armillaria mellea takes advantage of successive stress events to gradually colonize infected root systems. Greater mortality on exposed landforms may be associated with the ubiquitous presence of $A$. mellea. At the landscape level, the relative frequency with which A. mellea occurs alone is directly correlated with the interval between major stress events and with indices of overstory successional status.

Application of molecular tools to understand landscape genetic architecture of conifers. M.-S. KIM (1), B. A. Richardson $(1,2)$, N. B. Klopfenstein (2), G. I. McDonald (2), S. J. Brunsfeld (1), and K. S. Woo (1). (1) Dept. Forest Resources, University of Idaho, Moscow, ID 83844; (2) USDA Forest Service, RMRS, Moscow, ID 83843. Phytopathology 91:S156. Publication no. P-2001-0065-SSA.

Genetic diversity and structure across the landscape were investigated using Amplified Fragment Length Polymorphism (AFLP) and uniparentally inherited mitochondrial(mt) DNA and chloroplast(cp) DNA microsatellites (cpSSRs). AFLP analysis reveals comparative genetic diversity in western white pine (Pinus monticola) after 70 years of natural selection pressure from blister rust or two generations of artificial selection for rust resistance. MtDNA haplotypes indicated distinct regional distributions of whitebark pine ( $P$. albicaulis). This distribution was supported by cpSSR genetic structure. One ancestral and two derived mtDNA haplotypes suggested the existence of at least three glacial refugia and a subsequent expansion northward. Understanding changes in genetic architecture of conifers with respect to the landscape and its environmental influences is essential to the success of genetic conservation, breeding programs, and species management.

Application of molecular tools to understand genecological aspects of the genus Armillaria. N. B. KLOPFENSTEIN (1), M.-S. Kim (2), G. I. McDonald (1), and B. A. Richardson $(1,2)$. (1) USDA Forest Service, RMRS, $1221 \mathrm{~S}$. Main, Moscow, ID 83843 U.S.A.; (2) Dept. of Forest Resources, University of Idaho, Moscow, ID 83844 U.S.A. Phytopathology 91:S156. Publication no. P2001-0066-SSA.

Armillaria species occupy diverse niches and perform widely ranging roles in forest ecosystems. Species identification is a critical initial step toward understanding the ecological roles of Armillaria, and molecular genetic tools can augment or verify species identification and phylogeny. Molecular genetics can also provide detailed information at the population or individual (genet) level. Information on genetic structure, hybridization, and gene flow provide insight into the ecological processes that influence Amillaria populations and behavior. Genetic markers, such as those generated by Amplified Fragment Length Polymorphism (AFLP), can be analyzed to detect interrelationships with abiotic and biotic environmental factors. Such genetic data can be introduced into Geographic Information Systems (GIS) to provide georeferenced analyses of genecological relationships at the local or landscape level.

Bringing it all together: Using remotely sensed data, local plot data, and GIS models to map ecosystems and their functions. G. I. MCDONALD (1), J. E. Lundquist (2), N. B. Klopfenstein (1), and M.-S. Kim (3). (1) USDA Forest Service, Moscow, ID 83843; (2) USDA Forest Service, Fort Collins, CO 80526-2098; (3) Dept. Forest Resources, University of Idaho, Moscow, ID 83844. Phytopathology 91:S156. Publication no. P-2001-0067-SSA.

Accurate mapping of environmental variables across heterogeneous landscapes is key to truthful interpretation of ecosystem function. Plots defined in geographic and ecological terms are necessary to understand roles of genetic structure, selection pressures, disturbances, and numerous other forces on disease expression. Satellite imagery, digital terrain models, and phytosociology were integrated to create imputed (most similar neighbor analysis) maps of "ecosystems". Plot data connected to plant communities in crosswalk tables facilitated the mapping of ecosystem attributes such as fire regimes, Armillaria root rot, and soil carbon. Verified topoclimatic models can enable mapping of physical parameters, such as soil temperature, snow accumulation, cold air drainage, wind, soil moisture capacity, and amount of solar radiation. Understanding interrelationships among genes and environment will facilitate strategies to support true ecosystem sustainability. 


\section{Phytoremediation and Plant Health}

Developing a flow-confinement system for saline groundwater. A. FERRO (1) and F. Thomas (2). (1) Phytokinetics, Inc., N. Logan, UT 84341; (2) Meridian Alliance Group, Inc., Texas City, TX 77592. Phytopathology 91:S157. Publication no. P-2001-0068-SSA.

A small-scale field trial at a Texas City, TX site was started in 1999 to evaluate the ability of deep-rooted, salt tolerant trees to create a flow-confinement system for contaminated groundwater. The contaminated groundwater plume is highly saline and contains inorganic compounds including $\mathrm{Ba}, \mathrm{Cd}, \mathrm{Cu}, \mathrm{Pb}$, and Se. Clones of eucalyptus trees (Eucalyptus camaldulensis) and salt cedar trees (Tamarix gallica) were planted at the site at various locations relative to the plume boundary. Preliminary greenhouse studies indicated that the trees have high rates of water use and are tolerant of the contaminated groundwater at an electrical conductivity (EC) of less than about $40 \mathrm{mmohs} / \mathrm{cm}$. When groundwater EC exceeds this limit (e.g. during prolonged dry periods), a groundwater dilution system, regulated by electrical conductivity sensors, will automatically dilute the groundwater to an EC of $<40 \mathrm{mmohs} / \mathrm{cm}$.

The responses of terrestrial plants to hexahydro-1,3,5-trinitro-1,3,5triazine (RDX). L. E. WINFIELD (1), S. J. D'Surney (2), and J. H. Rodgers, Jr. (3). (1) US Engineer Research and Development Center, Vicksburg, MS 39180; (2) University of MS, University, MS 38677; (3) Clemson University, Pendleton, SC 29670. Phytopathology 91:S157. Publication no. P-2001-0069SSA.

Over 21,000 military installations have soils contaminated with explosives, like RDX. The responses of fifteen plants to short-term ( $<12$ days) RDX exposures $(0-4000 \mathrm{ppm})$ were evaluated to identify RDX sensitive plants. Sunflower, sanfroin, and corn were identified as RDX sensitive plants, however, sunflower was the more RDX sensitive of the three. Sunflower was exposed to RDX amended (0-100 ppm) Grenada soil to assess the effects of life stage (embryos and two-week old seedlings) and exposure length (2, 4, and 6 weeks) on growth and developmental responses. Statistically significant differences were measured in several growth parameters, however, there were no consistent patterns. The most consistent indicators of detrimental impacts from RDX exposures, regardless of life stage and exposure lengths, were the observed adverse developmental effects (under developed roots, bifurcated or fused leaves, wrinkled leaf surfaces, atypical bilateral symmetry, irregular leaf margins, necrotic lesions, etc.).
Enhancement of the heavy metal binding capacity and tolerance of algae through expression of foreign genes. S. Siripornadulsil (1), P. Rubinelli (2), J. Ewalt (3), D.P. Verma (4) and R.T. SAYRE (1,2,3). (1) Biophysics Program; (2) Department of Plant Biology; (3) Ohio State Biochemistry Program; (4) Department of Molecular Genetics, Ohio State University, 2021 Coffey Road, Columbus, OH, 43210. Phytopathology 91:S157. Publication no. P-2001-0070SSA.

The unicellular green alga, Chlamydomonas reinhardtii, is readily amenable to genetic manipulation to enhance its capacity to sequester and tolerate heavy metals. We have explored a variety of strategies to enhance its heavy metal binding properties including, 1) the expression of the heavy metal binding protein, metallothionein-II, in the cytoplasm and on the cell surface as a gene fusion, 2) the expression of plant stress tolerance genes that regulate amino acid synthesis, 3 ) the expression of heavy metal binding heptapeptides on the surface of recombinant algae, and 4) the identification and expression of heavy metalinduced genes that may alter heavy metal tolerance or binding. Algae expressing these genes have either an enhanced tolerance to grow in toxic concentrations of heavy metals (cadmium), an increased capacity (three-fold) to bind heavy metals, or both. Each of these strategies and outcomes will be described.

Biotechnology meets bioremediation: Development of transgenic plants for environmental cleanup. E. A. H. PILON-SMITS (1), M. Pilon (1), J. D Owen (1), J. L. Burkhead (1), Y. Zhu (2), and N. Terry (2). (1) Dept. Biology, Colorado State University, Fort Collins, CO 80523; (2) Dept. Plant Biology, UC Berkeley, Berkeley, CA 94720. Phytopathology 91:S157. Publication no. P-2001-0071-SSA.

We are interested in plant mechanisms involved in trace element tolerance and accumulation. We focus on three areas: the role of phytochelatins in metal tolerance, plant metabolism of selenium, and metal homeostasis in chloroplasts. Through overexpression of glutathione-synthesizing enzymes (glutamylcysteine synthetase and glutathione synthetase) transgenic Brassica juncea plants were created that have enhanced levels of glutathione and phytochelatins. These transgenics show enhanced heavy metal accumulation and tolerance. In another study, Arabidopsis and Brassica plants were engineered to show enhanced selenium tolerance and accumulation. This was achieved via overexpression of the enzymes ATP sulfurylase or selenocysteine lyase. To obtain a better understanding of metal tolerance in chloroplasts, we are studying the function of two novel plant genes: AtCutA and PAA1. Both encode chloroplast proteins: AtCutA a copper-binding protein, PAA1 a copper transporter.

\section{Spatial and Temporal Scaling in Epidemiology and Crop Loss Research}

Scale in ecology and epidemiology. H. MCCALLUM. Department of Zoology and Entomology, The University of Queensland Brisbane 4072 Australia. Phytopathology 91:S157. Publication no. P-2001-0072-SSA.

Transmission is the key process in any host-pathogen interaction, and inevitably involves issues of scale. Infected hosts can only pass the pathogen to susceptible hosts if both occur in some "neighborhood" within which interactions may occur. Determining the size of this neighborhood involves estimating the probability of pathogen transmission as a function of distance. Most existing models of animal pathogens assume that a "mean field" representation of the population is adequate, meaning that transmission can adequately be modeled as a function of average population densities of susceptible and infected hosts, without taking spatial configuration into account. I discuss some recent theoretical and empirical advances in modeling the dynamics of pathogen transmission, particularly the effect of spatial scale on the functional form of transmission, and propose new ways to represent transmission in epidemiological models.

A relativitistic approach to scaling time (and space) for ecological pathology and epidemiology. A. D. SPARROW. Dept. Plant \& Microbial Sciences, University of Canterbury, Christchurch 8020, New Zealand. Phytopathology 91:S157. Publication no. P-2001-0073-SSA.

Ecology has become acutely aware of the non-equilibrium, non-uniform nature of ecosystems, and the importance of temporal and spatial pattern. This has lead to sophisticated spatio-temporal models for populations and communities, including foraging, predation, parasitism and pathogens. The forms of such models can now be applied widely, but parameter values essential for prediction remain specific to systems or organisms i.e. predictive power always depends on prior study. Greater generalization is needed. Spatial scaling of organisms can be predicted on the basis of allometry (based on body energetics) and movement. I argue here that temporal scaling can also be argued using energetic concepts, and that temporal and spatial scaling linked by energy is consistent with observed patterns. The approach gives general epidemiological prediction across ecosystems of different characteristics (climate, fertility, etc.), and a basis to predict temporal and spatial patterns of a particular epidemic in a particular landscape, based on the differential energetic scaling by host and pathogen.

Effect of scale on plant disease incidence and heterogeneity in a spatial hierarchy. W. W. TURECHEK (1) and L. V. Madden (2). (1) Cornell University, Geneva, NY 14456; (2) L.V. Madden, The Ohio State University, Wooster, OH 44691. Phytopathology 91:S157. Publication no. P-2001-0074SSA.

Monte-Carlo simulation was used to study the effect of scale on disease incidence and heterogeneity in a 3-scaled spatial hierarchy, i.e., leaflet, leaf, and sampling unit. Results showed that incidence and heterogeneity of disease at the leaflet scale had the largest effects on incidence and heterogeneity of disease at the leaf scale. However, at a fixed level of incidence and heterogeneity at the leaflet scale, spatial arrangement of diseased leaflets among leaves within sampling units, sampling-unit size, leaf complexity (leaflets per leaf), and all interactions affected disease incidence and heterogeneity at the leaf scale. Incidence and heterogeneity of disease at the leaf scale were most affected by sampling-unit size when diseased leaflets were maximally aggregated within sampling units; increasing the number of leaves per sampling unit was associated with decreasing incidence and increasing heterogeneity at the leaf scale. Analysis of Phomopsis leaf blight data sets indicated that incidence and heterogeneity of incidence varied predictably between scales.

Issues of scale in disease and crop loss assessment. G. HUGHES. Institute of Ecology and Resource Management, University of Edinburgh, EH9 3JG, UK. Phytopathology 91:S157. Publication no. P-2001-0075-SSA. 
"What's a picture worth?" G.J. Holmes, E.A. Brown and G. Ruhl pose this question to set a context for their discussion of the use of moderntelecommunications in plant disease diagnosis in the December 2000 issue of Plant Disease. Unfortunately for those of us concerned with field scale disease management and crop loss assessment, the answer given by the authors is that digitally assisted diagnosis (DAD) is poorly suited when a course of action, e.g. fungicide application, may be prescribed, unless information on disease incidence or severity is available. This is an issue of scale. The authors of the Plant Disease article discuss the success of telemedicine, the delivery of health care over distance by clinicians, and suggest that DAD is analogous to telemedicine. But clinicians treat disease at the same scale at which they diagnose it (i.e., the individual patient) whereas plant pathologists concerned with disease management may diagnose at the level of the individual plant, but they treat at the level of the population. To answer the question, "What's a picture worth?" we need to be able to evaluate the information DAD can convey in the context of crop protection decision making.

Resource aggregation in the phyllosphere: implications for pathogen dynamics across spatial scales. L. L. KINKEL, M. R. Newton, and K. J.
Leonard. Dept. Plant Pathology, U of Minnesota, St. Paul, MN 55108. Phytopathology 91:S158. Publication no. P-2001-0076-SSA.

Microbial populations on leaves are aggregated at multiple spatial scales. Few studies have considered the implications of this spatial structure for microbial population ecology. We have developed models for quantifying the significance of various origins of small-scale aggregation, including localization of resources, density-dependent survival or growth, and immigration, to the dynamics of microbes on leaves. Results show that greater resource aggregation increases the probability that populations will be immigration- or growth-limited, and decreases the probability that populations will be resourcelimited. In addition, highly aggregated resources enhance the potential for inferior competitors to persist on leaves. Results indicate that distinct traits are likely to provide a selective advantage to microbes in highly aggregated resource environments compared with habitats in which resources are randomly or uniformly distributed. Consequently, information on small-scale patterns of resource availability is necessary to develop a comprehensive understanding of the ecology of phyllosphere microbes.

\section{Molecular/Cellular-Plant-Microbe Interactions}

\section{Genomics of Plant Pathogens: Current Status}

BLAST OFF! Magnaporthe grisea genome project successfully launched. R. A. DEAN. Fungal Genomics Laboratory, NC State University, Raleigh, NC 27695. Phytopathology 91:S158. Publication no. P-2001-0077-SSA.

Rice blast disease, caused by Magnaporthe grisea, is one of the most devastating threats to food security worldwide. The fungus is amenable to classical and molecular genetic manipulation and is a compelling experimental system for elucidating numerous aspects of pathogenesis, including infection-related morphogenesis, host species and cultivar specificity, and signaling pathways. In 1998, an international consortium (IRBGP) was established to sequence the rice blast genome. For this initiative, we used a $25 \mathrm{X}$ large insert $(130 \mathrm{~kb})$ HindIII BAC library to construct a physical map of the genome. BAC clones were fingerprinted and assembled into 188 contigs. These were aligned into a physical map by anchoring to mapped RFLP markers. Chromosome 7 (4.2 Mb) has been studied in the greatest detail and a set of 42 BAC clones representing a minimum tiling path covering $>95 \%$ of the chromosome has been deduced. The entire BAC library was end sequenced providing sequence tag connectors (STC) every 3-4 kb across the genome. A federated database integrating physical, genetic and expression data from relational and object-oriented databases is being developed. We have initiated a draft sequence $(\sim 5 \mathrm{X}$ coverage) of chromosome 7 using the "BAC by BAC" approach coupled with information from our STC/fingerprint databases. A comprehensive EST program has been launched. 30,000 ESTs will be derived from 8 cDNA libraries prepared from different stages of growth and development as well as cells subjected to various stress conditions. A set of $\sim 5,000$ ESTs representing unique genes will be further sequenced. The current status of the genome project and database development will be presented.

Genomics of Clavibacter (Leifsonia) xyli subsp. xyli, causal organism of ratoon stunting disease of sugarcane. S. M. BRUMBLEY (1), C. B. M. Vitorello (2), and L. E. A. Carmargo (2). (1) Bureau of Sugar Exp. Stations, Indooroopilly, QLD, AU 4068; (2) Dept. of Phytopathology, University of Sao Paulo, Piracicaba, SP, BRAZIL 13418-900. Phytopathology 91:S158. Publication no. P-2001-0078-SSA.

Clavibacter (Leifsonia) xyli subsp. xyli (Cxx) is a nutritionally fastidious, slow growing, Gram-positive, xylem limited, bacterial pathogen of sugarcane. It produces no reliable external or internal symptoms on sugarcane. All of this makes this phytopathogen extremely difficult to work with. However, it is the most economically important disease of sugarcane worldwide and better control measures are needed. Therefore, we developed the molecular tools necessary to study $\mathrm{Cxx}$ starting with transformation and transposon mutagenesis. We identified transposon mutants that could no longer colonize sugarcane and demonstrated we could complement these mutants with the wild type gene. Now we are testing marker exchange. In collaboration with my lab, the full genome of Cxx is being sequenced by the FAPESP ONSA Agronomical and Environmental Genomes group in Brazil. In addition, the flanking region from 750 independent transposon mutants of Cxx will also be sequenced and their precise location in the genome mapped.
Genomics-based approaches to control of fungal pathogens. J. MARGOLIS. Exelixis, Inc., South San Francisco, CA 94083-0511. Phytopathology 91:S158. Publication no. P-2001-0079-SSA.

Exelixis agriculture programs apply genomics, informatics and high throughput genetics to identify highly validated targets for pesticides or the development of pest-resistant plants. We have taken three general approaches to this problem. First, we are identifying broad spectrum targets in fungal pathogens through a series of deep genomic and EST sequencing projects in diverse species, such as Ustilago maydis. These data will then feed into large scale knockout programs to provide rapid genetic validation of potential targets. Second, in our Mechanism of Action program we genetically identify the protein targets of existing compounds with unknown biochemical activities. Knowing the target of a compound permits rapid development of new or improved chemistry. Finally, Exelixis Plant Sciences is using plant activation tagging to study host responses to fungal pathogens. Screening for plants either resistant or hypersensitive to a pathogen identifies novel resistance genes. Because activation tagging dominantly overexpresses plant genes, candidates can be rapidly cloned and retested in other species.

Phytophthora genomics consortium. S. T. LAM. Syngenta RTP, 3054 Cornwallis Road, RTP, NC 27709. Phytopathology 91:S158. Publication no. P2001-0080-SSA.

Molecular studies on Phytophthora have progressed slowly. Transformation efficiency remains low, and gene replacement by homologous recombination has yet to be demonstrated. Recently, gene silencing has been shown to occur, and has been used for functional analysis. With the current advances in genomic sciences, we believe now is the time to try to accelerate Phytophthora research through a new approach. With support from the Novartis Foundation, we have established a Phytophthora research consortium with the goal of developing the genomic resources useful for furthering our understanding of this group of organisms. The specific objectives of the consortium include: 1) Establish an extensive EST database, using biological materials contributed by consortium members, 2) Establish a gene expression profiling platform, and 3 ) improve gene function analysis methods. There are eight academic institutions involved. Syngenta acts as coordinator, stores all cDNA libraries, and provides the necessary sequencing. NCGR of Santa Fe, New Mexico provides the bioinformatics support. Progress of the consortium will be discussed.

Public funding of plant pathogen genomics. A. E. LICHENS-PARK Cooperative State Research, Education and Extension Service, United States Department of Agriculture, Washington, DC 20024. Phytopathology 91:S158. Publication no. P-2001-0081-SSA.

We are entering a new era of microbial genomics, which promises to provide critical insights into the complexities of plant pathogens and other microorganisms. Federal investment in microbial genomics research has contributed to the growth of this important area. Various Federal agencies provide funding to support structural and functional genomics of microorganisms as well as other critical areas such as bioinformatics. Until recently, Federal funding for genomics of agriculturally important microbes has been very limited. However, funding opportunities in this area have grown 
significantly over the last couple of years. Federal Programs that have supported or could support genomics of plant pathogens and other agriculturally important microbes will be discussed, including some of the projects that have been supported by these Programs.

Genome-wide analysis of fungal pathogenicity. O. C. YODER and B. G. Turgeon. Torrey Mesa Research Institute, 3115 Merryfield Row, San Diego, CA 92121. Phytopathology 91:S159. Publication no. P-2001-0082-SSA.

Until recently, molecular mechanisms of fungal virulence have been investigated by manipulating one gene at a time in the fungal genome. Availability of genomics technologies suggests a genome-wide assessment of pathogenic mechanisms is feasible. Because of its genetic tractability, we are applying whole genome technologies to the corn pathogen Cochliobolus heterostrophus. Availability of the genome sequence of this fungus allows a two-pronged functional analysis. First, candidate genes are deleted from the genome by targeted gene replacement; our initial emphasis is on genes encoding enzymes, such as polyketide synthases and nonribosomal peptide synthetases, which are dedicated to biosynthesis of secondary metabolites, molecules with possible roles in fungal virulence. Second, a library of random $(5-10 \mathrm{~kb})$ deletions is constructed and screened. Deletions causing phenotypes of interest are matched with the genomic sequence, and ORFs within the deleted region are targeted individually for deletion. Transformants are screened for readily scoreable phenotypes, including pathogenicity and lethality. Results of a pilot study suggest this strategy can lead to identification of both essential genes and virulence factors.

Results from high throughput gene discovery in parasitic nematodes. J. P. MCCARTER (1), D. Bird (2), S. Clifton (1), R. Waterston (1), and the GSC EST Lab Group (1). (1) Genome Sequencing Center, Washington University, St. Louis, MO 63108; (2) Plant Pathology, North Carolina State University, Raleigh, NC 27695. Phytopathology 91:S159. Publication no. P-2001-0083-SSA.

Projects are underway in our lab to generate 235,000 expressed sequence tags (ESTs) from 15 nematode species by 2003, including 103,000 ESTs from plant parasites (mostly Meloidogyne species). As of February 2001, we have submitted over 32,000 ESTs from eight nematode species to the dbEST public database. Analyzed samples include messages from $M$. incognita J2s, $M$. javanica eggs, and H. glycines J2's. We will report on our progress in sequence analysis, including the creation of the NemaGene gene index for each species by EST clustering and consensus sequence generation, identification of common and rare transcripts, and identification of genes with orthologs in $C$. elegans and other nematodes. All sequences are publicly available at www.ncbi.nlm.nih.gov/dbEST. Project Web site: www.nematode.net. Major funding by NIH-NIAID, the NSF Plant Genome Research Program, and a Merck / Helen Hay Whitney Foundation fellowship.

\section{Interactions Between Different Host Defense Pathways}

Resistance to Turnip crinkle virus: Understanding defense signaling against a viral pathogen of Arabidopsis. P. $\operatorname{KACHROO}(1,2)$, M. Cooley (2), H. Wu $(1,2)$, S. Pathirana (2), K. Yoshioka $(1,2)$, and D. Klessig $(1,2)$. (1) Boyce Thompson Institute, Ithaca, NY 14853; (2) Waksman Institute, Rutgers, State University of New Jersey, Piscataway, NJ 08854. Phytopathology 91:S159. Publication no. P-2001-0084-SSA.

Inoculation of Turnip crinkle virus onto resistant ecotype Di-17 of Arabidopsis leads to a hypersensitive response (HR) that is conferred by the dominant gene $H R T$. Extensive genetic analyses revealed that while $H R T$ is a prerequisite for resistance, another recessive locus $r r t$ also regulates resistance to TCV. HRT was cloned using a map-based approach. The chromosomal position of $H R T$ and its high homology to resistance gene $R P P 8$, which confers resistance to an oomycete pathogen, Peronospora parasitica, provides molecular evidence that sequence changes between closely related members of a multigene family can generate novel specificities for radically different pathogens. Both the HR and resistance conferred against HRT were dependent on salicylic acid, but neither required the NPRI-, ethylene- or jasmonate- signaling pathways, indicating that resistance to TCV requires a yet undefined SA-dependent, $N P R I$-independent signaling pathway.

Dissection of signaling networks triggering resistance to downy mildew in Arabidopsis. J. M. McDOWELL (1), T. Eulgem (2), J. L. Dangl (2), and E. B. Holub (3). (1) Virginia Tech, Blacksburg, VA, USA; (2) Univ. of North Carolina, Chapel Hill, NC, USA; (3) Horticulture Research International, Wellesbourne, UK. Phytopathology 91:S159. Publication no. P-2001-0085-SSA.

$R P P$ genes in Arabidopsis confer race-specific resistance to the oomycete Peronospora parasitica, and encode proteins with a putative nucleotide binding site and leucine-rich repeats. To determine whether different RPP genes utilize a common signaling mechanism, we tested the effect of defense signal transduction mutations on eight $R P P$ genes. We found that $R P P$ genes vary in their requirements for the NDR1, EDS1, and NPR1 genes, as well as salicylic acid (SA) accumulation. The RPP7 and RPP8 genes were not suppressed by any of the tested mutations, including double mutant combinations of $e d s 1 / n d r 1$ and coi/NahG. These results demonstrate that RPP genes can access different signaling networks to trigger resistance. Furthermore, $R P P 7$ and $R P P 8$ trigger resistance through a signaling mechanism that does not require SA or jasmonic acid perception.

The role of coronatine, a Pseudomonas syringae phytotoxin, in virulence on plants. B. N. KUNKEL, D. Brooks, V. Joardar, and A. Kloek. Department of Biology, Washington University, St. Louis, MO 63105. Phytopathology 91:S159. Publication no. P-2001-0086-SSA.

Upon microbial attack plants activate general defense responses believed to inhibit colonization by microorganisms. The ability to avoid detection and/or to suppress activation of antimicrobial defenses are traits that may distinguish successful pathogens from non-pathogenic organisms. The bacterial phytotoxin coronatine (COR) is an example of a virulence factor that may act by inhibiting host defenses. COR is produced by several strains of the bacterial pathogen
Pseudomonas syringae and has been demonstrated to contribute to virulence of $P$. syringae. The mechanism(s) by which COR contributes to virulence is not well understood. Based on structural similarities and the effects that it has on plants, COR is proposed to function as a molecular mimic of methyl jasmonate, a plant defense hormone. To investigate the role of COR in pathogenesis we are studying $A$. thaliana mutants insensitive to COR and $P$. syringae mutants impaired in COR production. Characterization of an $A$ thaliana coil mutant suggests that COR promotes virulence by inhibiting salicylic acid-dependent defenses and by promoting lesion formation.

Regulation of systemic acquired resistance by NPR1 and its partners. W. E. DURRANT, X. Li, Y. Zhang, W. Fan, M. Kinkema, J. D. Clarke, and X Dong. DCMB Group, LSRC Bldg., Research Dr., Duke University, Durham, NC 27708. Phytopathology 91:S159. Publication no. P-2001-0087-SSA.

Systemic acquired resistance (SAR) is a plant immune response activated after a local infection that confers long-lasting, broad spectrum resistance. SAR requires salicylic acid (SA). Removal of SA through the activity of salicylate hydroxylase blocks SAR while exogenous application of SA induces SAR. Using genetics, we identified the NPR1 gene of Arabidopsis thaliana as a positive regulator of SAR. To study the regulation of SAR, molecular and genetic approaches were taken. Using NPR1-GFP and NPR1GR fusions, we demonstrated that nuclear localization of NPR1 is essential but not sufficient for SAR-related gene expression. Through a yeast twohybrid screen we found that NPR1 interacts with TGA transcription factors. Using dominant-negative mutants of TGA, we showed that NPR1-TGA interaction occurs in planta. In a genetic screen for suppressors of $n p r l$, we found the snil mutant that restores responsiveness to SAR induction. This phenotype and the sequence of SNI1 suggest the wild-type SNI1 protein is a negative regulator of SAR. Thus, we believe that SAR is controlled by both positive and negative regulators.

Combining genetics and expression profiling for studies of signaling pathways controlling activation of plant defense responses. J. GLAZEBROOK, W. Chen, H.-S. Chang, G. Zou, B. Han, and T. Zhu. Torrey Mesa Research Institute, San Diego, CA 92121. Phytopathology 91:S159. Publication no. P-2001-0088-SSA.

Many Arabidopsis thaliana mutants with defects in activation of defense responses after pathogen attack have been isolated over the past several years. The transgene $n a h G$ and mutations in pad4, eds5, eds4, and $n p r l$ are known to interfere with salicylic acid (SA)-dependent signaling. Mutations in coil or ein2 interfere with jasmonic acid (JA) and ethylene (ET)-dependent signaling, respectively. To gain an overview of defense-related signaling, we have used Affymetrix GeneChip technology to profile the expression patterns of over 8,000 Arabidopsis genes in response to infection by the bacterial pathogen Pseudomonas syringae pv. maculicola ES4326. This data has allowed us to make predictions about the effects of previously uncharacterized mutations on signaling pathways and to identify three distinct sets of genes. One set is induced by SAdependent signaling and repressed by JA/ET-dependent signaling, a second set is induced by JA/ET signaling and repressed by SA signaling, and the third involves genes normally associated with SA signaling and JA/ET signaling. 


\section{Quorum Sensing in Plant-Associated Bacteria: Party Lines in the Rhizosphere-Are No Conversations Private?}

A new mechanism involved in the control of quorum sensing in Erwinia carotovora. M. WELCH. Department of Biochemistry, Tennis Court Road, Cambridge, UK. Phytopathology 91:S160. Publication no. P-2001-0089-SSA.

Erwinia carotovora subsp. carotovora (Ecc) is the causative agent of soft rot in potatoes. The organism does this by producing a plethora of cell wall degrading enzymes, which macerate the plant tissue, liberating the nutrients required for growth. Production of these virulence factors in Ecc is under the control of quorum sensing. Thus, one strategy for combating Ecc pathogenicity lies in understanding how quorum sensing itself is regulated. To this end, we have been addressing the question of what turns the quorum sensing system "off" in Ecc? Does the signaling molecule (N-3-oxohexanoyl-(L)-homoserine lactone, "OHHL") simply dissipate through passive processes (e.g., diffusion), or is it actively removed from the system? Evidence will be presented to suggest that the latter is the case, and that Ecc can actively turn over its own OHHL. This metabolic activity changes through the growth curve, suggesting that the process is highly regulated. This regulation is itself dependent on OHHL, i.e., the system is autoregulatory. The implications of these findings will be discussed.

Quorum sensing control of capsular polysaccharide synthesis in Pantoea stewartii subsp. stewartii - not quite the paradigm. S. VON BODMAN (1), T. Minogue (1), M. Wehland (2), and F. Bernhard (2). (1) Univ. of Connecticut, Storrs, CT; (2) Institut für Kristallographie, Freie Universität Berlin, Berlin Germany. Phytopathology 91:S160. Publication no. P-2001-0090-SSA.

Pantoea stewartii causes Stewart's wilt in maize as a result of polysaccharide (CPS) induced vascular dysfunction. EsaR, a LuxR homologue protein, governs the synthesis of CPS. Several observations suggest that EsaR acts as a repressor. For example, mutations in esaR alone and in esaI-esaR together lead to constitutive CPS synthesis. EsaR also regulates its own expression by signal-independent autorepression. An esaR reporter gene is fully active in absence of EsaR and is repressed proportionally to the amount of EsaR expressed in trans. Exogenous AHL alleviates repression in a dose-dependent manner. Electromobility shift assays and surface plasmon resonance (SPR) measurements show that Apo-EsaR binds a lux box-like fragment that spans the -10 region of the esaR promoter. EsaR protein, pre-incubated with AHL, has reduced DNA binding affinity., and fluorescence quenching measurements indicate a stoichiometric ligand/protein interaction.

Positive and negative communication among rhizobacteria: Effect on patterns of microbial gene expression. L. S. PIERSON III and J. Morello. Dept. Plant Pathology, The University of Arizona, Tucson, AZ 85721. Phytopathology 91:S160. Publication no. P-2001-0091-SSA.

The regulation of phenazine antibiotic production in the biological control bacterium Pseudomonas aureofaciens $30-84$ is a model system to study the influence of the root microbial community on patterns of microbial gene expression. One subpopulation of the rhizosphere community can stimulate phenazine ( $p h z)$ gene expression in strain 30-84 via the production of $N$-acyl homoserine lactone (AHL) signals. Yet another subpopulation produces a compound(s) that serves to inhibit phenazine production by interfering with expression of the $p h z$ biosynthetic genes. The nature of the negative-acting signal(s) is unclear, but they do not appear to be AHLs, furanones, or cyclic dipeptides. Positive and negative cross-signaling among the rhizobacterial community and an introduced strain may determine the success of biocontrol in the field. For example, the ability of strain 30-84 to inhibit growth of the takeall pathogen Gaeumannomyces graminis var. tritici in vitro was enhanced and reduced, respectively, in the presence of positive and negative crosscommunicating strains.
Signal mimic compounds from plants can affect quorum sensing-regulated behaviors in associated bacteria. W. D. BAUER, M. Teplitski, and M. Gao. Department of Horticulture \& Crop Science, Ohio State University, Columbus, OH 43210. Phytopathology 91:S160. Publication no. P-2001-0092-SSA.

$\mathrm{N}$-acyl homoserine lactone (AHL) signal molecules are used by many plantassociated bacterial species to regulate the expression of their genes in relation to local population density ("quorum-sensing"). A diversity of higher plants have been found to secrete unknown, AHL signal-mimic compounds that can either stimulate or inhibit various AHL-regulated behaviors in bacteria (Teplitski et al. 2000. Molecular Plant-Microbe Interactions 13:637-648). The ability of higher plants to specifically alter AHL-regulated behaviors in bacteria by production of AHL signal-mimic compounds could be of broad consequence. AHL signaling in bacteria and the synthesis of AHL signalmimic compounds by plants are briefly reviewed, with emphasis on some of the important questions concerning the roles that these plant signal-mimic compounds may play in natural encounters between plants and bacteria.

Plants genetically modified to produce $\mathbf{N}$-acylhomoserine lactones signal to bacteria. R. G. FRAY. School of Biological Sciences, Nottingham University, Sutton Bonington Campus, Loughborough LE12 5RD, UK. Phytopathology 91:S160. Publication no. P-2001-0093-SSA.

DNA constructs containing the yenI gene of Yersinia enterocolitica were used to test the feasibility of synthesizing bacterial AHL signaling molecules in planta. Transgenic tobacco plants in which YenI was targeted to the chloroplast tested positive for AHL production as judged by their ability to induce violacein production in the AHL Chromobacterium violaceum biosensor, CVO26. Both OHHL and HHL (the two cognate molecules normally produced by YenI) were produced. None of the plants in which the yenI construct lacked the targeting signal gave a positive reaction in this assay. The AHLs produced were sufficient to induce target gene expression in several bacterial biosensors and restored biocontrol activity and pathogenicity to AHL deficient strains of Pseudomonas aureofaciens and Erwinia carotovora respectively. Other AHL biosynthetic genes have been cloned into tobacco, tomato and potato. Results will be presented describing altered interactions of these plants with wild type bacterial species.

Quenching quorum sensing-dependent bacterial infection. Z. LIAN-HUI. Institute of Molecular Agrobiology, National University of Singapore. Phytopathology 91:S160. Publication no. P-2001-0094-SSA.

Bacterial cells sense their population density via a sophisticated cell-cell communication system, and trigger expression of particular genes when the density reaches a threshold. This type of gene regulation, which controls diverse biological functions including virulence, is known as quorum sensing. Quorum-sensing signals, such as acyl-homoserine lactones (AHLs), are the essential components of the systems. AHLs regulate virulence gene expression in a range of plant and animal (including human) bacterial pathogens. It appears that single-celled bacterial pathogens use quorum-sensing signals to synchronize virulence gene expression among family members as a concerted means to overwhelm host defenses. Quorum-sensing system thus represents a fascinating target for development of novel antipathogenic approaches. Recently, we showed that the aiiA gene from a gram-positive Bacillus $s p$. 240B1 encoded an enzyme capable of inactivating several AHLs. To test the feasibility of establishing a generic "quorum quenching" approach to control bacterial infection, i.e., to paralyze quorum-sensing systems of bacterial pathogens via inactivation of quorum-sensing signals, we have tested the effect of AiiA on different AHL signals, and introduced aiiA to potato and tobacco plants. The results on characterization of AiiA inactivation of AHL signals and the effect of the enzyme on bacterial infection will be presented.

\section{Secretion in Plant Associated Bacteria, Fungi, and Nematodes}

The Type III protein secretion system of Pseudomonas syringae. S. Y. HE. Department of Energy Plant Research Laboratory, Michigan State University, East Lansing, MI 48824. Phytopathology 91:S160. Publication no. P-20010095-SSA.

Bacterial pathogens are responsible for numerous diseases in plants, animals, and humans. These pathogens are very diverse in their taxonomical properties and hosts, and in the disease symptoms they cause. Remarkably, many of them contain a conserved protein secretion system known as the type III protein secretion system. This secretion system is believed to inject bacterial virulence proteins directly into host cells and plays a central role in bacterial pathogenesis. In plant pathogenic bacteria, many seminal findings, including the initial discovery, of the type III secretion system were made in Pseudomonas syringae. In this talk, several aspects of the $P$. syringae type III secretion system will be reviewed, including the evidence of type III delivery of effector proteins into Arabidopsis cells, biochemical and genomic inventory of type III effector proteins, the function of a novel pilus in guiding type III secretion, and the effects of type III effector proteins on Arabidopsis signaling and metabolism. 
The Agrobacterium T-DNA transfer system: a type IV secretion machine for macromolecular transfer to a wide range of eukaryotic cell types. P. J. CHRISTIE. The University of Texas-Houston, Health Sciences Center, Houston, TX 77030. Phytopathology 91:S161. Publication no. P-2001-0096SSA.

Bacterial secretion systems play important roles in the infection of plants and mammals. The focus of my laboratory is the type IV transfer system used by $A$. tumefaciens to deliver T-DNA to susceptible plant cells. The T-DNA transfer system is envisioned to be a supramolecular structure composed of a channel for substrate passage and a pilus for establishing cell-cell contacts. This system is exceptionally versatile in its ability to recognize and export diverse DNA and protein substrates to a wide variety of cell types, including susceptible plant cells, other bacteria, fungi, and HeLa cells. My talk will summarize our work aimed at i) defining the assembly pathway and architecture of the type IV system at the cell envelope, and ii) understanding the molecular basis for what seems to be an unrestricted capacity of this bacterium to transfer macromolecules intercellularly. I will describe our studies defining the roles of two proposed chaperones, VirE1 and VirB11, for substrate export and transporter biogenesis. I will also present evidence from mutational studies that this system can efficiently transfer substrates independently of the pilus.

Fungal transporters involved in secretion of natural toxic compounds and fungicides. M. A. DE WAARD. Laboratory of Phytopathology, Wageningen University, Wageningen, The Netherlands. Phytopathology 91:S161. Publication no. P-2001-0097-SSA.

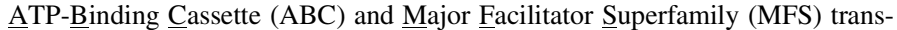
porters are membrane proteins that can transport toxic compounds of exogenous and endogenous origin. Their activity lowers toxin concentrations in cell compartments and provides protection against such compounds. In plant pathogens, the transporters can play a role in virulence by providing protection against plant defense compounds and secretion of host-specific and non-hostspecific toxins. Transporter activity can also affect fungicide sensitivity. We characterised multiple transporter genes from the saprophytic fungus Aspergillus nidulans, and the plant pathogens Botrytis cinerea and Mycosphaerella graminicola and analysed their function in fungicide sensitivity and virulence on host plants. Deletion mutants of particular ABC transporter genes from $B$. cinerea and $M$. graminicola indeed had a decreased virulence. Studies with deletion and overexpression mutants indicated that various genes are involved in sensitivity to modern fungicides and natural toxic products, suggesting that $\mathrm{ABC}$ and MFS transporters do play a role in multidrug resistance.

The role of secreted proteins of the pathogenic fungus Cladosporium fulvum in (a)virulence on its host, tomato. M. H. A. J. JOOSTEN, B. F. Brandwagt, R. A. L. van der Hoorn, C. F. de Jong, J. W. van 't Klooster, M. J. D. de Kock, M. Kruijt, R. Luderer, F. L. W. Takken, N. Westerink, and P. J. G. M. de Wit. Laboratory of Phytopathology, Wageningen University, Wageningen, The Netherlands. Phytopathology 91:S161. Publication no. P2001-0098-SSA.

Cladosporium fulvum is a biotrophic fungal pathogen, which secretes various low molecular weight proteins into the apoplast of tomato leaves. Some of these proteins are secreted by all strains of the fungus and are essential virulence factors called extra cellular proteins or ECPs, whereas others are race-specific avirulence factors (AVRs) that induce a hypersensitive response in tomato containing the matching resistance gene. All Ecp and Avr genes cloned to date encode proteins with a typical signal sequence for extracellular targeting and contain an even number of cysteine residues $(4,6$ or 8$)$. My presentation will focus on how Ecp and Avr genes have been isolated, how we think the encoded proteins are perceived by resistant plants and what kind of responses are induced in such plants.

Nematode esophageal gland cells: The key to understanding nematode parasitism of plants. R. S. HUSSEY. Dept. of Plant Pathology, University of Georgia, Athens, GA 30602. Phytopathology 91:S161. Publication no. P-20010099-SSA

Plant-parasitic nematodes evolved three large and complex esophageal glands that produce secretions required for plant parasitism. Each gland is a single large transcriptionally active secretory cell with a cytoplasmic extension that ends in a storage ampulla connected to the esophageal lumen by an elaborate valve. Secretory proteins are synthesized in the nuclear region of the cell and packaged in Golgi-derived membrane-bounded granules that are transported along microtubules in the gland extensions to the ampulla. Association of neural processes with the gland extensions indicates that the regulated secretion of proteins is controlled by the nematode's nervous system. During secretion, the secretory proteins are rapidly released from the granules by exocytosis into the membranous end-sac of the valve. The proteins then enter the esophageal lumen to be secreted through a protrusible stylet into plant tissues. Gland cell morphology and secretory proteins are under dynamic developmental regulation during nematode parasitism of plants. An understanding of the nature of these secretions and their function in parasitism is now beginning to emerge.

Nematode secretions: The makings of a plant parasite. T. J. BAUM. Dept. of Plant Pathology, Iowa State University, Ames, IA 50011. Phytopathology 91:S161. Publication no. P-2001-0100-SSA

Only a few members of the diverse nematode phylum have evolved to feed on living plants. What sets these parasites apart from non-parasitic nematodes? Besides obvious morphological features, there are molecular adaptations that mediate the intricate interactions between the parasite and the host plant. These molecular adaptations are referred to as parasitism genes. While the nematode's protrusible stylet and the large esophageal gland cells are the principal morphological adaptations, the proteins expressed from parasitism genes in the glands and secreted through the stylet are what makes a nematode a plant parasite. Several strategies have been employed to identify these stylet secretions and the parasitism genes encoding them. Following initial success with antibody methodologies, molecular technologies are now providing new insights into nematode parasitism genes. Among the identified parasitism genes are some that encode known enzymes as well as a growing number of genes that encode proteins with unknown functions. While only few of the putative parasitism genes have homologs in Caenorhabditis elegans, plantparasitic nematodes also appear to have borrowed genes from microbes.

\section{Suppressors of Gene Silencing}

RNA silencing and silencing suppression by potyviral P1/HC-Pro. L. K. JOHANSEN, K. D. Kasschau, A. D. Lellis, C. Llave, Z. Xie, and J. C. Carrington. Institute of Biological Chemistry, Washington State University, Pullman, WA 99164. Phytopathology 91:S161. Publication no. P-2001-0101SSA.

RNA silencing is an adaptive defense response triggered by virus infection, resulting in sequence specific degradation of viral RNA and other RNAs with homology to the viral sequence. RNA silencing occurs locally at the site of infection, and may also trigger a systemic response that potentially limits the extent of infection. The potyviral protein, HC-Pro, functions as an RNA silencing suppressor. This protein also functions to maintain genome replication at the single cell level, stimulate long-distance movement in plants, and catalyze autoproteolysis from the viral polyprotein. A genetic analysis revealed that the replication maintenance and long-distance movement functions of HC-Pro are likely due to proteinase-independent silencing suppressor activity. A transient assay was developed to rapidly analyze viral and cellular factors for their role in RNA silencing or silencing suppression. This enabled analysis of the activities of cellular silencing factors and viral silencing suppressors on local and systemic silencing triggered by strong and weak inducers.
Monocot host proteins that interact with a viral suppressor of gene silencing. T. E. MIRKOV, I. Ingelbrecht, A. Castillion, and J. Hernandez. Dept. Plant Pathology and Microbiology, Texas A\&M University Agricultural Experiment Station, Weslaco, TX 78596. Phytopathology 91:S161. Publication no. P-2001-0102-SSA.

Posttranscriptional gene silencing (PTGS) in plants is an important but poorly understood genetic control mechanism that is manifested as the sequencespecific degradation of RNA derived from transgenes, endogenous genes, or viruses. Several dicot infecting plant viral proteins have been identified as suppressors of PTGS. The potyviral helper component-proteinase (HC-Pro) can suppress silencing in tissues where it was already established and thus seems to disrupt the maintenance step of PTGS. We have demonstrated that the monocot infecting Sorghum mosaic virus (SrMV) P1/HC-Pro reverses silencing in transgenic sugarcane silenced for the SrMV coat protein, and have isolated host proteins potentially involved in PTGS by using the HC-Pro protein of SrMV as a bait in yeast two-hybrid screens. A protein with similarity to a viral RNase $\mathrm{H}$ has been confirmed to be a true interactor. Transgenic plants expressing SrMV HC-Pro develop tumors with multiple shoots at the internodes, therefore indicating that PTGS also plays an important role in normal plant development. 
Mechanistic analysis of RNA silencing suppression by the Cucumber mosaic virus 2b protein. S.-W. DING. Department of Plant Pathology, University of California, Riverside, CA 92521. Phytopathology 91:S162. Publication no. P-2001-0103-SSA.

The Cucumber mosaic virus $2 \mathrm{~b}$ protein $(\mathrm{Cmv} 2 \mathrm{~b})$, which carries a functional arginine-rich nuclear localization signal, represents one of the three types of viral suppressors of RNA silencing identified to date. When introduced after silencing is complete, $\mathrm{Cmv} 2 \mathrm{~b}$ is able to reverse RNA silencing in the newly emerging leaves although silencing in older tissues is not affected. We report here that when introduced before the initiation of RNA silencing, Cmv2b is capable of a partial suppression of local silencing and a complete block of systemic silencing. Thus Cmv2b suppresses RNA silencing most likely by preventing the systemic spread of RNA silencing as proposed previously. Data from a number of new silencing suppression assays focusing on the role of $\mathrm{Cmv} 2 \mathrm{~b}$ in the signaling of RNA silencing will be presented. We demonstrate that $\mathrm{Cmv} 2 \mathrm{~b}$ is also able to inhibit salicylic acid (SA)-mediated virus resistance. Additional data from the use of the NahG transgenic tobacco support a model in which SA enhances virus resistance by potentiating the RNA silencing response, which also explains why both virus resistance mechanisms are sensitive to $\mathrm{Cmv} 2 \mathrm{~b}$.

Suppression of gene silencing by the p19 protein of Tomato bushy stunt virus. H. B. SCHOLTHOF (1), S. Faure (1), J.-W. Park (1), and W. P. Qiu (2). (1) Dept. Plant Pathology and Microbiology, Texas A\&M University; (2) Dept. Fruit Science, Southwest Missouri State University. Phytopathology 91:S162. Publication no. P-2001-0104-SSA.

Expression of the 3' proximal p19 gene on the single-stranded positive-sense genome of Tomato bushy stunt virus (TBSV) contributes to various hostspecific events, including short or long distance spread, elicitation of defense responses, or systemic symptom induction. Inoculation of Nicotiana benthamiana plants transgenic for the green fluorescent protein (GFP) gene, with a TBSV coat-protein replacement vector containing the GFP gene, leads to systemic silencing of transgenic GFP expression. However, this induction of silencing is suppressed when the p19 gene is simultaneously expressed from the same vector. This suppression is incomplete, it depends on the dosage of silencer (GFP RNA) versus suppressor (p19 protein), and amino acids that are crucial for the various biological activities are also important for the suppressor activity. These results suggest that the dosage responsive biological activities of the p19 protein during infection might be related to its ability to suppress gene silencing.
Suppression of gene silencing by the 126-kDa protein of Tobacco mosaic virus: A novel mode of action? R. S. NELSON, A. Folimonov, N.-H. Cheng, S. A. Carter, and X. S. Ding. Samuel Roberts Noble Foundation, Inc., Ardmore, OK 73401. Phytopathology 91:S162. Publication no. P-2001-0105-SSA.

Specific mutants of Tobacco mosaic virus (TMV) are inhibited in systemic accumulation in Nicotiana tabacum. We studied a mutant TMV, altered in two amino acids within the $126 / 183 \mathrm{kDa}$ replicase-associated proteins, that accumulates in the inoculated leaves of $N$. tabacum, but displays no symptoms in systemic leaves. We determined that this virus enters the vascular tissue of $N$. tabacum, but does not accumulate extensively in systemic leaves. The phenotype was host specific and temperature sensitive. A spontaneous mutant was identified that extensively accumulated in systemic tissue and the nucleotide (amino acid) responsible for this phenotype was mapped to the $126 / 183 \mathrm{kDa}$ protein sequence. Through inoculation of transgenic plants expressing the $126 \mathrm{kDa}$ protein fused to the green fluorescence protein (GFP) we explored the ability of TMV, using both natural and the above mutants, to delay silencing of the transgene during virus infection. We also studied the ability of these viruses to suppress posttranscriptional gene silencing of free GFP in transgenic $N$. benthamiana plants expressing this gene.

Suppression of RNA silencing in plants. A. Mallory, T. H. Smith, B. Roth, and V. B. VANCE. Department of Biological Sciences, University of South Carolina, Columbia, SC 29208. Phytopathology 91:S162. Publication no. P2001-0106-SSA.

The term RNA silencing encompasses sequence-specific RNA degradation pathways found in a broad range of eukaryotic organisms. In plants, it is induced by transgenes that produce abundant and/or aberrant transcripts and by replication of DNA and RNA containing viruses. The fact that plant viruses can be both targets and inducers of RNA silencing led to the idea that RNA silencing may have evolved as an antiviral defense pathway. In accordance with this idea, many plant viruses encode proteins that suppress RNA silencing, suggesting a co-evolution of defense and counter-defense between the host and the invading viruses. Here we report studies using one such suppressor of silencing, the helper component proteinase (HC-Pro) of potyviruses as a tool to understand the mechanism of gene silencing. We show that HC-Pro suppresses several classes of RNA silencing and establish the point in the pathway where HC-pro functions. We have identified several cellular proteins that interact with HC-Pro in the yeast two-hybrid system. Experiments to over express or knockout expression of these proteins are providing clues about the regulation of gene silencing in plants.

MSA

\section{Cell Biology of Fungi}

Regulation of septation in Aspergillus nidulans. B. LIU and Y.-R. J. Lee. Section of Plant Biology, University of California, Davis, Davis, CA 956168537 USA. Phytopathology 91:S162. Publication no. P-2001-0107-SSA.

In Aspergillus nidulans, hyphae comprise multinucleate cells because septation is not always coupled with mitosis. After conidial germination, the first septum is laid down near the spore body after three rounds of mitosis. Cytoplasmic dynein, a microtubule motor protein, plays a role in spatial regulation of septation in A. nidulans. In the absence of the cytoplasmic dynein heavy chain, the first septum is formed near the hyphal tip rendering an anucleate apical cell and a basal cell of 8 nuclei. At $42^{\circ} \mathrm{C}$, the 8 -kDa dynein light chain, the smallest subunit in the dynein complex, is required for dynein function, and for basal placement of the septum. At $22^{\circ} \mathrm{C}$, however, the light chain is dispensable for dynein function. We propose that cytoplasmic dynein plays a role in retrograde transport of septation materials in the hyphae. The spindle pole body-localized SNAD protein plays a role in temporal regulation of septation and in conidiation in A. nidulans. It contains extensive coiled-coil domains, and likely is a scaffold protein that anchors septation-signaling molecule(s) to the spindle pole body. The signaling network involves an evolutionarily conserved protein MOB1. We have identified the Anmob1 gene in A. nidulans, and are studying the AnMOB1 protein's role in septation. We will test whether SNAD is required for AnMOB1 activity. Supported by UC CRCC and UCD FRGP grants.

Trends in imaging fungal pathogens for cell biological studies of plant disease. R. J. HOWARD (1), T. M. Bourett (1), K. E. Duncan (1), J. A. Sweigard (1), and K. J. Czymmek (2). (1) Dupont Crop Genetics, Wilmington, DE 19880-0402; (2) Department of Biological Sciences, University of
Delaware, Newark, DE 19713. Phytopathology 91:S162. Publication no. P2001-0108-SSA.

Advances in instrumentation and technique have accelerated the evolution of imaging in cell biology. This presentation will include examples of our recent work, and will cite examples from other laboratories, highlighting several new imaging applications in studies of fungal plant pathogens. The use of cryobased preparative procedures remains the standard for fixed specimens at the tissue and cellular levels, for both light and electron microscope studies. For example, we have used immunocytochemistry to map the microtubule cytoskeleton in whole, intact, cryo-fixed hyphae, documented in three dimensions using digital imaging and confocal laser scanning microscopy. CryoSEM, as well as TEM after high-pressure freezing, continue to be important tools for investigations of host-pathogen ultrastructure. CLSM brings another dimension to the study of pathogenesis, in allowing for 3-D documentation of spatial relationships throughout the disease process. We demonstrate the utility of this approach for imaging infection hyphae in (a) fixed, cleared tissues, and (b) living or fixed tissues invaded by fungal transformants expressing spectral variants of green fluorescent protein. We anticipate an ever-increasing role for laser imaging, including multiphoton microscopy, and the use of living specimens to achieve maximum spatial and temporal resolution in studies of fungi.

How mitotic spindles form in Aspergillus. B. R. OAKLEY. Dept. of Molecular Genetics, Ohio State University, Columbus, OH 43210 USA. Phytopathology 91:S162. Publication no. P-2001-0109-SSA.

We have investigated the mechanisms of regulation of mitotic spindle formation and of the establishment of bipolar spindles in Aspergillus nidulans. We have found that there is a rapid movement of tubulin into the nucleus immediately before spindle formation. This suggests that regulation of the 
movement of tubulin across the nuclear envelope may be an important component of the regulation of spindle assembly. Once the tubulin enters the nucleus, microtubule assembly is nucleated by gamma-tubulin. Microtubules that assemble from the two adjacent spindle pole bodies are initially parallel and for spindles to become bipolar they must be pulled or pushed into an antiparallel configuration. We have found that the C-terminal motor domain kinesin-like protein, KLPA, plays a major role in the establishment of spindle bipolarity. We have also found that KLPA is a minus-end-directed microtubule motor that is also capable of bundling microtubules. If KLPA is absent, a second, less efficient, mechanism establishes spindle bipolarity. Surprisingly, gamma-tubulin is essential for the operation of the second mechanism and it is also essential for the movement of chromosomes to poles in anaphase.

Nanobiotechnology: Applications and opportunities for cell biology. H. C. HOCH. Department of Plant Pathology, Cornell University, New York State Agricultural Experiment Station, Geneva, NY 14456 USA. Phytopathology 91:S163. Publication no. P-2001-0110-SSA.

Nanobiotechnology is an emerging area of scientific and technological advances that meld nano- and microfabrication with biological systems. It is an area that brings together collective efforts of biologists, engineers, physicists, and chemists. The ability to fabricate materials and pattern surface chemistry at small dimensions are the fundamental technologies on which the field of nanobiotechnology is based. It provides new analytical probes for interrogating biological systems (fungi, bacteria, mammalian cells, etc.) with unprecedented spatial resolution and sensitivity. Among the explorations being pursued in nanobiotechnology are development: of tools to detect and analyze small numbers of biologically relevant molecules and sparse cells, of bioselective surfaces on which site specific topographies and chemistries are created to influence and understand interactions between cells and their environment, of bioselective filtration devices for separating complex mixtures of molecules, and of molecular motors to power micro-devices useful in cell biology. Fabrication methodologies include lithography, micro-contact printing, and reactive etching in a wide array of materials. Research activities in this new area are the driving force for the Nanobiotechnology Center which is comprised of an aggregate of six universities and institutes (http://www.nbtc.cornell.edu).

Integrating cytoskeleton function in the insect-pathogenic zygomycete, Entomophaga aulicae. F. MURRIN. Department of Biology, Memorial University of Newfoundland, St. John s, NF, A1B 3X9, Canada. Phytopathology 91:S163. Publication no. P-2001-0111-SSA.

Integrins are a family of integral proteins of the mammalian plasma membrane which mediate cell-substrate and cell-cell attachment, and which are involved in signalling events. Recent evidence for integrin-like proteins in several fungi suggests their involvement in attachment of the plasma membrane to the cell wall and in the attachment of pathogens to host cells. In Entomophaga aulicae, and closely related entomopathogens, naturally occurring protoplasts multiply in the hemolymph of host larvae and there is evidence that they attach to internal host tissues during disease progression. We have identified a protein in protoplast extracts of E. aulicae which cross-reacts with antibodies to a mammalian beta-one integrin. On SDS-PAGE gels a reactive band migrates at $71 \mathrm{kDa}$ and its mobility is not influenced by DTT. Fluorescently tagged antibodies localize to the cell periphery, as would be predicted, although nonspecific staining is problematic. We are currently attempting to isolate and sequence the gene for this protein, using reverse transcriptase PCR, in order to compare it with the only integrin-like protein sequence available from a fungus, the human pathogen Candida albicans.

\section{Fungal Biodiversity}

Biodiversity of ascomycetes in freshwater habitats. C. A. SHEARER. Department of Plant Biology, University of Illinois, 505 S. Goodwin Ave., Urbana, IL 61801. Phytopathology 91:S163. Publication no. P-2001-0112-SSA.

Although specific efforts to collect and identify ascomycetes in freshwater habitats began about fifty years ago, most knowledge about this group has been generated in the past twenty years. About 450 species have been reported thus far at a ratio of 1:2:1, Discomycetes: Pyrenomycetes: Loculoascomycetes, respectively. Freshwater habitats appear to have selected for particular evolutionary lines as species numbers are concentrated in relatively few ascomycete orders, including Helotiales (99 sp.), Pleosporales (91 sp.), and Sordariales (83 sp.). Morphological and life cycle adaptations to life in water will be presented. About 25 species are geographically widespread with most of the remainder occurring 3:1 in temperate or tropical areas, respectively. Changes in species composition occur along latitudinal gradients with no species spanning an entire gradient. The percent composition of Discomycetes decreases while that of Pyrenomycetes increases with decreasing latitude. Species diversity is highest at mid-latitudes; whether or not this is an artifact due to the distribution of collectors is discussed.

A comparison of little slime molds in mesic forests of Hawaii and the Smokies. F. W. SPIEGEL (1), J. D. Shadwick (1), and D. E. Hemmes (2). (1) Department of Biological Sciences, SCIE 416, University of Arkansas, Fayetteville, AR 72701; (2) Department of Biology, University of Hawaii, Hilo, Hilo, HI 96720. Phytopathology 91:S163. Publication no. P-2001-0113-SSA.

Biogeographic studies of mycetozoans, aka slime molds, are in their infancy. It is often suggested that most species of myxomycetes are ubiquitous. However, recent work suggests that many species in some habitats or some parts of the world than others. Dictyostelids may have more obvious biogeographic patterns. Less information is available on the protostelids and the acrasids (s.s). Recent systematic collecting for both these groups in the Smokey Mountains and Hawaii is beginning to suggest that while almost all species will show up in a given habitat if enough collecting is done, many do appear to have certain habitat preferences. One question that may be asked is: Are any species found in mesic forests at both tropical and temperate latitudes preferentially tropical or temperate or preferentially found in mesic forests in general? All three cases may apply. Some species, such as Acrasis rosea, Schizoplasmodiopsis pseudoendospora and Cavostelium apophysatum may be tropical. Others, such as Protostelium nocturnum may be more temperate. Others, such as Protostelium mycophaga and Schizoplasmodium cavostelioides appear to prefer mesic forests in general. Until patterns are recognized, they cannot be explained. This study is showing us that patterns of distribution probably exist for the smaller slime molds.
Costa Rican national fungal inventory. G. M. MUELLER (1), M. Mata (2), L. Umana (2), S. Huhndorf (1), F. Fernandez (1), J. Carranza (3), and R. E. Halling (4). (1) Dept. of Botany, Field Museum of Natural History, Chicago, IL 60605-2496; (2) Mycology, INBio, Santo Domingo de Heredia, Costa Rica; (3) Dept. of Biology, University of Costa Rica, Costa Rica; (4) Inst. of Systematic Botany, New York Botanical Garden, Bronx, NY 10458-5126. Phytopathology 91:S163. Publication no. P-2001-0114-SSA.

Fungi are an integral part of the Costa Rican National Biodiversity Inventory, a multinational project coordinated by the Costa Rican National Biodiversity Institute (INBio). Protocols for the fungal inventory were developed through a series of workshops/planning sessions attended by an international team of mycologists (http:/www.inbio.ac.cr/papers/gt_Hongos/en/index.htm). Only a select group of taxa, macrofungi, collectable microfungi (i.e., Ascomycetes that are small but visible with or without the use of low magnification), and lichenized fungi, are being included in the Inventory at this time due to the great diversity of fungi and the very different protocols and scientific expertise necessary to sample and identify this diversity. These fungi were chosen based on their ecological and economic import, products to be developed, taxonomic expertise in Costa Rica, and established international cooperation. Quantitative (plot-based) and opportunistic sampling is being undertaken in five distinct geographic areas to develop comparative data from different ecological zones and to enable documentation of fine scale biogeographic distribution patterns. The projectís parataxonomists collect throughout the year in each area documenting phenology patterns for the different fungi in each of the included forest types.

Patterns in ectomycorrhizal community structure in pinaceous ecosystems. T. D. BRUNS (1). E. A. Lilleskov (1), M. I. Bidartondo (1), and T. R. Horton (2). (1) Dept. Plant \& Microbial Biol. Univ. Cal., Berkeley, USA; (2) Dept. Forest Sc. Oregon State Univ. USA. Phytopathology 91:S163. Publication no. P-2001-0115-SSA.

In the last six years below-ground studies have begun to yield a more detailed understanding of the taxonomic, genetic, and spatial structure of fungal ectomycorrhizal communities. Across site comparisons of mature pinaceous forests show that members of the Russulaceae, Thelephoraceae, and various non-thelephoroid resupinate taxa are often dominant. While in fire-disturbed communities Ascomycetes and Suilloid taxa are the typical dominants. There is good evidence that many of the latter are present in soil spore banks prior to disturbance. Within individual sites, species-level community composition varies at all spatial scales, and correlates with distance only at scales below two meters. Individual species can exhibit clumped or nearly random distributions. Genet mapping of species in the Russulaceae, Amanitaceae, and Thelephoraceae, reveal that individuals are spatially restricted, and that even in undisturbed forest settings spore colonization must be an important ongoing 
process. The fact that patterns are often seen at higher taxonomic levels, could lead one to conclude that many species are substitutable or "redundant". However, the one to one correspondence between many non-photosynthetic mycoheterotrophic plants and various fungal species, shows that individual fungal species may often have subtle, but direct, effects on plant community composition

Elevational trends in soil fungal biodiversity in an arid landscape. E. A. SOBEK and J. C. Zak. Dept. of Biological Sciences, Texas Tech University, Lubbock, TX 79412. Phytopathology 91:S164. Publication no. P-2001-0116SSA.

Desert ecosystems are unique in that unlike most terrestrial systems, biodiversity and productivity tend to increase with increasing elevation. The pattern is primarily due to the "island effect" where mountain peaks form lush centers for biodiversity encompassed in a xeric landscape. The reason for such dramatic shifts in biodiversity with elevation is likely due to the release of the two important abiotic constraints: temperature and moisture. Amelioration of maximum daily temperatures in high elevations allows for increased moisture retention, which correlates well with an increase in plant biodiversity. Accordingly, one would also expect an increase in fungal biodiversity, but unfortunately no studies exist that address the relationship. Our research in the Chihuahuan desert at Big Bend National Park examines the relationship between soil microfungi and elevation within the Pine Canyon watershed. Five distinct vegetation zones exist along the watershed and information will be presented on species diversity and functional diversity (catabolic potential) of the soil microfungi within each zone in relation to key environmental regulators. A major goal of this research is to understand the mechanisms that contribute to patterns in soil fungal taxonomic and functional diversity in extreme environments.

\section{Fungal Systematics: From Species Discovery to Phylogenetic Genomics}

Geological time, the common currency of systematics. J. W. TAYLOR (1) and M. L. Berbee (2). (1) Department of Plant and Microbial Biology, University of California, Berkeley, CA 94720-3102, USA, and (2) Department of Botany, University of British Columbia, Vancouver, BC, V6T 1Z4, Canada. Phytopathology 91:S164. Publication no. P-2001-0117-SSA.

Genera, families, orders and other fungal taxa above the species rank can be difficult to compare because different taxa of the same rank may contain different numbers of species and different levels of genetic diversity. When comparisons are made outside the fungi, the problem is worse. A solution to this problem may be found in molecular phylogenetic studies that have provided estimates of the rate of nucleotide substitution for various genes. These rates can be used to date the origins of fungal taxa. If fungal taxonomic names were followed by an estimate of the date of origin, mycologists and other biologists would have a means of comparing taxa throughout the fungi and beyond. For example, Coccidioides immitis (11ma) would tell the reader than this fungus last shared a common ancestor with the other species in the genus 11 million years ago.

Evolution of corticioid homobasidiomycetes. D. S. HIBBETT and M. Binder. Biology Department, Clark University, Worcester, MA 01610 USA. Phytopathology 91:S164. Publication no. P-2001-0118-SSA.

Homobasidiomycetes produce some of the most complex fruiting bodies in the fungal kingdom, including elaborate, developmentally integrated structures, such as veiled agarics (e.g., Amanita) and various gasteromycetes (e.g., Dictyophora, Sphaerobolus). Homobasidiomycetes also include relatively simple corticioid fungi, whose resupinate fruiting bodies can be little more than a layer of reproductive hyphae on a substrate. Corticioid homobasidiomycetes are clearly not monophyletic, but their precise relationships have been obscure. We are using phylogenetic analyses of a large molecular dataset to understand the historical pattern of switching between corticioid and pileate-erect forms. We are particularly interested in resolving whether the ancestor of the homobasidiomycetes was corticioid (as has been suggested). Finally, using maximum likelihood methods, we are investigating whether there is evidence of an evolutionary bias toward elaboration or reduction in the evolution of fruiting body forms in homobasidiomycetes.

Phylogenetic relationships among obscure microfungi: Why does it matter? A. Y. ROSSMAN, D. F. Farr, and L. A. Castlebury. Systematic Botany and Mycology Laboratory, USDA-ARS, Beltsville, MD 20705, USA. Phytopathology 91:S164. Publication no. P-2001-0119-SSA.
The majority of plant-associated microfungi occur on noneconomic plants and, for the most part, are understudied or not yet discovered. With the increased use of molecular systematics, the relationships of these relatively unknown fungi to those of importance to humankind have become evident. Species of Herpotrichiella that produce minute, black ascomata on rotten wood have been found to produce anamorphs that are the human pathogenic black yeasts. Likewise, Stachybotrys, an anamorphic genus that includes S. chartarum, the toxic air pollutant, belongs in the hypocrealean family, Niessliaceae, which are little known and rarely collected. The teleomorphs of several important biocontrol species of Trichoderma have recently been discovered and described as new species of Hypocrea that produce inconspicuous fruiting bodies on wood. The diaporthalean genus Schizoparme is the teleomorph of Coniella, a genus that includes a strain that has the potential to control purple loosestrife, an invasive weed. In most cases the connection was based on morphological studies with sequence data supplying additional evidence. Research that clarifies the phylogenetic relationships among these fungi contributes to understanding their biology and facilitates their use or control.

Trouble(s) with lichen(s). D. L. HAWKSWORTH. Departamento de Biologia Vegetal II, Facultad de Farmacia, Universidad Complutense, E-28040 Madrid, Spain; and MycoNova, 114 Finchley Lane, Hendon, London NW4 1DG, UK. Phytopathology 91:S164. Publication no. P-2001-0120-SSA.

The concept of 'lichen' as a biological not a systematic category still causes problems. As composites they have no names, while their components do; the fungal name serves as a surrogate. Some of the fungi have different biologies at different stages, from parasites to separate lichens. A single genus can include lichen-forming, lichen-dwelling (lichenicolous), and bark saprobic species. While the taxonomy of the fungus logically should be based on its own characters, features from the composite thallus are commonly used even at genus level. In the parmelioid lichens thallus characters and chemistry have been used to separate increasing numbers of new "genera", but many have not been accepted as they were not based on differences in the reproductive structures similar to those employed as generic criteria in other fungi. rDNA gene sequences have failed to resolve the problem, but the mtDNA SSU appears to. The results of analyses of 31 new sequences, including ones from the type species of 23 generic names, show that some segregates are distinct, but others come together. The emerging groups appear to correlate with differences in ascospores, conidia, wall carbohydrate chemistry, and ultrastructure. But trouble extends to species level, where complex patterns of variation in rDNA genes occur in morphospecies, including clones with wide geographical ranges.

\section{Molecular Mechanisms of Fungal Pathogenesis}

Signaling during pathogenic development in Sclerotinia and Colletotrichum. M. B. DICKMAN, J. A. Rollins, S. Memmot, C. Chen, and Y.-S. Ha. Dept. of Plant Pathology, University of Nebraska, Lincoln, NE 68583. Phytopathology 91:S164. Publication no. P-2001-0121-SSA.

The ability to respond to developmental and environmental cues is a characteristic that extends from single cells to complex multicellular organisms. We are studying signal transduction during pathogenic develpoment in two fungal pathosysytems. Colletotrichum trifolii, causal agent of alfalfa anthracnose, coopts host surface cuticular lipids to activate gene expression (via a specific protein kinase), which is required for infection structure (appressorium) formation. Appressorium development is essential for colonization of intact host tissue. Sclerotinia sclerotiorum is an exremely broad host range pathogen which acidifies its environment by producing oxalic acid. Oxalic acid is an essential virulence determinant and in addition, the reduction in $\mathrm{pH}$ apppears to be important for a number of activities related to pathogenesis including sclerotia formation and the suppression of the host plant oxidative burst. Experimental data supporting these observations will be presented. 
The genetics of the Ustilago maydis-maize interaction: Messages from the fungus and from the host. S. E. GOLD, M. D. Garcia-Pedrajas, D. L. Andrews, A. D. Martínez-Espinoza, J. D. Egan, and K. E. Snyder. University of Georgia, Department of Plant Pathology, Athens. Phytopathology 91:S165. Publication no. P-2001-0122-SSA.

Ustilago maydis, the cause of corn smut disease, alternates between a budding haploid saprophyte and a filamentous dikaryotic pathogen. We have used this dimorphic growth transition as a morphological marker for understanding the disease process. This work has produced a framework regarding signal transduction as a critical factor in fungal disease development. Haploids mutant in adenylate cyclase (uacl-) are converted from budding to constitutively filamentous. Mutagenesis of a uacl- strain allowed the isolation of budding suppressor mutants named $u b c$ (Ustilago bypass of cyclase). Five $u b c$ genes required for filamentous growth have been identified. $u b c l$ encodes the regulatory subunit of the cAMP dependent protein kinase. $u b c 3, u b c 4$ and $u b c 5$ encode members of a pheromone response MAP kinase cascade. Finally, the $u b c 2$ gene appears to encode a novel adaptor protein that interacts genetically with $u b c 4$ (MAPKKK). Additionally, we have isolated fungal transcripts that are differentially expressed at specific morphological stages, and also both host and pathogen genes induced in the formation of plant galls. We have begun to mutate these genes to test their roles in morphogenesis, mating and pathogenesis.

A genomics approach to understanding pathogenicity of Cochliobolus to corn. J. Wu (1), B. Robbertse (1), O. C. Yoder (1), and G. TURGEON (1,2). (1) Torrey Mesa Research Institute, 3115 Merryfield Row, San Diego, CA 92121 USA and (2) Department of Plant Pathology, Cornell University, Ithaca, NY 14853 USA. Phytopathology 91:S165. Publication no. P-2001-0123-SSA.
We are taking a genome-wide approach to the identification of the pathogenicity gene set in Cochliobolus heterostrophus, a pathogen of maize. The project involves three elements: (1) Sequencing the fungal genome; (2) Directed mutagenesis aimed at evaluating candidate genes whose products are suspected of being involved in fungal pathogenesis, and (3) Saturation mutagenesis of the genome by random deletion of 8-10 kb fragments. Availability of genome sequences grants access to the transcriptome, proteome, and metabolome, and the combined knowledge contributes to basic understanding of not only the mechanics of disease development but also the evolution of pathogenicity.

Genome-scale mutagenesis and functional analysis in the phytopathogenic fungi. T. M. DEZWAAN, L. Hamer, M. Tanzer, R. Heiniger, K. Adachi, S. Mahanty, C. Lo, W. Zhang, J. Shuster, and J. E. Hamer. Paradigm Genetics, RTP, NC 27709. Phytopathology 91:S165. Publication no. P-2001-0124-SSA.

The filamentous fungi include a number of organisms that cause disease in agricultural crops. Although there is a paucity of full genome information for these fungi, recent advances in DNA-based technologies allow for large-scale gene function analyses. At Paradigm Genetics, Inc. we have developed one such approach that is comprised of a rapid mutagenesis and gene identification method, Transposon Arrayed Gene Knock Out (TAGKO(TM)), a bioinformatics pipeline, and a broad spectrum high throughput phenotypic analysis program. We will show recent results using this technology in the pathogenic fungi Magnaporthe grisea and Mycosphaerella graminicola, the causal agents of rice blast and wheat blotch respectively.

\section{Ustilago maydis}

From bud to appressorium: Morphology of the Ustilago maydis transition from saprobic to parasitic growth. K. M. SNETSELAAR and M. P. McCann. Biology Department, Saint Josephs University, 5600 City Ave, Philadelphia, PA 19131. Phytopathology 91:S165. Publication no. P-20010125-SSA.

Under growth-limiting conditions and in the presence of pheromone, haploid cells of U. maydis stop budding and instead form mating filaments. These filaments grow toward higher concentrations of compatible pheromone, often in a zig-zag pattern. Compatible filaments locate each other precisely and complete the mating process by fusing. The resulting dikaryotic filament is larger in diameter than the mating filaments, and in liquid and solid media it tends to grow straight and up into the air. Dikaryotic filaments elongate more quickly in response to exogenous pheromone but they do not grow directionally toward pheromone sources. Infection filaments adhere to epidermal cells and may grow on their surfaces for long distances. Entrance into the plant is preceded by formation of an appressorium, usually over the junction between two cells. Ustilago maydis appressoria do not appear to be melanized although their walls may persist after the fungal cytoplasm has left the filament. After the two nuclei move into the appressorium it becomes delimited from the surface hypha by a septum. Infection filaments enter the leaf between two epidermal cells, immediately penetrate anticlinal cells, and then begin intracellular growth. Mutations in genes involved in pheromone signaling and response result in deficiencies in one or more of these mating and infection behaviors.

Signal transduction in the in vitro dimorphic transition of Ustilago maydis (corn smut). A. D. MARTINEZ-ESPINOZA (1,2), J. Ruiz-Herrera (2), C. G. Leon-Ramirez (2), and S. E. Gold (1). (1) Plant Pathology Department, Univ. of Georgia. Athens, GA, 30602-7274, USA; (2) Departamento de Ingenieria Genetica, CINVESTAV-IRAPUATO. Apartado Postal 629, 36500 Irapuato, Gto. Mexico. Phytopathology 91:S165. Publication no. P-2001-0126-SSA.

In its haploid saprophytic phase, the fungus Ustilago maydis grows as a budding yeast. A pathogenic dikaryotic mycelium is produced after fusion of compatible sporidia. Alternatively to mating, media with an acid $\mathrm{pH}$ can induce the yeast to mycelium dimorphic shift. Analyses of mutants in two important signal transduction pathways (cAMP dependent and mitogen activated, protein-kinases) suggested how the mycelial induction through acid $\mathrm{pH}$ might be operating. Filament formation in vitro was inhibited by the addition of exogenous cAMP in all growth conditions. cAMP levels drop significantly and were maintained at low levels when the fungus was grown at $\mathrm{pH}$ 3.0. Mutants defective in rPKA showed a mycelial phenotype at low $\mathrm{pH}$ and was still inhibited by addition of cAMP. With respect to the MAP kinase pathway, mutations in any of the members: MAPK, MAPKK, MAPKKK or a putative adaptor protein, lost their capacity to form mycelia in vitro. Mutation of the pheromone response transcriptional regulator prf1, was capable of forming mycelium under acidic conditions. These results suggest that the normal condition of growth of $\mathrm{U}$. maydis is budding, which is maintained at least in part, by a mechanism of repression exerted through PKA signaling. When levels of cAMP decrease, the fungus exhibits a filamentous morphology using a mechanism that requires the MAPK pathway.

Morphological mutants of Ustilago maydis. M. BOLKER and L. Leveleki. Dept. of Biology, University of Marburg, 35032 Marburg, Germany. Phytopathology 91:S165. Publication no. P-2001-0127-SSA.

The phytopathogenic fungus Ustilago maydis exhibits a dimorphic life style. Haploid sporidia grow yeast-like by budding and are non-pathogenic. After fusion of compatible haploid cells a dikaryon is formed which is pathogenic and grows as a filament. U. maydis is very amenable for genetic analysis and therefore serves as a model system for the study of fungal dimorphism and pathogenicity. A number of mutants have been identified that are affected in morphology. Among those were components of signal transduction pathways, regulators of vesicle fusion and motor proteins. We have concentrated on mutants that are impaired in cytokinesis and fail to separate after nuclear division and primary septum formation. The don1 gene encodes a guanine nucleotide exchange factor (GEF) specific for members of the Rho/Rac/Cdc42 family; the don3 gene codes for a member of the STE20-like protein kinases. The Ras-like GTPase Cdc42 is supposed to be involved in this regulatory cascade. We could show that Don1 and Don3 control the growth of a secondary septum, which is required to form a fragmentation zone. To characterize the role of $\mathrm{Cdc} 42$ in more detail we have generated mutant alleles of cdc42. Expression of dominant activated $\mathrm{Cdc} 42$ in wild type cells results in filament formation whereas dominant negative mutants induce lateral budding.

Sex, signaling and morphogenesis in smut fungi. J. KRONSTAD, N. Lee, K. Wake, G. Jiang, J. Klose, J. Schein, M. Marra, and S. Jones. University of British Columbia, Biotechnology Laboratory; 1B.C. Genome Sequence Centre, B.C. Cancer Agency, Vancouver, B.C., Canada. Phytopathology 91:S165. Publication no. P-2001-0128-SSA.

The basidiomycetes Ustilago maydis and Ustilago hordei (smut fungi) are useful for studying the role of mating and signaling in fungal virulence. In these fungi, the $\mathrm{a}$ and $\mathrm{b}$ mating-type genes control cell fusion as well as subsequent establishment and maintenance of the filamentous, infectious dikaryon. The $\mathrm{a}$ and $\mathrm{b}$ genes are on separate chromosomes in U. maydis (tetrapolar mating) and on the same chromosome in U. hordei (bipolar mating) We are comparing the mating-type regions to identify conserved features and the underlying genomic differences that distinguish bipolar and tetrapolar mating. This work led to the discovery that the MAT region in U. hordei is at 
least 500-kb in size. We have constructed a physical map of the U. hordei genome by BAC clone fingerprinting. This map will serve as a platform for genomic comparisons between $\mathrm{U}$. maydis and $\mathrm{U}$. hordei and for sequencing the MAT-1 region. We are also studying signaling in the smut fungi and we are characterizing downstream targets of cAMP signaling in U. maydis. This work identified the product of the hgll gene as a potential regulatory factor that controls dimorphism, pigmentation and sporulation. We also identified the lip1 gene as a direct or indirect target of regulation by the hgl1 product. The lip1 gene also influences pigmentation and morphogenesis.

\section{Plant Disease Management}

\section{Second I.E. Melhus Graduate Student Symposium: New Frontiers in Plant Disease Losses}

Harpin-induced resistance for the control of blue mold of apples. G. de CAPDEVILLE (1), S. V. Beer (1), C. B. Watkins (2), C. L. Wilson (3), and J. R. Aist (1). (1) Dept. Plant Pathology and (2) Dept. Horticulture, Cornell Univ., Ithaca, NY 14853; (3) USDA-AFRS, Kearneysville, WV 25430. Phytopathology 91:S166. Publication no. P-2001-0129-SSA.

Harpin, a protein produced by Erwinia amylovora and involved in its pathogenesis of apple, induces resistance in many plants. Messenger ${ }^{\mathrm{TM}}$, the commercial formulation of harpin, was studied for its ability to induce resistance in apple fruits to blue mold caused by Penicillium expansum and affect physiological parameters of the fruits. Apple trees of three varieties were sprayed with different concentrations of Messenger ${ }^{\mathrm{TM}}$, 8 or 4 days before harvest. Fruits were harvested, wounded inoculated with the fungus, and stored in a commercial cold room. Significantly fewer fruits treated with Messenger ${ }^{\mathrm{TM}}$ became infected than the controls, mostly in treatments with the highest concentrations. Messenger ${ }^{\mathrm{TM}}$ affected most of the physiological parameters evaluated, with the greatest effect being a reduction of the number of fruits with disorders such as breakdown. Spraying apple trees with Messenger ${ }^{\mathrm{TM}}$ few days before harvest is promising for reducing blue mold decay and postharvest physiological disorders during storage.

Assessing the risk of Stewart's disease of corn through improved knowledge of the role of the corn flea beetle vector. P. D. ESKER and F. W. Nutter, Jr., Department of Plant Pathology, Iowa State University, Ames, IA 50011. Phytopathology 91:S166. Publication no. P-2001-0130-SSA.

Forecasting Stewart's disease of corn, caused by Pantoea stewartii involves analysis of winter weather variables and the dynamics of total and infested populations of Chaetocnema pulicaria (vector). Using mean monthly air temperatures for Dec, Jan, and Feb, and the Iowa State Method for forecasting, the predicted risk was moderate-to high in 1999 and 2000 throughout the entire state of Iowa. The prevalence of Stewart's disease from inspection of Iowa seed corn fields was 58 percent in both years (1317 and 1304 fields inspected, respectively). Using sweep netting and yellow sticky cards, the overwintering, first and second generation of C. pulicaria were observed in 1999 and 2000. ELISA was used to determine the presence or absence of $P$. stewartii in $C$. pulicaria. The proportion of infested $C$. pulicaria ranged from 0.04 to 0.19 , 0.04 to 0.86 , and 0.08 to 0.53 in 1998,1999 , and 2000 , respectively. This improved knowledge will increase the effectiveness of forecasting Stewart's disease of corn and improve management of the disease.

Ontogenic resistance and plant disease management: A case study of grape powdery mildew. A. FICKE (1). (1) Dept. Plant Path., Cornell University, NYSAES, Geneva. Phytopathology 91:S166. Publication no. P2001-0131-SSA.

Knowledge of the dynamics of susceptibility as plants develop can be an important component in disease management. I investigated the timing of ontogenic resistance in grape berries to Uncinula necator and its morphological, biochemical and genetic basis. In response to ontogenic resistance, conidia on 4-wk old berries did not produce hyphae, established colonies expanded more slowly, the latent period increased, and finally, hyphae died. This understanding helped to target pesticide applications to the critical, early phase of berry development, during which infections still occur and expand rapidly. Diffuse, non-sporulating powdery mildew colonies, invisible to the naked eye, predisposed berries to bunch rot and spoilage microorganisms, and reduced wine quality. Hence, fungicides directed only at conspicuous disease may allow diffuse powdery mildew, and thereby reduce crop and wine quality. Understanding ontogenetic changes in host susceptibility may improve current disease management programs in many pathosystems.

Management of grape black rot based on disease epidemiology and fungicide activity. L. E. Hoffman. Dept. Plant Path. Cornell U., NYSAES, Geneva, NY 14456. Phytopathology 91:S166. Publication no. P-2001-0132-SSA.

Guignardia bidwellii is traditionally managed with 7-8 fungicide sprays from approximately $3^{\prime \prime}$ shoots until veraison, but incorporating sanitation and making use of the ontogenic resistance phenomenon provided complete control of fruit rot while reducing fungicide use. In 1999 and 2000, Vitis vinifera cvs. Chardonnay and Riesling and V. labrusca cv. Concord fruit inoculated with $10^{5}$ conidia/ml were susceptible from bloom until 6-7 and 4-5 wks later, respectively. In spray-timing trials conducted from 1997-2000, 3 sprays of myclobutanil $(112 \mathrm{~g} / \mathrm{ha}) \mathrm{imm}$. prior to bloom, and 2 and 4 wks later provided complete control under good sanitation (i.e. mummies removed from trellis during hand-pruning). It provided better control than the program currently in use under poor sanitation (i.e. mummies retained in trellis by mechanicalpruning). Primary inoculum was available from budbreak through early July when sanitation was good, but through harvest when poor. Myclobutanil provided complete control and antisporulant activity when applied up to 8-10 and $14 \mathrm{~d}$ postinfection, respectively, on $\mathrm{cv}$. Riesling seedlings whereas azoxystrobin only reduced the lesion size and number and number of pycnidia when applied 2-10 d postinfection.

The spatiotemporal genetic structure of Phytophthora capsici in Michigan and implications for disease management. K. H. LAMOUR and M. K. Hausbeck. Dept. Plant Pathology, Michigan State University, East Lansing, MI 48824. Phytopathology 91:S166. Publication no. P-2001-0133-SSA.

Phytophthora capsici isolates (3500) were hierarchically recovered from pepper and cucurbit hosts in Michigan from 1998 to 2000. All isolates were screened for compatibility type and mefenoxam sensitivity. Isolates (646) from seven locations were analyzed using AFLP markers and 70 percent (454) had unique AFLP profiles. Clonal reproduction was significant within years but no clones were recovered between years or locations. Populations had high levels of genetic diversity with 39 to 49 percent of the 94 possible AFLP bands polymorphic. Estimated heterozygosities ranged from 0.16 to 0.19 . There was no correlation between genetic and geographical distance. The frequency of mefenoxam insensitivity did not decrease in insensitive populations tracked over two years without mefenoxam use. These data suggest that sexual reproduction plays a significant role in survival, maintaining genetic diversity, and the development of genetically diverse mefenoxam insensitive populations. The impact of these findings on current management strategies is discussed.

\section{Application of GIS and GPS Precision Agriculture Technologies in Nematology and Plant Pathology}

Embracing the emerging precision agriculture technologies-symposium introduction. H. Melakeberhan. Department of Entomology, Michigan State University, East Lansing, MI 48824. Phytopathology 91:S166. Publication no. P-2001-0134-SSA.

Precision agriculture (PA), an information revolution utilizing global positioning (GPS) and geographic information (GIS) systems and remote sensing (RS) for better decision making, is gaining momentum to site-specifically manage (SSM) crop yield-limiting biotic and abiotic factors and their interactions in a wide range of production systems. Characterizing the nature of the problem(s) and public education are among the challenges that scientists, producers and industry face when adapting PA technologies. In order to apply SSM, spatiotemporal characteristics of the problem(s) need to be determined and variations within a field demonstrated. Spatiotemporal characteristics of a given pathogen or pest problem may be known, but it may not be the only or primary cause of the problem. Hence, the exact cause-and-effect relationships need to be established by incorporating GIS, GPS and RS generated data and possible interactions as well. Exploiting the potential of PA technologies in sustainable ways depends on whether or not we first ask "Are we doing the right thing?" (strategic) as opposed to "Are we doing it right?" (tactical). 
Site specific management in plant pathology. J. E. Kurle. Dept. of Plant Pathology, University of Minnesota, St. Paul, MN 55108. Phytopathology 91:S167. Publication no. P-2001-0135-SSA.

Site-specific management may provide powerful tools for the plant pathologist. Currently site-specific management practices emphasize assessment of relatively stable factors such as soil $\mathrm{pH}$ or soil fertility. Often these factors do not explain yield variation in intensively mapped fields. By broadening understanding of seasonally or spatially variable biotic factors, such as plant pathogens, the plant pathologist can increase the effectiveness of site-specific management practices. GIS, GPS, yield monitors, and remote sensing technologies are also powerful tools for analysis and description of the effects of plant pathogens. The spatial information they provide combined with variable rate technologies can become a tool for managing plant disease. For instance, maps of nematode population density have been used to guide nematicide application and models of site topography or microclimate have been used to prescribe fungicide use. This predictive capability linked to variable rate planters or sprayers enables manipulation of management factors such as variety, planting rate or the application of pesticides to control plant diseases.

Site-specific management of nematodes: Pitfalls and practicalities. K. EVANS(1), R. M. Webster (2), P. D. Halford (1), A. D. Barker (1), and M. D. Russell (1). (1) Plant-pathogen Interactions Division, IACR-Rothamsted, Harpenden, Herts, AL5 2JQ, UK; (2) Agriculture and the Environment Division, IACR-Rothamsted, Harpenden, Herts, AL5 2JQ, UK. Phytopathology 91:S167. Publication no. P-2001-0136-SSA.

The greatest constraint to potato production in the UK is damage by potato cyst nematodes (PCN) Globodera pallida and G. rostochiensis. Management of PCN depends heavily on nematicides, which are costly. Of all the inputs in UK agriculture, nematicides offer the largest potential cost savings with spatially variable application, and these savings would be accompanied by environmental benefits. We mapped PCN infestations in potato fields and monitored the changes in PCN population density and distribution that occurred when susceptible potato crops were grown. The inverse relationship between preplanting population density and multiplication rate of PCN makes it difficult to devise safe spatial application procedures, especially when the pre-planting population density is just below the detection threshold. Also, the spatial dependence found suggests that the coarse sampling grids used commercially may produce misleading distribution maps.

Utilization of GIS/GPS based information technology in commercial crop decision making in California. C. S. THOMAS (1), P. W. Skinner (2), A. Fox (3), and C. A. Greer (1). (1) Field Wise, Inc., Bodega Bay, CA; (2) Terra Spase, St. Helena, CA 94574; Fox Weather, Oxnard, CA 93035. Phytopathology 91:S167. Publication no. P-2001-0137-SSA.

Ground-based weather/plant measurements and imagery were georeferenced in GIS software using an integrated approach to determine insect and disease risk and crop cultural requirements. Weather forecasts and disease weather forecasts for agricultural areas were constructed with elevation, weather and satellite data. Models for 6 pests and 12 diseases for various crops were calculated and presented daily in georeferenced maps for agricultural areas in N. CA and WA. Grape harvest dates/yields were also predicted with high accuracy. The data generated from the GIS/GPS analyses were used to make management decisions over a large number of acres in the western US. Information is distributed daily over the Internet as regional weather and disease risk maps. Site specific weather and disease risk data is available for a fee. Use GIS/GPS technology to analyze data, semiautomated, is discussed.

Integration of GIS and remote sensing for perennial crop management. P. V. OUDEMANS. Dept. of Plant Pathology, Rutgers University, 125a Lake Oswego Rd., Chatsworth, NJ 08019. Phytopathology 91:S167. Publication no. P-2001-0138-SSA.
Woody perennial crops, such as cranberries and blueberries exhibit tremendous variability in crop yields and quality as imposed by variations in soil properties and crop stress (diseases and weed competition). These factors result in persistent yield losses and crop quality reductions. To identify losses and develop crop management strategies, state of the art methodologies (GIS, GPS, remote sensing) are used to quantify and map spatial variation of crop yield. Hyperspectral aerial remote sensing is inter-related with ground-sampled data using geostatistical methods to identify stress and quantify yield variation. Ultimately, development of accurate yield maps will provide field professionals with sufficient information to classify crop loss and take action during a growing season. The information is delivered as user-friendly maps accessible in a digital format and can be downloaded to hand-held computers for easy in-field reference. Issues currently being tackled include the timing and frequency of aerial over flights as well as the spatial and spectral resolution necessary for accurate interpretation of crop condition.

Monitoring hemlock forest health using satellite change detection techniques. R. G. Lathrop (1) and D. D. Royle (1). (1) Center for Remote Sensing \& Spatial Analysis, Rutgers University, New Brunswick, NJ 08901 Phytopathology 91:S167. Publication no. P-2001-0139-SSA.

The eastern hemlock (Tsuga canadensis) has been declining in health and vigor in eastern North America due to infestation by an introduced, sap-feeding insect, the hemlock woolly adelgid (HWA) (Adelges tsugae). HWA defoliation is characterized as a slow loss of needles and a reduction in new growth, resulting in a gradual thinning of the hemlock forest canopy. In order to monitor the spatial extent and severity of HWA-associated hemlock decline, we have investigated the application of various forms of remotely sensed change detection. Using medium scale satellite remote sensing systems, such as the Landsat Thematic Mapper, we have demonstrated that it is feasible to quantify the decline in hemlock across spatially heterogeneous forested landscapes. As defoliation occurs in the forest, the biomass of green foliage is reduced resulting in decreased near infrared and increased red reflectance, a change captured in the remotely sensed vegetation index. By differencing preinfestation vs. post-infestation vegetation index images of near infrared to visible red wavebands, it is possible to rank the decline into five broad classes: healthy, light, moderate, severe and dead. Using a time series of vegetation index images, we are investigating temporal and spatial patterns in the infestation and decline process over the past decade. Based on the success of this methodology, we are now expanding our study to monitor hemlock decline across the entire Mid-Atlantic U.S.A. region.

Use of GIS and remote sensing to detect the plant stress caused by soybean cyst nematode. F. W. NUTTER, Jr. (1), G. L. Tylka (1), J. Guan (1), A. J. D. Moreira (1), C. Marett (1), J. P. Basart (2), and C. S. Chong (2). (1) Dept. Plant Pathology, (2) Dept. of Electrical \& Computer Engineering, Iowa State Univ., Ames, IA 50011. Phytopathology 91:S167. Publication no. P-2001-0140-SSA.

Integrating remote sensing and geographic information systems (GIS) technologies into cropping system offers tremendous new opportunities to narrow yield gaps. In 2000, $9952 \times 3$ m soybean quadrats infested with SCN were established and SCN population densities were determined. Ground and aerial remote sensing measurements were obtained every other week during the growing season. Soybean yield, protein and oil concentration were obtained. Geospatially referenced maps were generated to depict within-field variation in yield, protein, oil concentration, and SCN population densities. Quadrats with low SCN densities had a different temporal pattern in percentage reflectance $(810 \mathrm{~nm})$ compared to quadrats with high SCN densities. Percentage reflectance $(810 \mathrm{~nm})$ explained up to $90 \%$ of the variation in soybean yield and up to $52 \%$ of the variation in SCN population density. Remote sensing data obtained at the ground level explained up to $95 \%$ of the variation in aerial images.

\section{Discussion: Chitin and Chitinase in Soil}

Chitin as biomass, its origin and role in nutrient cycling. M. L. SMITHERKOPPERL. Entomos LLC, 4445 SW 35th Terr., Suite 310, Gainesville, FL 32608. Phytopathology 91:S167. Publication no. P-2001-0141-SSA.

Chitin and cellulose are the most abundant polymers produced in nature. Chitin is the major structural component in exoskeletons of the arthropoda; it is also present in the mollusca, including the egg cases of nematodes, protozoa and the hyphal walls of fungi. The chemical structure of chitin is N-acetyl glucosa- mine, and its deacetylated form is chitosan. Chitinases have been characterized from bacteria, fungi, plants and animals. Chitin plays a key role in the retention of nutrients and nutrient cycling in soil. The biomass of chitin in soil is substantial; typically fungi make up the largest component, between 500-5000 $\mathrm{kg} / \mathrm{ha}$, of which $6-12 \%$ is chitin. Arthropods and nematodes, including those that feed on soil fungi, are also significant contributors of chitin in soil. Chitin is a major component of soil organic matter and is a substrate for bacteria, including actinomycetes, and fungi. As chitin decomposes, ammonium is produced, which contributes to the nitrogen cycle. Although our understanding 
of global nutrient cycling is incomplete, chitin is a major component in geochemical cycling of both nitrogen and carbon.

Chitin amendments for suppression of plant parasitic nematodes and fungal pathogens. N. KOKALIS-BURELLE. USDA, ARS, U. S. Horticultural Research Lab, Fort Pierce, FL 34945. Phytopathology 91:S168. Publication no. P-2001-0142-SSA.

Chitin amendments to soil and foliage have proven effective for control of phytopathogenic nematodes and fungi. The primary source of chitin used in agriculture is waste from commercial seafood industries. Chitin powder or flakes can be applied directly to soil, as seed coatings, as amendments to transplant mixes, or can be hydrolyzed and applied to foliage as a colloidal suspension. Direct and indirect effects of chitin on antagonists of plant parasitic nematodes and fungi have been attributed with disease suppression. Chitin causes populations of microorganisms to shift in favor of antagonists that can parasitize pathogens directly or can kill or inhibit pathogens through the production of toxins, metabolites or enzymes. Numbers of nonparasitic nematodes often increase in response to shifts in microbial populations resulting in correlated decreases in pathogenic nematode populations. Chitin can also elicit a resistance response in the host plant. Control of pathogenic nematodes, soilborne and foliar fungal pathogens, and induction of systemic resistance in response to chitin application have resulted in increased yields of numerous crops.

Chitosan, disease suppression and SAR. N. BENHAMOU. Dept. Phytology, Pavillon C.E. Marchand, Laval University, Quebec, Canada, G1K 7P4. Phytopathology 91:S168. Publication no. P-2001-0143-SSA.

The work on induced resistance has led to a remarkable awareness of the key role being played by some natural compounds in stimulating defense gene expression in plants. A promising option in the context of elicitor-mediated induced resistance concerns the use of chitosan as an inducer of plant defense mechanisms. Recent investigations showed that chitosan-mediated induced resistance was a multifaceted process requiring the contribution of several mechanisms including accumulation of phenolic compounds and formation of structural barriers in areas of potential pathogen penetration. In this review, we will concentrate on the tomato-Fusarium oxysporum f. sp. radicis-lycopersici interaction that has been the focus of much interest as a model in both basic and applied research. Results obtained upon treatment of tomato with chitosan will be described in relation to the cytologically visible consequences of the elicitation stimulus on the infection process. Exploiting chitosan as an alternative strategy of disease and pest management clearly meets with the current needs towards sustainable agriculture at a lower environmental cost.

Role of the endochitinase Ech42 in parasitism by Trichoderma and factors determining its expression. A. HERRERA-ESTRELLA. Cinvestav. Unidad Irapuato, Gto., México. AP 627. Phytopathology 91:S168. Publication no. P2001-0144-SSA.

The mycoparasite Trichoderma harzianum has been extensively used in biocontrol of a wide range of phytopathogenic fungi. Hydrolyzing enzymes secreted by the parasite have been implicated in the lysis of the host during this phenomenon. The chitinolytic system of T. harzianum involves the action of up to seven enzymes. Among them the endochitinase Ech42 has been the most studied. Expression of the corresponding gene (ech42) is induced during a fungus-fungus interaction and is affected by other environmental factors, such as nutritional stress, controlled via a MAP kinase pathway. Induction of ech42 is contact-independent, and a diffusible molecule produced by the host is the signal that triggers its expression in vivo. In greenhouse experiments, no differences in the efficacy of the ech 42 gene disruptants to control Rhizoctonia solani or Sclerotium rolfsii were observed, as compared to the control. However, multicopy transformants allowed about $10 \%$ lower disease incidence. Furthermore, $30 \%$ higher degradation of the chitin content in the $R$. solani cell walls was observed during interaction with the overexpressing Trichoderma.

\section{Promises and Pitfalls of GMO Crops in the Tropics}

Attitudes towards the introduction of genetically modified crops into West Africa. M. SÉTAMOU (1), A. H. Bokonon-Ganta $(1,2)$ and G. Gbehounou (2). (1) Texas A\&M University, Department of Entomology, Bio-Control Center 115 Agronomy Road, College Station, Texas 77843; (2) Plant Protection Service, Direction of Agriculture, 01 B.P.58, Porto-Novo, Republic of Benin; current. Phytopathology 91:S168. Publication no. P-2001-0145-SSA.

In West Africa, increasing food production to attain food security for a growing population is the top priority. Although biotechnology is not a silver bullet, it can contribute to solving the agricultural and food security problems by targeting the many production constraints through genetically modified crops. Policy makers, who sometimes ignore the needs of West African farmers and consumers, are slowly accepting the importance of biotechnology. In general, there is no common attitude towards the use of genetically modified foods in West Africa. Almost all the West African countries are characterized by political instabilities, strong monetary constraints, lack of adequate infrastructures, and skilled human resources that limit research on, and the implementation of biotechnology. This paper discusses the potential of biotechnology in improving crop production, and the attitudes of people towards its adoption in West Africa.

The science and politics of genetically-modified plants in Latin America. L. A. CALVERT. Centro Internacional de Agricultura Tropical (CIAT), A.A. 6713, Cali, Colombia. Phytopathology 91:S168. Publication no. P-2001-0146SSA.

Both public institutions and private companies are developing genetically modified plants for the agricultural systems in Latin America. In many countries, technology has advanced more rapidly than the policies for the regulation of transgenic plants. There are technical issues such as gene flow to native plants and the safety of consuming transgenic plants, and each individual country is obligated to develop a national policy for the testing and release of genetically modified plants. Also, there are groups that are opposed to the use of any genetically modified organism. This makes the regulation both a scientific and political process. This process is further complicated by the lack of infrastructure, training and information for those developing and implementing the regulations, as well as the issue of intellectual property rights. Some key areas of research, the current state of regulations, and the need for accurate public information on genetically modified plants in Latin America will be briefly reviewed.
Rainbow and sunup for papaya ringspot virus control: The Hawaiian experience. S. FERREIRA. Dept. Plant \& Environmental Protection Sciences, University of Hawaii, Honolulu, HI 96822. Phytopathology 91:S168. Publication no. P-2001-0147-SSA.

In May 1992, papaya ringspot virus (PRSV) became established in the commercial papaya growing region of Puna, where 95 percent of Hawaii's papayas were grown. Within 3 years, PRSV caused serious losses and growers could not grow papayas successfully in Puna. The only solution to the PRSV problem was the use of coat protein transgenic resistance in two commercial papaya lines: Rainbow and SunUp. Both varieties were commercialized in May 1998, after licenses were obtained. Fruits have been sold in Hawaii and the mainland US since June. By December 2000, 48 million pounds of fruit was produced compared to 34.7 million pounds in 1998. Transgenic fruit guarantees stable fruit production despite the presence of PRSV, and both transgenic and nontransgenic lines can be planted. Thus, a percentage of the production can be sold in markets where transgenics have not been deregulated, as in Japan and Canada. The Japan market is important to Hawaii growers because of its superior price structure. The experience with transgenic papaya in Hawaii will be discussed further from the technical and the grower/consumer perspective.

Genetically modified crops in the Pacific Islands: Attitudes and opportunities. M. N. PEARSON. School of Biological Sciences, The University of Auckland, Private Bag 92019, Auckland, New Zealand. Jacqui Wright, Secretariat of the Pacific Community, Private Mail Bag, Suva, Fiji. Phytopathology 91:S168. Publication no. P-2001-0148-SSA.

This paper considers the potential for use of genetically modified crops in the 22 Pacific Island countries (PIC's), covered by the Secretariat of the Pacific Community (American Samoa, Cook Islands, Federated States of Micronesia, Fiji, French Polynesia, Guam, Kiribati, Marshall Islands, Nauru, New Caledonia, Niue, Northern Mariana Islands, Palau, Papua New Guinea, Pitcairn Islands, Samoa, Solomon Islands, Tokelau, Tonga, Tuvalu, Vanuatu, Wallis and Futuna). Many subsistence crops are grown with root and tuber crops of particular importance. Copra, sugar cane, cacao and coffee are exported. This paper presents information on the crops currently grown in the Pacific Islands, those for which genetically modified cultivars are currently available or being actively developed, and those for which genetic modification would be an advantage. Summarises of current opinions on genetically modified crops, the laws and regulations governing their use and movement, and the procedures being developed for regional and national risk assessment. 


\section{Spectacular Resistance Crashes: Accidents Waiting to Happen}

Evolution of resistance breakdown and gene evolution: Soybean cyst nematode and rhg1. D. A. LIGHTFOOT (1), E. Ruben (1), K. Triwitakorn (1), J. Aziz (1), J. Afzal (1), K. Meksem (1), and P. R. Arelli (2). (1) Soybean Center for Excellence. Dept. Plant Soil and Gen. Ag., So. IL Univ., Carbondale, IL 62901 ga4082@siu.edu; (2) Dept. Agron., Univ. of MO, Columbia, MO 65211. Phytopathology 91:S169. Publication no. P-2001-0149-SSA.

Resistance to soybean cyst nematode (SCN) is subject to breakdowns caused by a nematode adaptation. One gene, $r h g l$, is in every cultivar with resistance to SCN. Alleles derived from Plant Introduction 88788 dominate $~ 90 \%$ of resistant cultivars in the US ( 10\% derive from 'Forrest'). Candidate gene sequences from positional cloning were used to isolate alleles and paralogs from several sources of resistant and susceptible cultivars. The Forrest allele contains 76 leucines in 13 extra-cellular GXXP motifs a transmembrane domain and a kinase on the intracellular domain with homology to Xa21. The PI88788 allele appears to be truncated like $C f 2$. A gene closely homologous to the PI88788 rhgl is found in the Forrest Rhg4 interval. Gene duplication and LRRs repeats implies the rhg genes function by dimerization, which can explain the breakdowns, specificity and temperature sensitivity of hostpathogen recognition. This research was supported by the USB and the ISPOB.

Strategies to avoid the boom and bust cycle. C. C. MUNDT. Dept. of Botany and Plant Pathology, 2082 Cordley Hall, Oregon State Univ., Corvallis, OR 97331-2902. Phytopathology 91:S169. Publication no. P-2001-0150-SSA.

Alternatives exist to the use of single, major genes for resistance, which are often not durable. The effectiveness of quantitative resistance has often been underestimated as such resistance looks less impressive in small plots than in commercial fields. Further, the inheritance of quantitative resistance is simpler and easier to select for than was initially anticipated. The durability of major genes for resistance can be increased through deployment in multiline cultivars and cultivar mixtures, and this approach is being increasingly utilized in commercial production. The effectiveness of mixtures for disease control is highly sensitive to experimental procedure and spatial scale of deployment. Several factors may inhibit the ability of pathogens to accumulate multiple virulence towards resistance genes used in mixtures. Pyramids can be very effective in increasing the durability of resistance genes, though the mechanism(s) through which this durability is achieved are yet unclear. The use of molecular markers in the host and pathogen, can increase the feasibility of using pyramids effectively.
EPA and regulation of pesticide resistance management: Protection of $\mathrm{Bt}$ S. R. MATTEN. US Environmental Protection Agency, Office of Pesticide Programs, Washington D.C. 20460. Phytopathology 91:S169. Publication no. P-2001-0151-SSA.

The U.S. Environmental Protection Agency (EPA) regulates insect resistance management (IRM) for Bacillus thuringiensis (Bt) plant-pesticides produced in transgenic corn, cotton, and potatoes. This is done by mandating specific requirements on the registration of these pesticidal substances: research data, refuge requirements, resistance monitoring, remedial action plan, grower education, and annual sales reporting. EPA believes that protecting the susceptibility of Bt is in the "public good." EPA has not mandated specific IRM requirements for Bt microbial products. In 2001, EPA proposed voluntary resistance management labeling guidelines based on mode/target site of action for agricultural uses of pesticides as part of a North American Free Trade Agreement Project. These guidelines include Bt microbial products and encourage rotation of different modes/target sites of action.

Breaking the treadmill: Emerging needs and resistance strategies for pearl millet. J. P. WILSON (1), R. P. Thakur (2), C. T. Hash (2), K. N. Rai (2), and C. R. Casela (3). (1) USDA-ARS, Tifton, GA; (2) ICRISAT, Patancheru, India; (3) EMBRAPA, Sete Lagoas, Brazil. Phytopathology 91:S169. Publication no. P-2001-0152-SSA.

Disease epidemics are primarily an artifact of simplified ecosystems, and tend to be less significant in natural plant communities, landrace cultivars, and cross-pollinated forage crops. There is a higher potential for epidemics in hybrid crops, and the potential is greatest in inbred cultivars. Pearl millet is a unique model system in which to examine durable resistance concepts, since it is or has been grown as landrace, open-pollinated forage, and hybrid cultivars. The move toward higher-yielding hybrid cultivars has resulted in rapid selection for virulent biotypes of downy mildew in India and rust in the U.S. Resistance in production systems must be maintained by finding new resistance genes and developing and deploying appropriate cultivars. Stable production depends on the existence of new resistance genes, which are summarily rendered ineffective by the pathogen. Alternative strategies of using genes must be developed to slow or halt the erosion of available resistance genes, which are currently being used as "nonrenewable", or "disposable" resources.

\section{Professionalism/Service/Outreach}

\section{Extension.edu}

Adult learners and technology. B. B. DRAPER. Southwest State University, Marshall, MN 56258. Phytopathology 91:S169. Publication no. P-2001-0153SSA.

Many of us as educators and trainers, teach as we were taught as children or young adults. As we offer programs and courses to adult learners, these teaching methods are less effective. Teaching with technology adds another layer of complexity. To encourage more effective learning in this increasingly complex environment, we need to understand how adult learners learn and how to blend methods and technology. At this session we will discuss learning styles, adult learner characteristics, and effective teaching methods for adult learners.

Web page design: Starting from scratch $\&$ effective use of graphics. D. M. EASTBURN. University of Illinois, Urbana, IL 61801. Phytopathology 91:S169. Publication no. P-2001-0154-SSA.

For those who have not done so, the construction of a Web page may seem like a daunting task. However, with a simple text editor and a rudimentary knowledge of web page code, known as HTML (hypertext markup language), a simple yet effective Web page can be put together quite easily. HTML used tags to indicate titles, headings, paragraphs, and links to other documents. By using specialized HTML editing programs, or even by using some word processing programs, creating a web page can be as simple as saving an existing document in HTML format with little or no modification. With a few guidelines on page design and file organization, even the novice can construct a series of interlinked web pages without a great deal of effort or the need for specialized web programmers. And without the having to purchase expensive equipment or software, images can be added to web pages with little additional effort. To make page accessible on the internet, an HTML file must be loaded onto a "server" that is connected to the internet. Server space is readily available through many educational institutions and most Internet service providers.

Its infectious: Plant disease on the Web. J. A. CHATFIELD. Ohio State University, Wooster, OH 44691. Phytopathology 91:S169. Publication no. P2001-0155-SSA.

Imagine it is ten years ago. Imagine a world in which from your office or home you have 24-hour access to plant pathology jobs worldwide, a roster of APS members, a way to instantaneously submit abstracts for meetings, to order and pay for everything from a "Don't Get Caught With Your Plants Down" t-shirt to the latest plant disease compendium, to read journal articles in their entirety, to submit peer-reviewed articles that would receive worldwide access mere weeks after acceptance. Imagine a world in which you key "dogwood anthracnose" into your computer and receive 123 printable fact sheets. Imagine online diagnostic guides. Imagine keys for mycorrhizal fungi at your fingertips. Imagine: a microscope at a remote field location, a wet mount, a digital camera, a computer and Phytophthora is tentatively speciated within hours in a lab many miles and hours away. Imagine a weekly electronic disease digest for practitioners with symptoms, severity, and environmental, host resistance and chemical controls, complete with disease image links. Imagine this - it is now our world. Come learn of the top phytopathological websites condensed from a survey of plant pathologists nationwide. 
Hide and seek on the Internet: A guide to effective searching and listing. K. K. Brewer. Utah State University, Logan, UT 84322. Phytopathology 91:S170. Publication no. P-2001-0156-SSA.

Nature magazine published a report in July 1999 that estimated the World Wide Web consisted of over 800 million pages and that no search engine indexed more than $16 \%$ of that total. However, by using metatags to describe your web site's content, in conjunction with proper html coding, you can overcome the expanse of the Internet and assure your site will be found. Additionally, by listing your web site with Internet search engines and subject directories will, in combination with proper coding techniques, increase the likelihood your web site will be at the top of search engine results. Early in 2000 Inktomi and NEC Research Institute estimated that the size of the web had surpassed 1 billion documents while IDG estimates the Web will exceed 13 billion documents within the next two years. Literally, searching the web is like finding the proverbial needle in a haystack. Compounding this is the fact that not all Internet search engines are created equal; neither the size of the Internet indexed by each search engine nor the manner in which search engines allow the user to search the Internet. This presentation details how users can become effective searchers by identifying appropriate search strategies and techniques as well as which are the best search engines to use and when.

\section{Workshop: Fungi and Indoor Air Quality}

Fungi in indoor environments: Detection and identification. R. A. SAMSON. Centraalbureau voor Schimmelcultures, P.O. Box 85167, 3508 AD Utrecht, The Netherlands. Phytopathology 91:S170. Publication no. P-20010157-SSA.

Many techniques have been described for sampling and detection of fungi in indoor environments, but some methods currently used will result in inappropriate data. The various volumetric sampling methods will be shortly discussed. For detection of moulds and yeasts, direct plating on recommended agar media will often give good information about the species involved. For isolation at least two different media are required. From wet environments, such as water tanks and bathrooms, Water agar or 2\% Malt Extract Agar can be used. For drier conditions, Dichloran 18\% Glycerol agar (DG18) and 2\% Malt
Extract Agar (MEA) are recommended. Identification of fungal isolates from indoor environments to species level is strongly recommended.

Fungal diseases associated with indoor environments. M. R. McGinnis. Department of Pathology, University of Texas Medical Branch, Galveston, Texas. Phytopathology 91:S170. Publication no. P-2001-0158-SSA.

A number of ascomycetous fungi have been associated with human disease following exposure to them in indoor environments. Human disease is typically allergic in nature, even though mycotoxins have been implicated in some instances. Infection has been described in severely immunocompromised patients following transplantation surgery. In some of these cases, the etiologic agent of infection was demonstrated to be a component of the patient's indoor home environment rather than that of the hospital.

\section{Mycotoxins: Achieving Food Security and Food Quality}

The costs of mycotoxin management to the USA. J. Robens. Agricultural Research Service. Phytopathology 91:S170. Publication no. P-2001-0159-SSA.

The costs of mycotoxin management in the US have primarily been associated with aflatoxin, because it is recognized to be highly toxic at exceedingly low levels, because it has been strictly regulated by the Food and Drug Administration, and because it occurs in a wide variety of crops and is so closely correlated with unavoidable drought. In some crops and locations aflatoxin may occur every year as in cottonseed in Arizona, and in other crops and locations it occurs only very sporadically as with corn in Illinois, Iowa (Corn Belt). As the FDA has come to recognize and regulate mycotoxins from Fusarium sp. the costs associated with these fungi have been both increased and recognized more specifically. Costs associated with mycotoxin management are associated with both loss of crop and with expenses of regulation. They include the following: 1. Costs associated with production of a contaminated crop when it can't be sold or is sold at a lesser value because of aflatoxin contamination; 2 . Loss of profit on alternative crop that might have been grown on the land, had not the crop susceptible to aflatoxin been planted; 3. Cost of sampling, handling and analyses for aflatoxin to producers - applies to both affected and non affected crops, includes loss of the value of the sample; 4. Costs to regulatory agencies to carry out regulatory control programs, includes both actual laboratory analyses and administrative costs; 5 . Lost markets, particularly export markets because of fear of aflatoxin contamination; 6. Loss of an otherwise useful rotational crop; 7. Costs of segregation of the affected crop and any disposal costs. The presentation will explain these points as they pertain to losses in particular crops and present estimates of the losses in selected cases.

Potential impact of FDA fumonisin guidelines for corn in the U.S.A. G. P. Munkvold. Iowa State University, Dept. of Plant Pathology, Ames, IA 50011. Phytopathology 91:S170. Publication no. P-2001-0160-SSA.

Recognizing the potential food and feed safety implications of fumonisins in corn grain, the U.S. Food and Drug Administration recently proposed guidelines for safe fumonisin levels in corn-based food and animal feed. Recommended levels are 2-4 ppm or less for dry-milled products or corn intended for masa, and $1-50 \mathrm{ppm}$ for animal feed. Surveys during the mid1990 's indicated that $1-10 \%$ of corn grown in the corn belt contains 5 ppm or more of fumonisins and would not meet the FDA recommendations for human foods. Conversely, grain handlers and food processors are already managing fumonisins in grain and milled products typically contain less than $1 \mathrm{ppm}$ fumonisins. It is anticipated that the proposed FDA guidelines will be defined as advisory levels or action levels. Advisory or action levels could significantly impact grain marketing, causing increases in testing costs, handling costs, and loss of grain value through price reduction or rejection of grain. The economic impact of FDA guidelines will depend on the extent to which grain buyers increase their implementation of testing procedures and use the recommendations as a justification for rejecting grain or docking its price.

Fusarium species and mycotoxins in Nepalese food grains: a case study of smallholder farms. A. E. DESJARDINS (1), G. Manandhar (2), H. K. Manandhar (2), R. D. Plattner (1), C. M. Maragos (1), K. Shrestha (2), and S. P. McCormick (1). (1) National Center for Agricultural Utilization Research, USDA-ARS, Peoria, IL, USA, 61604; (2) Plant Pathology Division, Nepal Agricultural Research Council, Khumaltar, Lalitpur, Nepal. Phytopathology 91:S170. Publication no. P-2001-0161-SSA.

Infection of cereal grains with Fusarium species can cause contamination with mycotoxins that affect human and animal health. Grain samples of maize, wheat, and rice were collected from smallholder farms in the foothills of the Nepal Himalaya. All samples were analyzed for the presence of Fusarium species and selected samples were analyzed for fumonisins and for the trichothecenes nivalenol and deoxynivalenol. Mycotoxigenic species present included $F$. verticillioides in maize and rice, $F$. fujikuroi in rice, $F$. proliferatum in maize, wheat, and rice, and $F$. graminearum in maize, wheat, and rice. Nivalenol and deoxynivalenol were not detected in wheat, and fumonisins were not detected in rice, but all of these mycotoxins were detected in maize. The contamination of maize may be increased by maturation of the crop during the summer monsoon season when rains hinder the drying that is necessary to prevent mycotoxin production in stored grain. Fumonisins and trichothecenes were not eliminated by traditional fermentation for producing maize beer, however Nepalese rural and urban women were able to detoxify contaminated maize by hand-sorting visibly diseased kernels. Thus, initiatives to reduce the risks of Fusarium mycotoxins in Nepalese maize should inform consumers about the occurrence of mycotoxins, and educate them to recognize and discard visibly diseased kernels.

Regulatory standards and risk: Trade issues vs. protection of public health. S. H. HENRY, G. Wood, P. M. Bolger, and T. C. Troxell. U.S. Food and Drug Administration, Washington, D.C. Phytopathology 91:S170. Publication no. P-2001-0162-SSA.

Regulatory standards for food additives, residues of veterinary drugs and pesticides, naturally occurring toxicants, and human-derived contaminants in commodities moving in world are set by the Codex Alimentarius. This body, currently composed of some 165 member countries was formed after World War II to facilitate world trade and to protect international public health. Aflatoxin regulatory standards have been set by Codex in peanuts and in milk/milk products moving in international trade. Previously, Codex had 
recommended that levels of aflatoxins in foods be kept as "low as practicable". But as analytical methods became ever more sensitive, this approach was creating a non-tariff barrier to world trade, as well as wasting valuable food sources. In 1997 and again in 2001, Codex's international advisory body, the Joint Food and Agriculture Organization/World Health Organization Expert Committee on Food Additives (JECFA) has performed two risk assessments for aflatoxins in peanuts and in milk/milk products. The risks of liver cancer to humans from aflatoxin exposure were estimated in relation to other risk factors for liver cancer. This paper will discuss Codex's regulatory standards for aflatoxins in the context of world trade and international perspectives regarding cancer risk.

Child health and consumption of aflatoxin contaminated foods across four agroecologies of West Africa. K. F. CARDWELL, A. Hounsa, S. Egal, C. P. Wild, A. J. Hall, Y. Y. Gong, and P. C. Turner. International Institute of Tropical Agriculture, Cotonou, Benin Molecular Epidemiology Unit, School of Medicine, University of Leeds, UK; London School of Hygiene and Tropical Medicine, London, UK. Phytopathology 91:S171. Publication no. P-20010163-SSA.

Aflatoxin is a risk factor for hepatocellular carcinoma in humans. In animal models, as well as being hepatocarcinogenic, it causes growth faltering and immune suppression. To determine if there is growth faltering due to aflatoxin exposure in children, a cross-sectional study was conducted in 480 children (aged 12 to 48 months) across 4 agro-ecological zones in Benin and Togo. Blood aflatoxin-albumin adduct (pg AFB-lysine eq./mg albumin) levels were used as a biomarker of exposure and compared to standard anthropometric variables and current health of the children. Household economics, food basket assessment and sampling, and food consumption patterns were measured as covariates. Risk of food contamination by aflatoxin was affected by agroecological zone and the A. flavus strain present in the food. In $79 \%$ of the households, maize was used as the primary weaning food 7 days a week. $90.7 \%$ of white maize samples were infected with A. flavus (L strain) and $21.9 \%$ with A. flavus (S strain). Significant correlations were observed between aflatoxin-albumin levels and total A. flavus cfu. Maize sampled from household stores in the southern Guinea savanna (SGS) had significantly more AFB1 and cfu L while samples from the northern savannas (SS and NGS) had significantly more cfu/g S strain and B\&G toxins. $98 \%$ of the children had detectable blood aflatoxin which ranged from 25.3 to $128.5 \mathrm{pg} / \mathrm{mg}$. Aflatoxinalbumin levels were inversely related to weight for age and height for age after adjustment for age, sex, zone and weaning status $(\mathrm{p}=0.0005$ and 0.0001 respectively).

\section{School and Community Gardens: Nourishing Bodies, Expanding Minds: Why YOU Need a Garden at Your Child's School}

Youth garden programs around the U.S. J. Flint. National Gardening Association, 180 Flynn Avenue, Burlington, VT 05401. Phytopathology 91:S171. Publication no. P-2001-0164-SSA.

America's children's gardens represent a colorful array of cultural and horticultural diversity, with each garden evolving its own design and vision. Kids' gardens can be found in the corners of schoolyards, within community gardens, as display gardens near libraries or museums, or as interactive botanical theme gardens. Regardless of size, shape, or setting each kids' garden has a story to tell and ideas to share. This presentation features slides of community and school gardens across the United States, where teachers, parents, and volunteers are working together to turn kids on to gardening, learning, and fun. These gardens, designed by and for kids, are becoming dynamic outdoor learning centers, where children develop a deeper understanding of plants and a sense of responsibility for the earth and its care. Many grants and resources are available to help your school or community to start and sustain a children's garden. We'll show you how to find them in this workshop!

How to organize and set up a school garden: Funding, materials \& supplies, volunteers, and linkages. R. N. Raid. University of Florida, Everglades Research and Education Center, Belle Glade, FL 33430. Phytopathology 91:S171. Publication no. P-2001-0165-SSA.

School gardens serve as outdoor classrooms and provide our youth with environmental and agricultural awareness. In addition to hands-on instruction, school gardens routinely provide real-world relevance for lessons in virtually

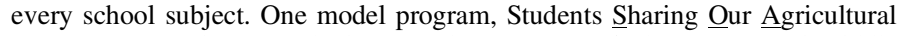
Roots (SOAR), is currently in operation at over 25 elementary and middle schools in Palm Beach County, FL. Coordinated by the University of Florida's 4-H and Youth Programs, Students SOAR relies solely on extramural funding, donations, and in-kind support for its operation. This presentation will focus on the diverse types of school gardens, as well as addressing gardening goals, objectives, and methods for achieving them. In addition, sources and methods for gathering financial support, supplies, volunteers, and linkages will be outlined and discussed.

School gardens: Behavioral and nutritional aspects. M. E. Reuter. University of Florida, Everglades Research and Education Center, Belle Glade, FL 33430. Phytopathology 91:S171. Publication no. P-2001-0166-SSA.

Information on the behavioral effects of school gardening through the SOAR (Sharing Our Agricultural Roots) program at 25 elementary and middle schools in Palm Beach County, FL, will be presented. While quantitative data on academic achievements are still being gathered, interviews with teachers and participant observation confirm others' findings that school gardens can be wondrous things for children, encouraging them to learn, and exposing them to hands-on experience. A second, equally important, observation is that school gardens can entice children to eat a more nutritious diet. Students are more likely to eat something they have grown themselves than to taste the same vegetable coming from a supermarket. Healthy eating habits and nutritional education can, thus, be built into school gardening programs from kindergarten through middle school.

School gardens...expanding minds. The relevance of school gardens to the curricula. D. Spielmaker. Utah State University, National Ag in the Classroom, Salt Lake City, Utah. Phytopathology 91:S171. Publication no. P2001-0167-SSA.

Gardening concepts fit naturally into science, math, social studies, economics and nutrition lessons. For instance, just planning a garden requires math for plant and row spacing, pest management brings in biology and science, maintenance of a garden log involves language and spelling, and eating the fruits of your labor provides lessons in nutrition. Ag in the Classroom is a national program which adapts gardening and agricultural lessons to various statewide educational standards. Learn to implement gardening lessons that are fun, for both teachers and students, into your classroom curricula and to satisfy educational standards at the same time. Numerous hands-on approaches will be discussed and demonstrated.

\section{Town Meeting: Ask the Plant Doctor About Your Ornamental Plants}

What is a plant doctor? M. ELLIS. The Ohio State University, Wooster OH 44691. Phytopathology 91:S171. Publication no. P-2001-0168-SSA.

A slide presentation and informal lecture will be given. The information presented is intended for a nontechnical audience comprised primarily of "Master Gardeners" from around the Salt Lake City area. The information will describe what the science of plant pathology is, the general nature and importance of plant diseases, and where people go for information or help with plant health problems. The session is intended to be an informal outreach activity to help educate the general public about the importance of plant diseases and plant pathology. We envision the Master Gardening program and Master Gardeners as very valuable customers and potential partners for APS outreach activities.

Diagnosing plant health problems. P. SELLERS. Purdue Univ., West Lafayette, IN 47907. Phytopathology 91:S171. Publication no. P-2001-0169-SSA.

Diagnosis of plant problems is necessary before control recommendations can be given. To help audience members understand the process of diagnosis, a review of causal agents of abiotic (noninfectious) and biotic (infectious) diseases will be given. The process of diagnosis will be described using a series of steps that focus on gathering missing puzzle pieces. Diagnosing plant 
problems is like putting the pieces of a puzzle together; the more information that is gathered, the more accurate the diagnosis. Finding those missing puzzle pieces can sometimes be the clue to solving the puzzle.

Principles of plant health management for ornamental plants. $M$. DAUGHTREY. Cornell University, Riverhead, NY 11901. Phytopathology 91:S172. Publication no. P-2001-0170-SSA.

Ornamental plants provide us with aesthetic sustenance, and thus we make every effort to protect them against disfigurement or death by disease. Choosing the right species and cultivars of plants is one key to achieving a healthy landscape. Far too many landscapes are marred by flowering trees that require (but rarely receive) repeated fungicide applications to maintain their beauty. Gardeners should invest time in choosing a disease resistant species or cultivar whenever possible in order to save time over the life of the garden. Resistant plants are the best defense against notorious disease such as black dogwood. Kousa dogwoods are naturally resistant to both powdery mildew and anthracnose. Plant pathologists and plant breeders are working together to develop more resistant lines of our native flowering dogwood. Careful tending of ornamental plantings is another key principle. Plants grown under optimum cultural conditions are less prone to disease. By eliminating overhead watering, blights on the flowers of azaleas, peonies and other garden plants can be minimized. Gathering up plant debris in autumn and judicious pruning can also contribute to the health of the garden. Recently, biorational fungicides including bicarbonates have been developed to provide new, environmentallyfriendly options for the management of some diseases.

Diseases of ornamental plants in Utah. S. V. THOMSON. Utah State Univ., Logan, UT 84322. Phytopathology 91:S172. Publication no. P-2001-0171-SSA.
Utah is the second driest state in the United States, which creates difficult conditions for most fungal and bacterial plant pathogens to get established. Most of the diseases we encounter in urban plantings are present because of the artificial environmental conditions created by irrigation. Foliar diseases are infrequent and root diseases usually only occur when irrigation is excessive. Improper cultural actions rather than fungi cause most turf problems. Despite these arid conditions we still observe a lot of problems because well-meaning gardeners often create favorable conditions. Diagnosis is a very important skill for both amateur and professional gardeners to develop. Recognizing whether the plant problem is caused by a pathogen or by an abiotic stress aids in the control or alleviation of the problem. It is far better to spend some quality time diagnosing a problem rather than trying to treat a problem with numerous guesses. County agents are a good resource for assistance in diagnosis as well as a valuable resource for information. If they can't determine the cause then Utah State University has a Plant Pest Diagnostic Laboratory to assist in the diagnosis of plant problems.

Open forum: Ask the plant doctor. Phytopathology 91:S172. Publication no. P-2001-0172-SSA.

The open forum will consist of an informal "free-for-all" where participants will have the opportunity to ask plant pathologists questions about plant diseases and plant pathology. The general focus of the open forum will be on ornamental plant diseases; however, the plant pathologists of "Plant Doctors" present will try to answer questions related to plant diseases and on other crops as well. Stations or areas within the meeting room will be manned by Plant Doctors with expertise to answer questions and discuss various aspects of plant health. One station will emphasize books, extension publications, and other materials that are useful to gardeners. Participants will be encouraged to bring diseased plant specimens for diagnosis and discussion.

\section{SON}

\section{Evolution of Parasitism in Nematoda}

An overview of evolution of parasitism in nematodes. M. R. SIDDIQI. Department of Entomology \& Nematology, IACR-Rothamsted, Harpenden, Herts., AL5 2JQ, United Kingdom. Phytopathology 91:S172. Publication no. P-2001-0173-SSA.

Nematodes have a simple body plan of a tube-within-a-tube but have survived successfully for the last 600 million years. Most of them are free-living occupying all habitable aquatic and terrestrial habitats, but others have developed relationships with other animals and plants from commensalism/phoresis to parasitism. A large number of genera belonging to several orders of nematodes are known to have colonized animals, from earthworm to man, to feed on their body contents. Lower animals and plants must have been parasitized by nematodes feeding on bacteria, fungi and algae in the Devonian period, some 300 million years ago. Four orders - Tylenchida, Aphelenchida, Dorylaimida and Triplonchida - have evolved a feeding stylet and pumping mechanism to feed on plant and fungal tissues, and the first two orders achieved parasitism of insect and mite haemocoels. Cretaceous must have seen a sudden rise of angiosperms, birds and mammals which were then invaded and successfully parasitized by many groups of nematodes. Ancient saprobiont Rhabditida and Oxyurida-Drilonematida complexes must have been highly adaptive and given rise to modern parasites of higher plants and vertebrates. Phylogenetic studies on these parasites must b based on the analyses of their morphological, molecular, biochemical, cytogenetic, physiological, ecological, behavioral and biogeographical data as well as on their adaptive radiations and survival strategies including cryptobiosis and aging.

Trends in the evolution of insect parasitism by nematodes. G. O. POINAR, Jr. Department of Entomology, Oregon State University, Corvallis, OR 97331. Phytopathology 91:S172. Publication no. P-2001-0174-SSA.

The duration of insect parasitism by specific nematode groups can be established with fossils. Discoveries in amber show parasitism by Mermithidae in the Early Cretaceous, by Tetradonematidae, Sphaerulariidae and rhabditids in the Eocene and by Allantonematidae and Diplogasteridae in the mid-Tertiary. While there are no confirmed fossils of entomopathogenic nematodes, it is likely that their association with arthropods extended back to the Paleozoic. The evolutionary history of entomopathogenic nematodes is complicated since it involves the selection of a bacterium that can be utilized as a food source, the retention of that bacterium by the dauer and the ability to invade the arthropods body cavity. With the Heterorhabditidae, which appears to have evolved from a Pelliodites-like ancestor in an arenicolous marine habitat, parasitism initially may have involved littoral crustaceans as well as intertidal insects. Evolution of the Steinernematidae appears to have occurred in a completely terrestrial environment from an early member of the Rhabitophanes clade.

Evolution of insect parasitism in mermithids. E. G. PLATZER. Department of Nematology, University of California, Riverside, CA 92521. Phytopathology 91:S172. Publication no. P-2001-0175-SSA.

Analysis of the evolutionary history of invertebrate groups is dependent on preservation of past life and activities. As a consequence of the relatively delicate nature of nematodes, there is a void in the classic lithic fossil records. However, fossiliferous amber has provided a record for mermithid nematodes from the Mesozoic and Cenozoic. Further biogeographic-paleogeologic studies by Poinar have extended the potential evolutionary record for mermithid life history patterns to the late Paleozoic. In addition to the fossil record for early development of mermithid parasitism, there is evidence provided by the marimermithids for early development of the life history characteristics of parasitism as a juvenile in invertebrates for enoplids. Development of an ephemeral odontostyl within the mermithids may also reflect the potential of microbivory in the development of invertebrate parasitism. Further studies on the developmental history and the evolutionary relationships of specific gene products within the enoplids should facilitate the understanding of the evolution of life history characteristics of mermithid nema.

Evolution of insect parasitism in rhabditid and diplogastrid nematodes. $W$. SUDHAUS. Department of Zoology, Free University, 14195 Berlin, Germany. Phytopathology 91:S172. Publication no. P-2001-0176-SSA.

Parasitism of nematodes in insects arose independently since silurian times in more than 20 lineages. We exclude entoecy, entomopathogeny and necromeny and use the term parasitism only for nematodes that obtain nutrients from a living host. Therefore, many published examples of "parasitic" Rhabditida are classified anew. A short overview is given on the different modes of parasitic life of nematodes in insects: 1) with a change between free-living stages and parasitic larval stages only or 2) parasitism in later stages including adults or only as adults; 3 ) insects used as paratenic or intermediate hosts for parasites in vertebrates; 4) without a clear-cut distinction between entoecy and parasitism. A diagram depicts the evolutionary steps toward these different parasitic types. The evolution of a dauer juvenile in the Secernentea and special adaptations as inhabitants of patchily distributed habitats formed by decaying material are prerequisites for parasitism. Internal phoresy was a crucial step. From knowledge of the life cycles of parasitic and closely related free-living species associated with insects hypotheses are formulated about how obligate parasites have evolved. 
Evolution of host search strategies in entomopathogenic nematodes. J. F. CAMPBELL. USDA ARS Grain Marketing and Production Research Center, Manhattan, KS 66502. Phytopathology 91:S173. Publication no. P-2001-0177SSA.

Entomopathogenic nematodes in the families Heterorhabditidae and Steinernematidae are lethal insect parasites with an infective stage that actively seeks out new hosts. Within the genus Steinernema, there is considerable variation in the behaviors exhibited by host-searching infective juveniles (e.g., standing and jumping behavior, attraction to host associated volatile cues, area concentrated search in response to contact cues, vertical distribution in soil, etc.). This behavioral variation is correlated with variation along a continuum between ambush and cruise host-search strategies. Infective juvenile behavior was characterized and mapped onto a molecular phylogeny of the genus. This comparative approach enables hypotheses to be developed about the evolution of foraging strategy as well as the assembly of the suite of traits associated with different search strategies. It is proposed that the ancestral Steinernema infective juvenile was an intermediate forager and that both ambush foraging and cruise foraging specializations have evolved within this genus.

Evolution of plant parasitism in nematodes. T. O. POWERS (1), B. J. Adams (2), P. G. Mullin (1), and A. L. Szalanski (1). (1) Dept. Plant Pathology, Univ. Nebraska-Lincoln, 406 Plant Science, Lincoln, NE 68583; (2) Dept. of Entomology and Nematology, Univ. of Florida, Gainesville, FL 32611. Phytopathology 91:S173. Publication no. P-2001-0178-SSA.

It is generally agreed that plant parasitism evolved independently on several occasions during the course of nematode evolution. The nature of plantparasitic nematode ancestors has been a fertile topic of speculation among systematists. Proposed progenitors of plant-parasites include algal and fungal feeders, as well as predaceous nematodes. Some of these taxa include Hexatylus, Psilenchus, anguinid, aphelenchid, cephalobid, and diplogasterid nematodes. Phylogenetic trees based on molecular characters provide a means to independently test different contrasting theories regarding the origin of plant parasitism. The expanding $18 \mathrm{~S}$ ribosomal DNA tree serves as a framework to examine the relationship of nematode taxa believed to be involved in early evolutionary stages of plant parasitism.

Evolution of parasitism in insect-transmitted plant nematodes. R. M. GIBLIN-DAVIS (1), K. A. Davies (2), K. Morris (3), and W. K. Thomas (3).
(1) Univ. of Florida, Davie, FL 33314, (2) Adelaide Univ., S.A., 5064, and (3) Univ. of Missouri, Kansas City, MO 64110. Phytopathology 91:S173. Publication no. P-2001-0179-SSA.

In the Aphelenchida (Aphelenchoididae), Bursaphelenchus cocophilus, the B. xylophilus group, and Schistonchus spp. probably evolved independently from dauer-forming, mycophagous ancestors that were phoretically transmitted to breeding sites of their insect hosts in plants. Mycophagy probably gave rise to facultative or obligate plant parasitism because of opportunities due to insect host switches or peculiarities in host behavior. In the Tylenchida, there is one significant radiation of insect-associated plant parasites involving Fergusobia nematodes (Neotylenchidae) and Fergusonina flies as mutualists that gall myrtaceous plant buds or leaves. These dicyclic nematodes have different phases that are parasitic in either the insect or the plant hosts. Sequence comparisons within flies (mtDNA) and nematodes (rRNA) show a high degree of host specificity. The evolution of this association is unclear, but phylogenetic hypotheses are being generated from rDNA sequence data from Fergusobia and contemporary insect-parasitic and plant-parasitic forms in the Hexatylina.

Evolution of mollusk parasitism in nematodes. P. S. GREWAL, S. K Grewal, and L. Tan. Department of Entomology, Ohio State University, Wooster, OH 44691. Phytopathology 91:S173. Publication no. P-2001-0180SSA.

Although, there are no confirmed fossil records of mollusk parasitic nematodes, diverse associations of a wide array of nematodes with slugs and snails provide a fertile ground for speculation of the evolution of mollusk parasitism in nematodes. Slugs and snails are often recorded as intermediate hosts to nematode parasites of vertebrates. However, there are many nematode species that appear to be obligate parasites of slugs and snails. Studies of nematodes associated with slugs and snails reveal that bacteria-feeding nematodes in the genera Caenorhabditis, Panagrolaimus, Diplogaster, and Phasmarhabditis colonize the shell cavity under the mantle. The discovery of Rhabditiophanes in slugs, a nematode believed to be an ancestral form of entomopathogenic nematodes in the family Steinernematidae suggests that similarities between insect and mollusk parasitism in nematodes. Based on morphological and life history studies of the bacteria-feeding nematodes associated with slugs, hypotheses are formed on how the obligate parasitism of mollusks might have evolved in nematodes.

\section{Molecular Systematics, Evolution, and Status of Microbes Suppressing Nematodes}

Strains from the Burkholderia cepacia complex: Relationship to opportunistic pathogens. P. A. R. VANDAMME (1) and E. Mahenthiralingam (2). (1) Laboratorium voor Farmaceutische Microbiologie, Universiteit Gent, Belgium; (2) Cardiff School of Biosciences, Cardiff University, UK. Phytopathology 91:S173. Publication no. P-2001-0181-SSA.

B. cepacia is a versatile organism with soil, water, animals, plants and humans as niches. Although first known as a plant pathogen, it is now recognized as a useful organism with many biotechnological applications. It simultaneously has become notorious as a life-threatening pathogen in immune suppressed human hosts. During the past decade, a polyphasic taxonomic study including comparative 16S rDNA and RecA sequence analysis, DNA-DNA hybridization, whole-cell protein and fatty acid analyses, various DNA fingerprinting methods, and biochemical characterization, was performed on over $2500 \mathrm{~B}$. cepacia like isolates. This study revealed the presence of various organisms that are regularly misidentified as $B$. cepacia. It also demonstrated that $B$. cepacia is a complex of at least nine closely related species, which are all present in environmental and human samples. Candidates for biotechnological applications occur in most of these species. However, there are several salient differences between the members of the B. cepacia complex.

Burkholderia cepacia complex as human pathogens. J. J. LiPuma. Dept. Pediatrics, University of Michigan Medical School, Ann Arbor, MI 48109. Phytopathology 91:S173. Publication no. P-2001-0182-SSA.

Although generally nonpathogenic for healthy persons, Burkholderia cepacia has long been recognized as capable of causing sporadic human infection. Individuals with chronic granulomatous disease (CGD), a primary immunodeficiency marked by dysfunctional white blood cells, are particularly susceptible to infection. During the late 1970s B. cepacia also emerged as a significant pathogen in persons with cystic fibrosis (CF), a much more common inherited disease. Inherent broad-spectrum resistance renders most infections refractory to effective antimicrobial therapy; outcomes vary from chronic infection to rapidly fatal illness. Recent studies indicate that although all species of the $B$. cepacia complex can infect persons with $\mathrm{CF}$, the distribution of species in this patient population is quite disproportionate, suggesting a differential capacity to cause human infection. Studies employing isolate genotyping have demonstrated the existence of some clonal lineages that seem to have an enhanced capacity for transmission and persistence within patient groups. Ongoing studies seek to identify bacterial virulence factors and to better define host-pathogen interactions.

Evolution of parasitism among nematode-trapping fungi. D. AHRÉN and A. Tunlid. Microbial Ecology, Ecology Building, Lund University, 22362 Lund, Sweden. Dag.Ahren@mbioekol.lu.se Phytopathology 91:S173. Publication no. P-2001-0183-SSA.

The evolution of parasitism among a group of ascomycetes that use traps to infect nematodes is studied. These fungi are soil-living organisms and can grow both as saprophytes as well as parasites. To study the evolution of parasitism among the nematode-trapping fungi a molecular phylogenetic tree based on the 18S rDNA sequences was reconstructed. The tree is in concordance with the different trapping structures but not with traditional taxonomy. A large-scale sequencing project is underway to identify putative virulence factors in the nematode trapping fungus Monacrosporium haptotylum. By filtration of the fungus it is possible to investigate the differential gene expression of the infection structure compared to the mycelia of the nematode-trapping fungus. Results from a population study of a net forming nematode-trapping fungus, Duddingtonia flagrans, based on sequencing and AFLP techniques (Amplified Fragment Length Polymorphism) will be presented.

Pasteuria spp.: Systematics-phylogeny of these unusual bacterial parasites of phytopathogenic nematodes. J. F. PRESTON (1), D. W. Dickson (2), J. E. Maruniak (2), J. A. Brito (2), L. M. Schmidt (1), and J. M. Anderson (2). (1) Microbiology and Cell Science Dept.; (2) Entomology and Nematology Dept., 
University of Florida, Gainesville, FL 32611. Phytopathology 91:S174. Publication no. P-2001-0184-SSA.

Pasteuria spp. are endospore-forming bacterial parasites of phytopathogenic nematodes. Propagation requires attachment of soil-borne endospores to juveniles of nematode hosts, infection, growth, sporulation, and release of endospores that repeat the cycle of infection and propagation. Efforts in three laboratories have sequenced the 16S ribosomal RNA genes from Pasteuria isolated from root-knot (Meloidogyne spp.), soybean cyst (Heterodera glycines), and sting (Belonolaimus longicaudatus) nematodes, allowing their designation as distinct but closely related species within a clade of endosporeforming bacteria, including the cladoceran parasite, $P$. ramosa. Isolates of $P$. penetrans from different Meloidogyne spp. showed identical sequences, indicating host-recognition evolves within a given species. Distribution of an adhesin epitope on polypeptides from Pasteuria isolates provides an immunochemical approach to differentiate isolates with specific host preferences for biocontrol applications.

\section{Nematicides in the Past, Present, and Future}

Hurdles for integrated nematode pest management. J. O. BECKER. Department of Nematology, University of California, Riverside, CA 92521. Phytopathology 91:S174. Publication no. P-2001-0185-SSA.

For the last half-century, growers of high-value crops have frequently relied on pesticides as a major tool to manage plant parasitic nematodes. However, compared to other categories of plant protection compounds such as fungicides, herbicides or insecticides, the number of registered nematicides and their overall use in agriculture or horticulture has always been fairly low. This does not necessarily reflect the lack of demand or severity of nematode-caused problems but rather our inability to effectively, selectively, and safely target mobile pest organisms in soil. Historically, nematode management has involved a multitude of strategies and this concept is now referred to as IPM. However, increasing pressure to develop safer and more environmentally sound nematode control strategies necessitates the expansion of our management tools and their implementation. The main focus of this presentation will be on hurdles for the development of biological nematicides and biocontrol microorganisms.

\section{Nematode Parasitism Genes}

Gene discovery in the soybean cyst nematode. E. L. DAVIS. Department of Plant Pathology, North Carolina State University, Raleigh, NC 27695-7616. Phytopathology 91:S174. Publication no. P-2001-0186-SSA.

Reverse-genetic and genomic strategies are being used to identify parasitism genes whose products are expressed in the esophageal gland cells and secreted through the stylet of the soybean cyst nematode (SCN) during plant parasitism. Genes encoding endogenous beta-1,4-endoglucanases (cellulases) were cloned from SCN and their sequence similarity suggests that some SCN parasitism genes may have been acquired via horizontal gene transfer. The cellulases are expressed and secreted by only the migratory stages of SCN. cDNA libraries have been constructed by RT-PCR using mRNA isolated from the microaspirated contents of SCN esophageal gland cells at different stages of plant parasitism. Initial analyses have identified at least twenty different genes expressed in SCN gland cells during parasitism that encode putative secretory proteins. Some of these genes are expressed exclusively within the single dorsal or two subventral esophageal gland cells of SCN and are differentially regulated during plant parasitism. Expressed sequence tag (EST) and microarray analyses are being employed with the gland-cell cDNA libraries for comprehensive parasitism gene discovery in SCN.

Novel approach to the discovery of parasitism genes in the potato cyst nematode. G. SMANT (1), Q. Ling (1), P. Prins (1), A. Goverse (1), A. Schots (2), J. T. Jones (3), J. Helder (1), and J. Bakker (1). (1) Lab. Nematology and (2) Laboratory of Molecular Recognition and Antibody Technology, Wageningen Univ. and Research Centre, PO-box 8123 Wageningen, NL6700ES the Netherlands; (3) Mycology, Bacteriology, and Nematology Unit, SCRI, Invergowrie, Dundee DD2 5DA, UK. Phytopathology 91:S174. Publication no. P-2001-0187-SSA.

Expressed sequence tags have proven to be efficient tools to identify genes involved in parasitism of plant-parasitic nematodes. This identification depends on the presence of informative homologues in databases. Similarly, cDNAAFLP has proven to be an efficient procedure to analyze expression patterns in these parasites. Based on a specific expression pattern, genes involved in parasitism can be selected from thousands of transcripts. This selection uses the endonuclease restriction sites and the fragment length as a unique identifier and can, therefore, be made without knowledge of the complete DNA sequence. We have developed computer software, GenEST, which enables us to make a bidirectional link in silico between the information captured in EST databases and the expression profiles produced by cDNA-AFLP. The software generates virtual transcript-derived-fragments from ESTs and compares them with the ones that are displayed on gels. Examples are given to illustrate the power of the software in finding candidate parasitism genes among ESTs of the potato cyst nematode including 'pioneering' sequences.

Genome projects for human nematode parasites. S. A. WILLIAMS. Dept. Biological Sciences, Smith College, Northampton, MA 01063 and Molecular and Cellular Biology, University of Massachusetts, Amherst, MA 01003. Phytopathology 91:S174. Publication no. P-2001-0188-SSA.

Lymphatic filariasis (LF) is caused by the nematodes Brugia malayi and Wuchereria bancrofti. These parasites infect 130 million people worldwide: 44 million are incapacitated or disfigured by the disease and 76 million have damage to their renal/lymphatic systems. LF has recently been recognized as the second leading cause of permanent/long-term disability worldwide. A related filarial nematode, Onchocerca volvulus, is the causative agent of river blindness and infects 18 million people living in sub-Saharan Africa. The Filarial Genome Project was launched in 1994 to study the genome of $B$. malayi while the River Blindness Genome Project was organized in 1997 to study the genome of $O$. vovlulus. The major goal of these two genome projects has been the identification of new drug targets and vaccine candidates using EST-based gene discovery. To this end, 22,000 ESTs have been sequenced from B. malayi (8,000 genes identified) and 14,000 from $O$. volvulus $(5,000$ genes identified). These data provide a vast resource that will assist in the identification of new targets for chemotherapy and for the development of vaccines.

Applied genomics in nematode discovery: An industry perspective. L. X. LIU. Cambria Biosciences, 2 Preston Court, Bedford, MA 01730. Phytopathology 91:S174. Publication no. P-2001-0189-SSA.

Now that we are in the era of total genomes, what constitutes a desirable molecular target for intervention to control plant and animal parasitic nematodes? Although the unmet needs in crop protection are very different from those in animal health, economic considerations for both markets dictate that any new anti-nematode molecules be not only potent and safe, but also effective against a broad spectrum of parasitic species affecting many different hosts. This argument suggests that we should target shared processes in nematode physiology and behavior, rather than parasitism functions that are particular to a specific, highly evolved parasite-host association. The freeliving nematode Caenorhabditis elegans provides a wealth of information and tools for nematode biology, including complete delineation of its development, anatomy, neuroanatomy, and genome, and well-established techniques for systematic forward and reverse genetics. Furthermore, C. elegans is readily adaptable to microplate-based liquid handling for use in high-throughput chemical screens. I will discuss the power of C. elegans, using specific examples, for "gene-to-screen" discovery of candidate nematicides. 